\title{
DESARROLLO DE PROTEÍNAS RECOMBINANTES PARA EL DIAGNÓSTICO Y PREVENCIÓN DE LA FIEBRE HEMORRÁGICA ARGENTINA
}

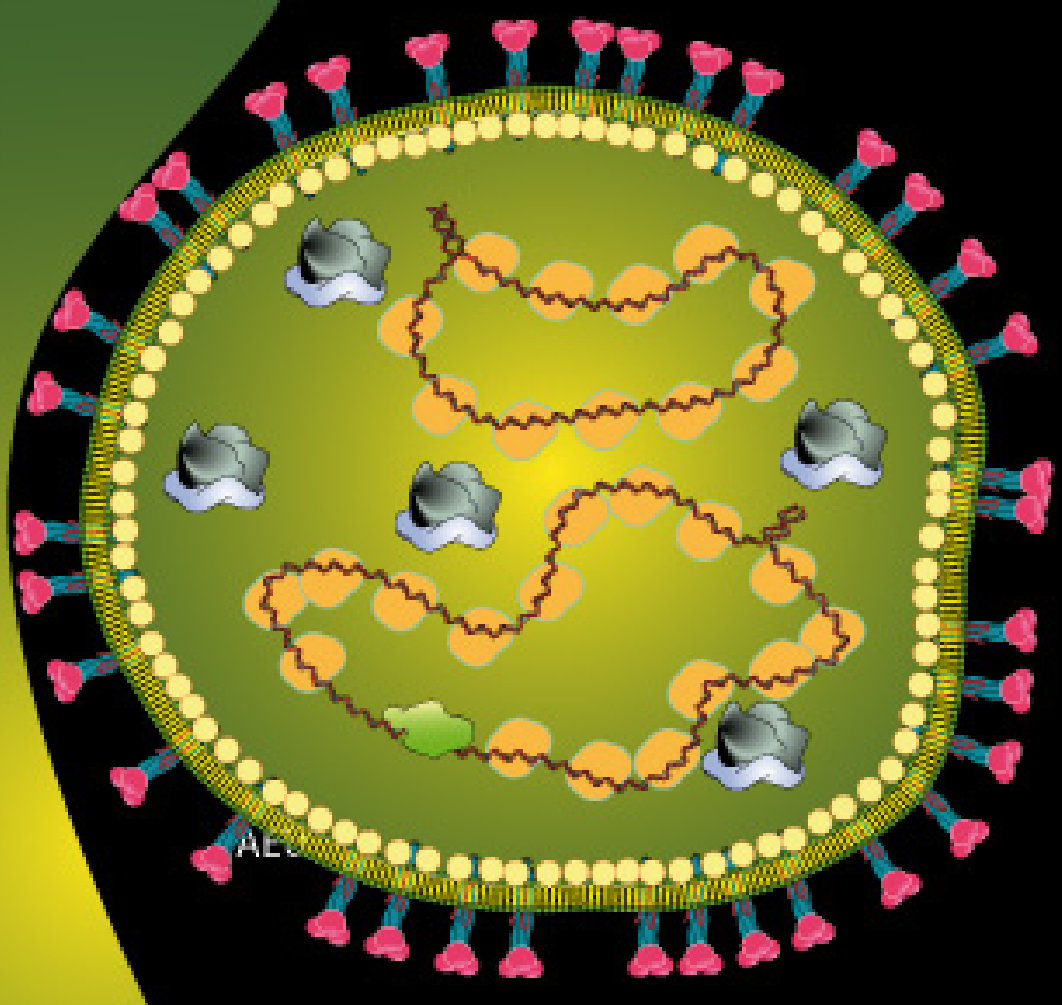

\section{Agustín E. Ure}

Víctor Romanowski

Director

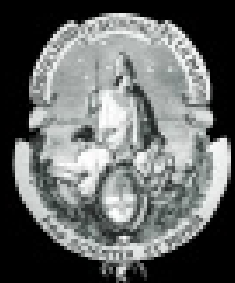

Universidad Nacional de La Plata

Facultad de Ciencias Exactas

Departamento de Ciencias Biológicas

Instituto de Biotecnología y Biología Molecular (IBBM)
Ricardo M. Gómez

Co-director

CONICET 

TESIS DOCTORAL

DESARROLLO DE PROTEÍNAS RECOMBINANTES PARA EL DIAGNÓSTICO Y PREVENCIÓN DE LA FIEBRE HEMORRÁGICA ARGENTINA

\section{UNIVERSIDAD NACIONAL DE LA PLATA FACULTAD DE CIENCIAS EXACTAS DEPARTAMENTO de CienCIAS BIOLÓGICAS}

$\begin{array}{ll}\text { DOCTORANDO: } & \text { AGUSTIN ENRIQUE URE } \\ \text { DIRECTOR: } & \text { VICTOR ROMANOWSKI } \\ \text { CO-DIRECTOR: } & \text { RICARDO MARTín GÓMEZ }\end{array}$

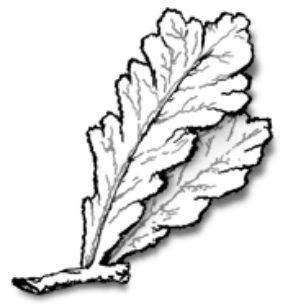



I presente trabajo de Tesis para optar al grado de Doctor de la

EFacultad de Ciencias Exactas de la Universidad Nacional de La plata, ha sido realizado en el Instituto de Biotecnología y Biología Molecular (IBBM) perteneciente a la UNLP - CCT La Plata - CONICET, bajo la dirección de los Dres. Víctor Romanowski y Ricardo M. Gómez. 
gradezco a la Universidad Nacional de La Plata, a la Facultad de Ciencias Exactas, al Departamento de Ciencias Biológicas y al IBBM, por brindarme el ámbito para realizar mis estudios de posgrado. También quiero reconocer al Consejo Nacional de Investigaciones Científicas y Técnicas (CONICET) por otorgarme una beca para poder llevar a cabo el presente trabajo. 
ÍNDICE

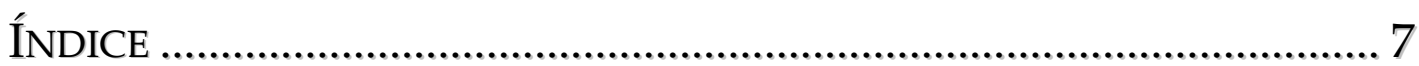

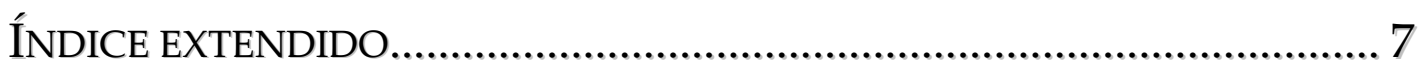

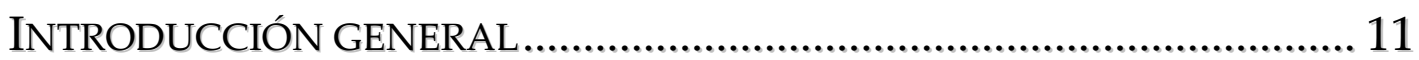

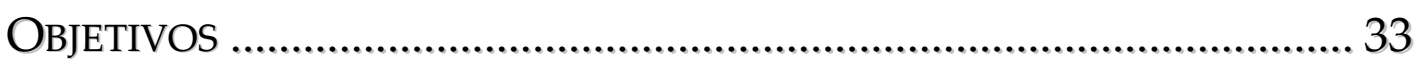

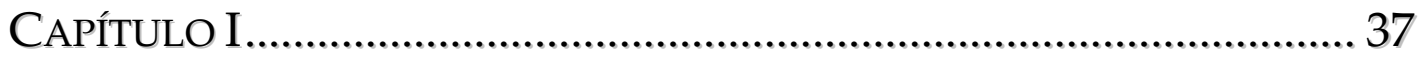

ENSAYO DE DIAGNÓSTICO BASADO EN LA PROTEÍNA

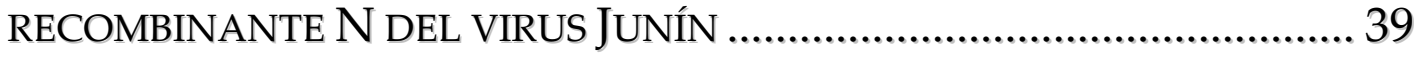

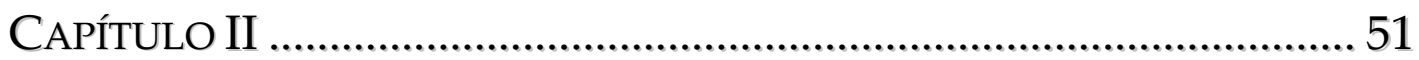

MAPEO DE ANTICUERPOS MONOCLONALES Y

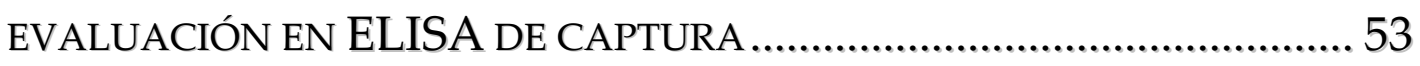

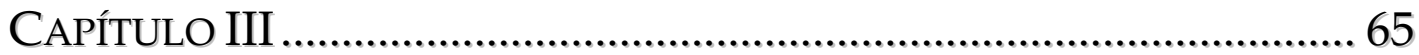

EXPRESIÓN DE PROTEÍNAS QUIMÉRICAS RECOMBINANTES

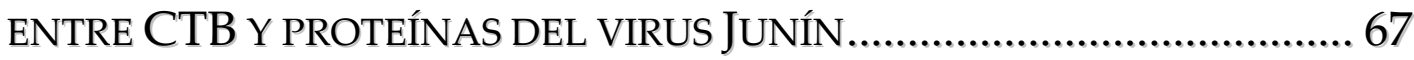

CONCLUSIONES GENERALES Y PROYECCIONES FUTURAS …................... 87

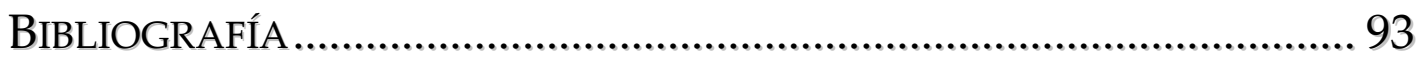

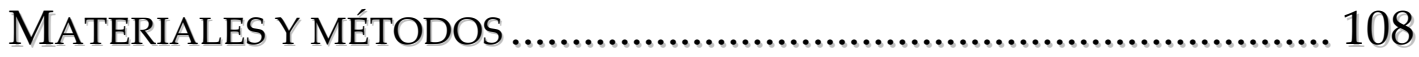

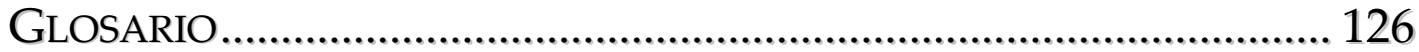

\section{ÍNDICE EXTENDIDO}

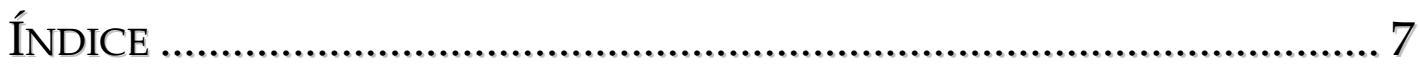

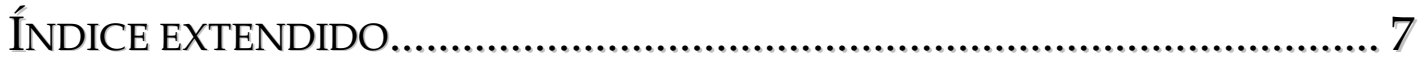

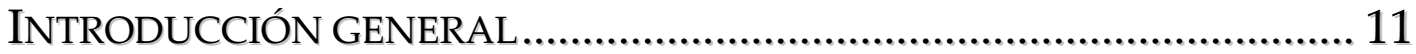

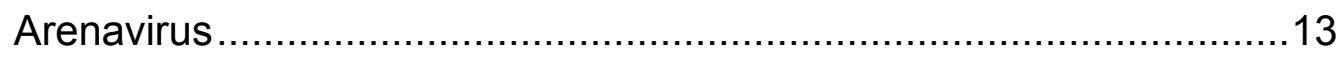

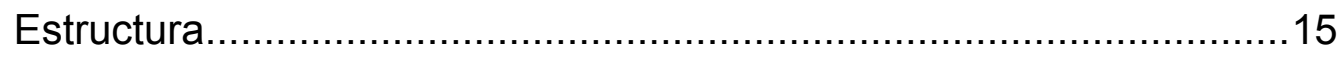

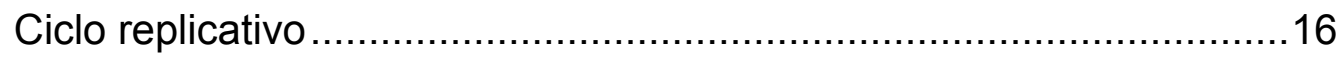

Fiebre Hemorrágica Argentina .................................................... 18

Epidemiología de la fiebre hemorrágica argentina ............................20

Fisiopatología de la infección por arenavirus del nuevo

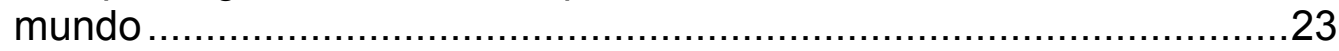

Manifestaciones clínicas de la enfermedad ..................................24 


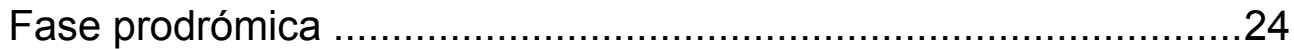

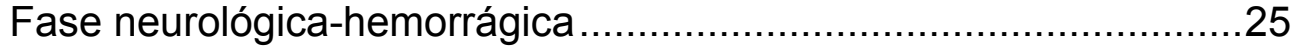

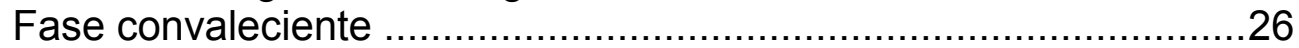

Diagnóstico clínico y de laboratorio ..............................................26

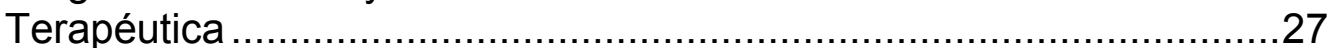

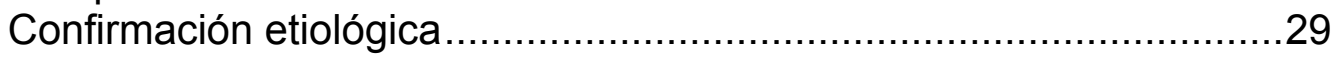

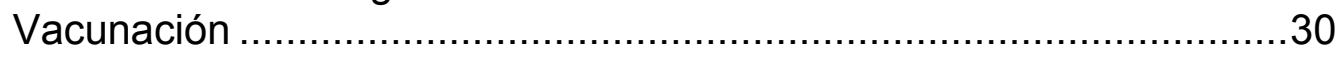

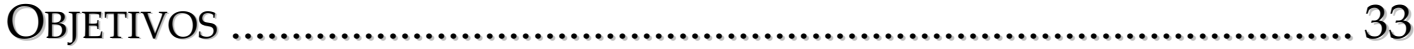

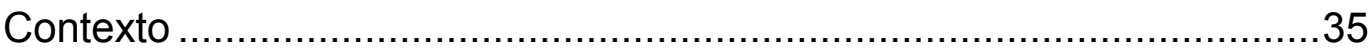

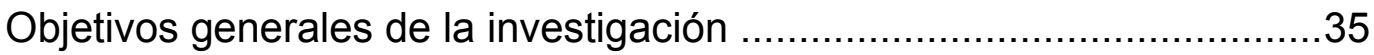

Objetivos particulares de la investigación..............................................36

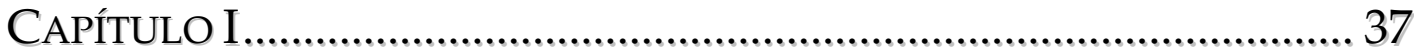

ENSAYO DE DIAGNÓSTICO BASADO EN LA PROTEÍNA

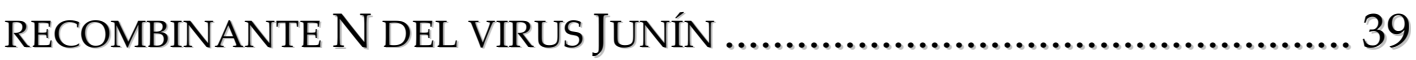

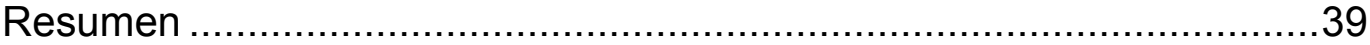

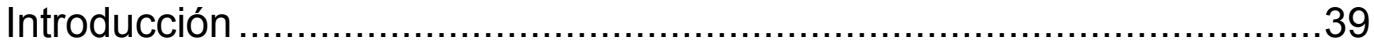

Baculovirus como sistema de expresión de proteínas ..........................39

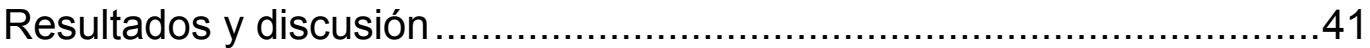

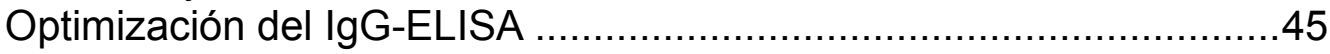

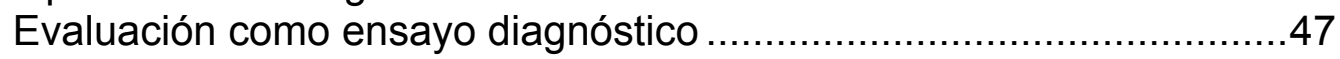

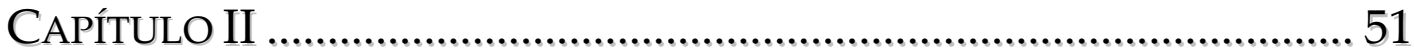

\section{MAPEO DE ANTICUERPOS MONOCLONALES Y}

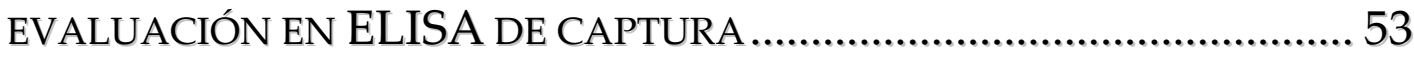

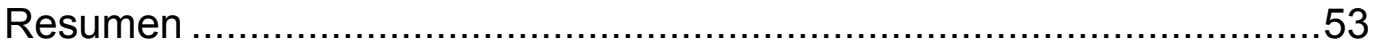

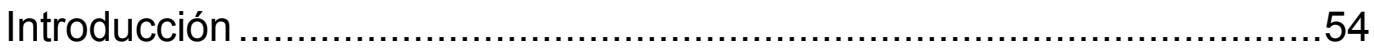

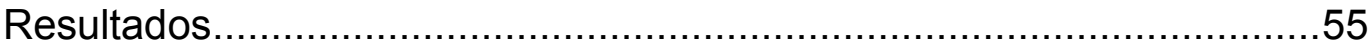

Reactividad de anticuerpos monoclonales frente a

nucleopro-teínas de arenavirus......................................................5

Desarrollo de ELISA de captura de Ag. ........................................56

Mapeo de los epitopes reconocidos por los anticuerpos

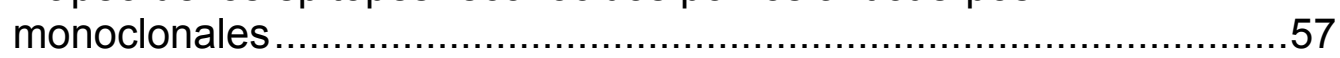

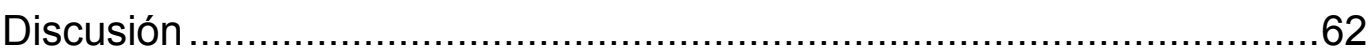

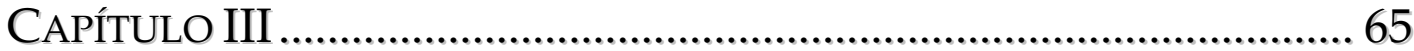

EXPRESIÓN DE PROTEÍNAS QUIMÉRICAS RECOMBINANTES

ENTRE CTB Y PROTEÍNAS DEL VIRUS JUNÍN............................................ 67

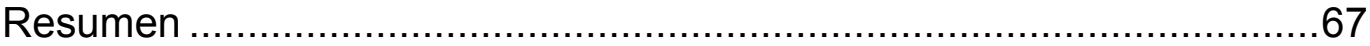

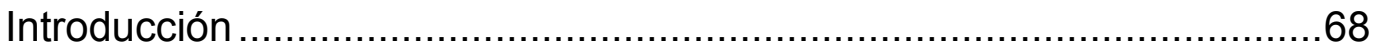

Toxina colérica y su utilidad como adyuvante ...................................68

Estrategia general para la clonación de proteínas de

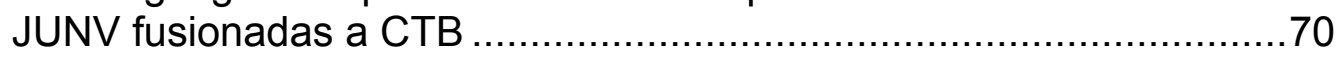

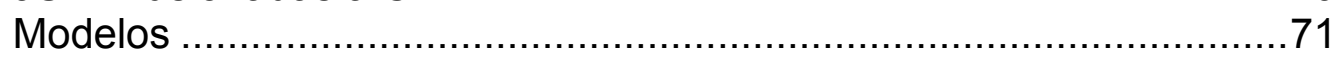

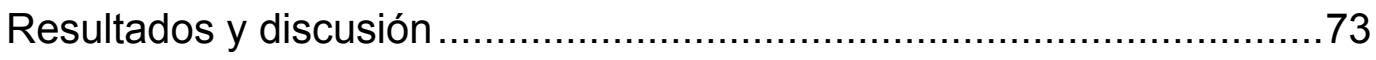


Clonado de genes virales fusionados a $\operatorname{ctx} B$

Expresión y antigenicidad de proteínas virales fusionadas

a CTB

Purificación por IMAC

.78

Recuperación de la conformación nativa ..........................................79

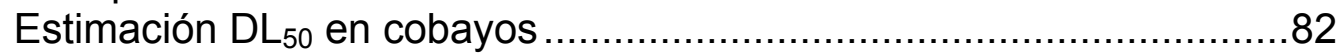

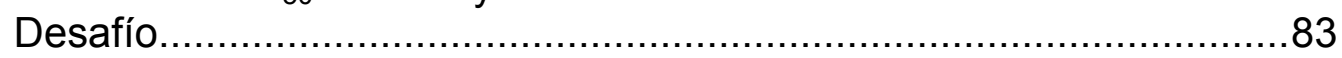

CONCLUSIONES GENERALES Y PROYECCIONES FUTURAS ....................... 87

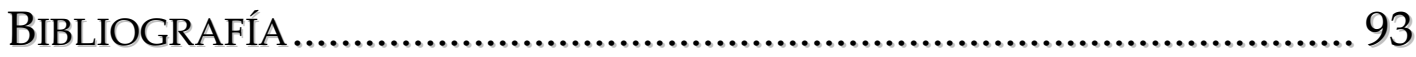

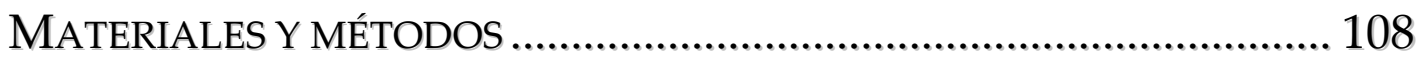

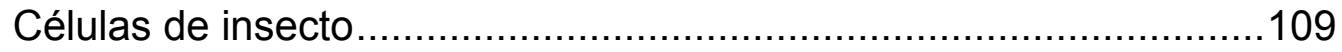

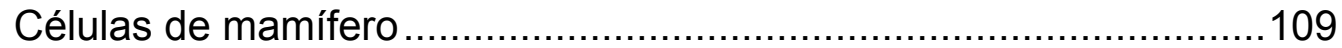

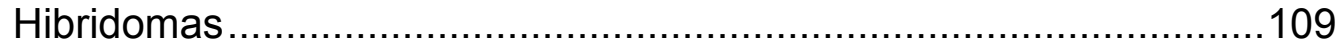

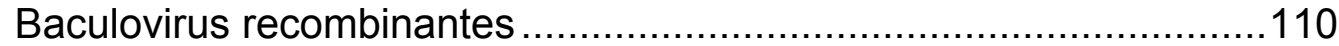

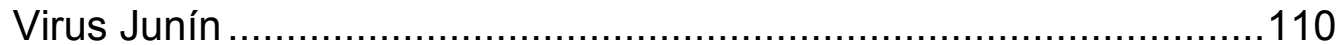

Infección de células de insecto con Baculovirus .............................111

Infección de células de mamífero con JUNV ................................111

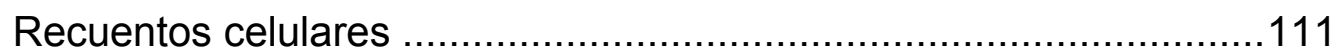

Cinética de expresión de $\mathrm{N}$ en células de insecto...........................112

Expresión y purificación parcial de antígenos para ELISA..................113

Expresión de versiones truncadas de N de JUNV ...........................113

Titulación de baculovirus...........................................................113

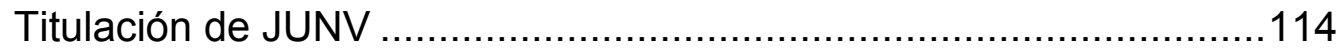

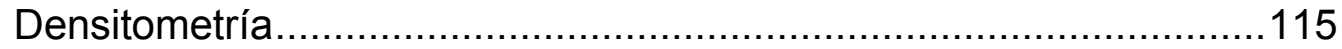

Cuantificación de proteínas.......................................................115

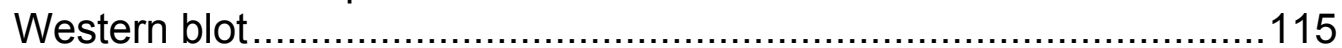

Optimización del protocolo de IgG-ELISA por el método

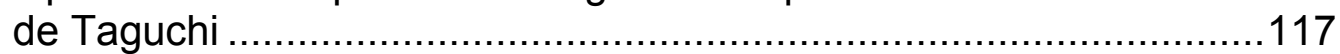

Muestras de sueros humanos .................................................118

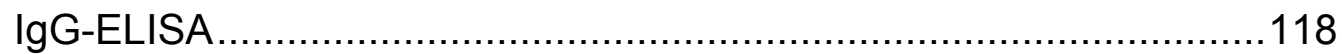

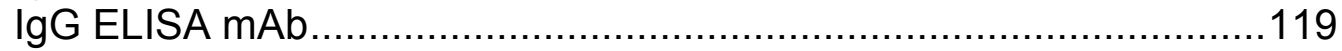

Producción de anticuerpos monoclonales......................................120

Mapeo de los epitopes de los anticuerpos monoclonales .................120

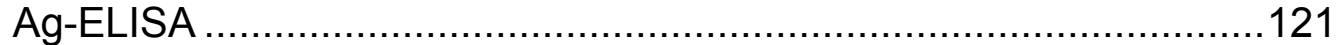

Expresión en pequeña escala.................................................122

Inmunización y vacunación de cobayos ........................................122

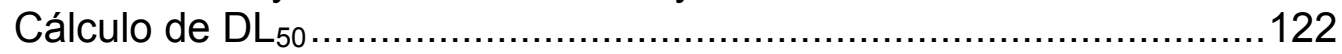

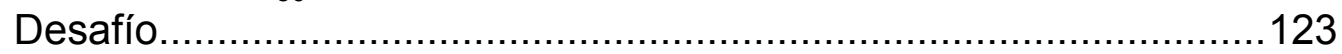

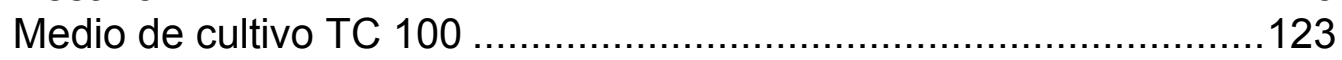

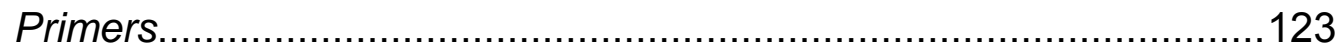

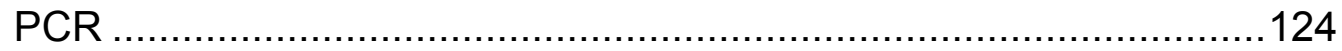

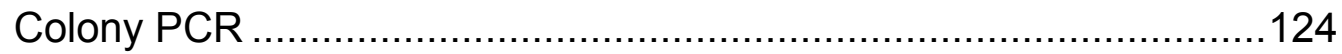

Números de acceso de GeneBank ................................................125

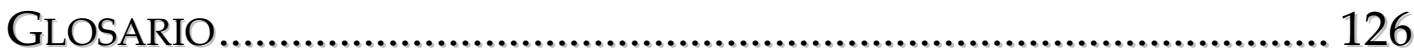




\section{ÍNDICE DE TABLAS}

Tabla 1. Familia Arenaviridae................................................................

Tabla 2. Condiciones óptimas y ANOVA para el IgG-ELISA ......................46

Tabla 3. Modelos animales para el estudio de FH producidas

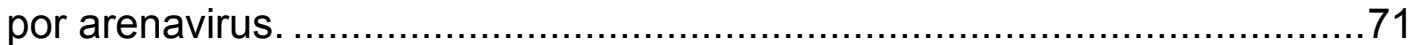

Tabla 4. Síntomas de la enfermedad en humanos y cobayos. ....................72

Tabla 5. Amplificación de genes virales por PCR para el

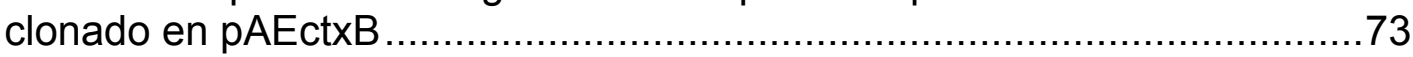

Tabla 6. Supervivencia de cobayos desafiados con JUNV .........................84

Tabla 7. Factores y niveles evaluados para optimizar el IgG

ELISA con el método de Taguchi.

\section{ÍNDICE DE FIGURAS}

Figura 1. Micrografía electrónica de arenavirus. ......................................15

Figura 2. Esquema de un arenavirus. ...............................................16

Figura 3. Organización genómica, transcripción y replicación de los RNA

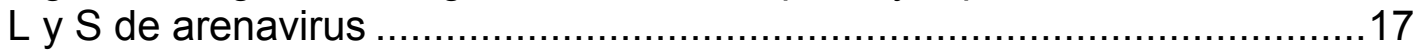

Figura 4. Tasa de mortalidad de FHA …............................................18

Figura 5. Incidencia de FHA y número de vacunados con Candid \#1 .........19

Figura 6. Área endémica de la FHA ....................................................19

Figura 7. Expresión de $\mathrm{N}$ en células de insecto .....................................42

Figura 8. Cinética de expresión proteica en células Sf9. ..........................43

Figura 9. Cinética de expresión proteica en células High Five.....................44

Figura 10. Reactividad de sueros positivos para arenavirus frente a

proteínas $\mathrm{rN}$.......................................................................... 4

Figura 11. Curva ROC para el IgG-ELISA basado en rN. ........................48

Figura 12. Diagrama de puntos y curvas de especificidad y sensibilidad. ..49

Figura 13. Reactividad de los mAb generados con $\mathrm{N}$ de distintos

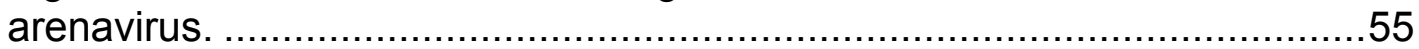

Figura 14. Reactividad de mAb en ELISA de captura de Ag....................57

Figura 15. Reactividad de mAb C6-9, C11-12 y E4-2 con fragmentos de

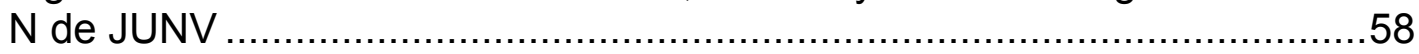

Figura 16. Ensayo de bloqueo de mAb en ELISA ……........................59

Figura 17. Determinación de los epitopes de $\mathrm{N}$ reconocidos por los mAb ..60

Figura 18. Esquematización de $\mathrm{N}$ y la unión con los $\mathrm{mAb}$...........................61

Figura 19. La toxina colérica y su interacción con el receptor......................69

Figura 20. Estrategia de clonado en el vector pAEctxB..........................70

Figura 21. Generación de los vectores pAEctxB-GPC, G1 y G2 ................74

Figura 22. Generación de los vectores pAEctxB-EGFP, N y Z. .................75

Figura 23. Cromatograma de los ORF con sitios Hindlll pre-existentes .....76

Figura 24. Reconocimiento de CTB en proteínas quiméricas ......................77

Figura 25. Fluorescencia de EGFP...............................................

Figura 26. Proteínas quiméricas purificadas ...........................................79

Figura 27. Proteínas quiméricas re-naturalizadas y purificadas ...................80

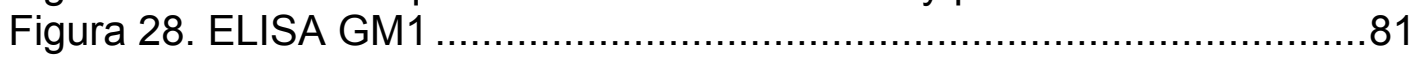

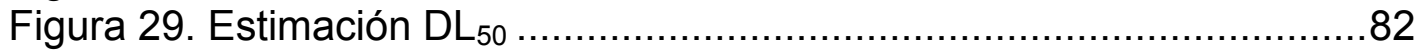

Figura 30. Desafío de cobayos con JUNV . ........................................... 
Introducción general 



\section{Arenavirus}

La familia Arenaviridae está formada por un único género de virus (Arenavirus) e incluye veintidós miembros formalmente reconocidos por el International Committee for the Taxonomy of Viruses (ICTV) (Tabla 1). A su vez, ocho presuntas nuevas especies virales fueron caracterizadas recientemente, entre ellas Kodoko (Lecompte et al., 2007), Chapare (Delgado et al., 2008), Skinner tank (Cajimat et al., 2008), Catarina (Cajimat et al., 2008), Dandenong (Palacios et al., 2008), Lujo (Briese et al., 2009), Morogoro y Pinhal. Estos últimos aislados por Günther y Bisordi, respectivamente (datos no publicados; ver Charrel et al., 2008). Estas especies deben ser confirmadas como tales por el ICTV. A tal fin, se utiliza un criterio basado en la asociación a uno o unos pocos huéspedes, la presencia en un área geográfica definida, la capacidad (o no) de provocar enfermedad en humanos, las diferencias antigénicas de reactividad cruzada y las diferencias en composición aminoacídica con respecto a otros miembros del género (Salvato et al., 2005).

Los arenavirus han sido aislados de roedores (Tabla 1), salvo en el caso del virus Tacaribe, aislado de un murciélago frugívoro del género Artibeus (Downs et al., 1963; Salazar-Bravo et al., 2002). La infección que establecen en los roedores es persistente y con poca o ninguna sintomatología. Sin embargo, ocasionalmente pueden ser transmitidos a los seres humanos a través de la inhalación o contacto con material contaminado con excretas de los roedores infectados, pudiendo provocar algunos de ellos fiebres hemorrágicas $(\mathrm{FH})$ severas (Salvato et al., 2005). 


\begin{tabular}{|c|c|c|c|c|c|c|c|}
\hline Junín & JUNV & NW-B & Argentina & Calomys. musculinus & Sí & Sí & (Parodi et al., 1959) \\
\hline Machupo & MACV & NW-B & Bolivia & Calomys callosus, Calomys. laucha & Sí & Sí & (Johnson et al., 1965) \\
\hline Guanarito & GTOV & NW-B & Venezuela & Zygodontomys brevicauda & Sí & Sí & (Salas et al., 1991) \\
\hline Sabiá & SABV & NW-B & Brasil & desconocido & Sí & Sí & (Lisieux et al., 1994) \\
\hline Lassa & LASV & OW & NO-África & Mastomys sp. & Sí & Sí & (Fabiyi, 1976) \\
\hline LCM $^{*}$ & LCMV & OW & Mundial & Mus musculus & Sí & No & (Armstrong y Lillie, 1934) \\
\hline Mobala & MOBV & OW & Rep. Centroafricana & Praomys sp. & $\mathrm{NI}$ & No & (Gonzalez et al., 1983) \\
\hline Mopeia & MOPV & OW & Mozambique & Mastomys natalensis & $\mathrm{NI}$ & No & (Wulff et al., 1977) \\
\hline Ippy & IPPYV & OW & Rep. Centroafricana & Arvicanthus sp. & $\mathrm{NI}$ & No & (Swanepoel et al., 1985) \\
\hline Flexal & FLEV & NW-A & Brasil & Oryzomys spp. & Sí & No & (Bowen et al., 1996b) \\
\hline Pichindé & PICV & NW-A & Colombia & Oryzomys albigularis & $\mathrm{NI}$ & No & (Mifune et al., 1971) \\
\hline Paraná & PARV & NW-A & Paraguay & Oryzomys buccinatus & $\mathrm{NI}$ & No & (Webb et al., 1970) \\
\hline Allpahuayo & ALLV & NW-A & Perú & Oecomys bicolor & $\mathrm{NI}$ & No & (Moncayo et al., 2001) \\
\hline Pirital & PIRV & NW-A & Venezuela & Sigmodon alstoni & $\mathrm{NI}$ & No & (Fulhorst et al., 1997) \\
\hline Tacaribe & TCRV & NW-B & Trinidad & Artibeus spp. (murciélagos) & Sí & No & (Downs et al., 1963) \\
\hline Cupixi & CPXV & NW-B & Brasil & Oryzomys capito & $\mathrm{NI}$ & No & (Bowen et al., 1998) \\
\hline Amaparí & AMAV & NW-B & Brasil & Oryzomys capito-Neacomys guianae & $\mathrm{NI}$ & No & (Pinheiro et al., 1966) \\
\hline Oliveros & OLVV & NW-C & Argentina & Bolomys obscurus & $\mathrm{NI}$ & No & (Bowen et al., 1996a) \\
\hline Latino & LATV & NW-C & Bolivia & Calomys callosus & $\mathrm{NI}$ & No & (Webb et al., 1975) \\
\hline Whitewater arroyo & WWAV & NW-rec & EEUU & Neotoma spp. & Sí & No & (Fulhorst et al., 1996) \\
\hline Tamiami & TAMV & NW-rec & EEUU & Sigmodon hispidus & $\mathrm{NI}$ & No & (Calisher et al., 1970) \\
\hline Bear Canyon & BCNV & NW-rec & EEUU & Peromyscus sp. & $\mathrm{NI}$ & No & (Fulhorst et al., 2002) \\
\hline Kodoko & & OW & Guinea & Nannomys minutoides & $\mathrm{NI}$ & - & (Lecompte et al., 2007) \\
\hline Morogoro & & OW & Tanzania & Mastomys sp. & $\mathrm{NI}$ & - & Günther, no publicado. \\
\hline Dandenong & & OW & Australia & desconocido & Sí & - & (Palacios et al., 2008) \\
\hline Pinhal & & NW-C & Brasil & Calomys tener & $\mathrm{NI}$ & - & Bisordi, no publicado \\
\hline Catarina & & NW & EEUU & Neotoma micropus & $\mathrm{NI}$ & - & (Cajimat et al., 2007) \\
\hline Skinner Tank & & NW & EEUU & Neotoma mexicana & $\mathrm{NI}$ & - & (Cajimat et al., 2008) \\
\hline Chapare & & NW-B & Bolivia & desconocido & Sí & - & (Delgado et al., 2008) \\
\hline Lujo & & Equidistante de OW y NW & Zambia & desconocido & Sí & - & (Briese et al., 2009) \\
\hline
\end{tabular}

"LCM: virus de la coriomeningitis linfocitaria. Hasta la doble línea se detallan los virus reconocidos por el International Committee for the Taxonomy of Viruses (ICTV), la autoridad máxima para la taxonomía de virus. Debajo se describen los virus recientemente caracterizados (aún no reconocidos oficialmente). Los países listados corresponden al lugar de aislamiento. Categoría A: Los virus incluidos en esta clasificación (por los CDC) representan los patógenos con el mayor potencial para uso como arma biológica. Abreviaturas: NI, no informado; NW (A,B,C): linajes A, B y C de los arenavirus del Nuevo Mundo; NW-rec: arenavirus del nuevo mundo recombinantes de ancestros de dos 


\section{Estructura}

Los viriones son pleomórficos, con un tamaño que oscila entre 70 y $120 \mathrm{~nm}$ de diámetro. Poseen una cápside con simetría helicoidal e incluyen un número variable de ribosomas en su interior dando un aspecto granulado o "arenoso" en micrografías electrónicas (Figura 1). Durante la brotación de las células adquieren una envoltura lipídica derivada de la membrana citoplasmática.

Su genoma está constituido por dos moléculas de RNA monocatenario, denominadas $L$ y $S(7,2 \mathrm{~kb}$ y $3,5 \mathrm{~kb}$, respectivamente). Cada una de ellas posee dos marcos de lectura abierto, no superpuestos y de polaridad opuesta, que dieron origen a la denominación ambisense (Auperin et al., 1984) para diferenciar esta estrategia de las conocidas para otros genomas de RNA de cadena simple (negative y positive sense). EI RNA L contiene la información para la proteína de matriz, Z, y una RNA polimerasa dependiente de RNA, L. Por su parte, el RNA S, codifica el precursor de las glicoproteínas, GPC. Éste es luego procesado para dar origen a G1, G2 y el péptido señal estable (SSP). Por último, el RNA $S$ codifica la proteína
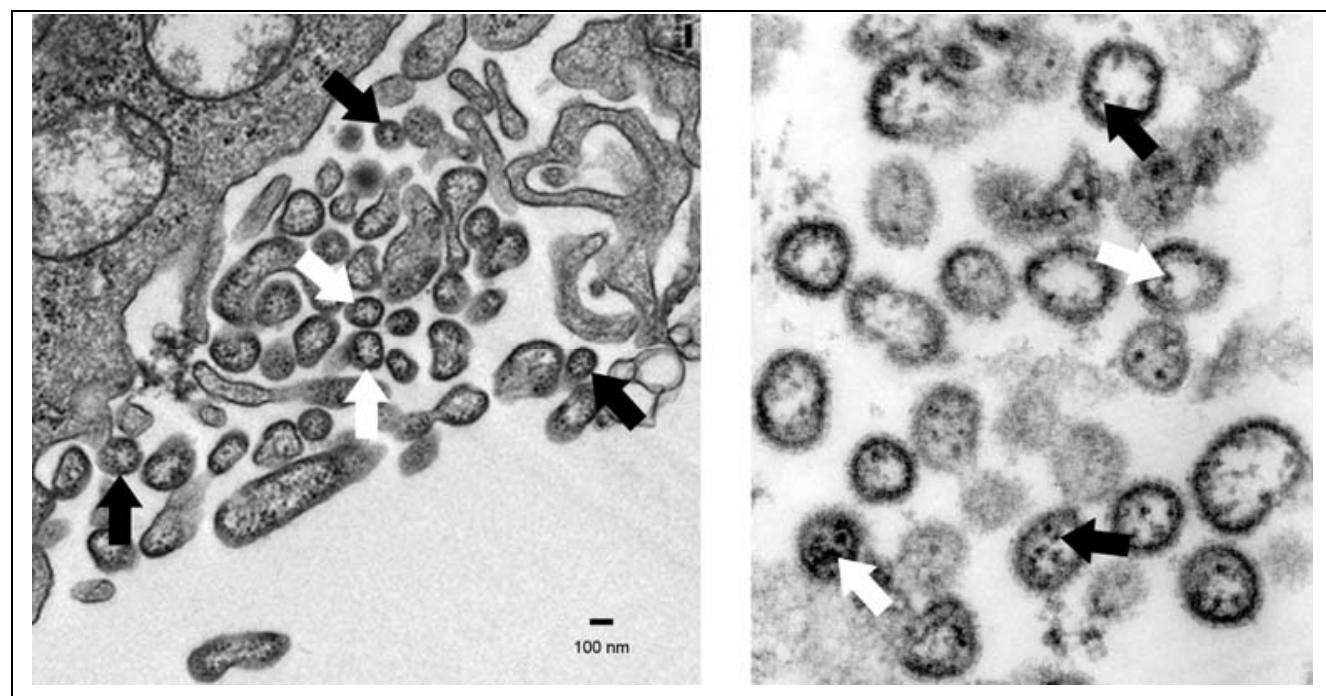

Figura 1. Micrografía electrónica de arenavirus.

Fotografías de microscopía electrónica de transmisión del virus Lassa. En la imagen de la izquierda se señalan con flechas los viriones (barra de $100 \mathrm{~nm}$ ). En la de la derecha las flechas destacan los ribosomas que dan el aspecto arenoso a los viriones. Imágenes de boletín de la organización mundial de la salud, http://www.who.int/bulletin/volumes/86/12/08-011208/en/index.html y School of Veterinary Medicine, University of California, http://www.vetmed.ucdavis.edu/viruses/download.html. 


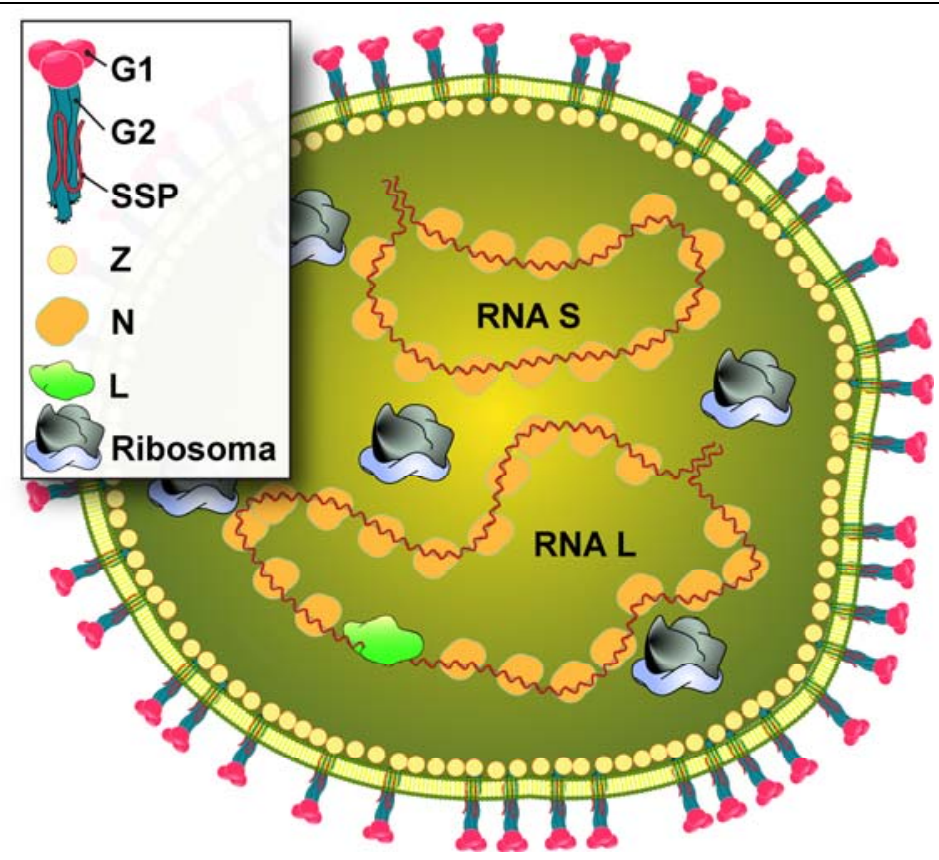

Figura 2. Esquema de un arenavirus.

Sólo se muestran los componentes estructurales. La proteína de superficie G1 reconoce al receptor celular y se encuentra asociado a la proteína de transmembrana G2. Ésta, junto con el péptido señal estable (SSP), participa en la fusión de membranas mediada por la acidificación del endosoma. $\mathrm{N}$, la nucleoproteína, está asociada al RNA. Z es una proteína de matriz. L es una RNA polimerasa dependiente de RNA. Los ribosomas son incorporados en la partícula viral durante su morfogénesis (fuente: esta tesis).

mayoritaria de la nucleocápside, N (Ghiringhelli et al., 1991; Meyer et al., 2002; Strecker et al., 2003). En la Figura 2 se esquematiza un arenavirus con todos sus componentes estructurales.

\section{Ciclo replicativo}

La interacción virus-célula comienza con el establecimiento del contacto de la proteína G1 de las espículas virales con el receptor celular. Éste es adistroglicano, en el caso de arenavirus del viejo mundo y linaje $\mathrm{C}$ del nuevo mundo, o el receptor de transferrina, en los linajes $A$ y $B$ de los del nuevo mundo (Cao et al., 1998; Radoshitzky et al., 2007; Radoshitzky et al., 2008; Reignier et al., 2006; Rojek y Kunz, 2008). La interacción virus-receptor provoca la curvatura de la membrana celular para dar lugar a la endocitosis, seguida de la fusión entre las membranas del virus y de la vesícula endocítica mediada por el cambio conformacional de G2 (Rojek y Kunz, 2008; York et al., 2004). A continuación, se liberan las nucleocápsides (RNA + proteína) que actúan como moldes para la transcripción y replicación viral 


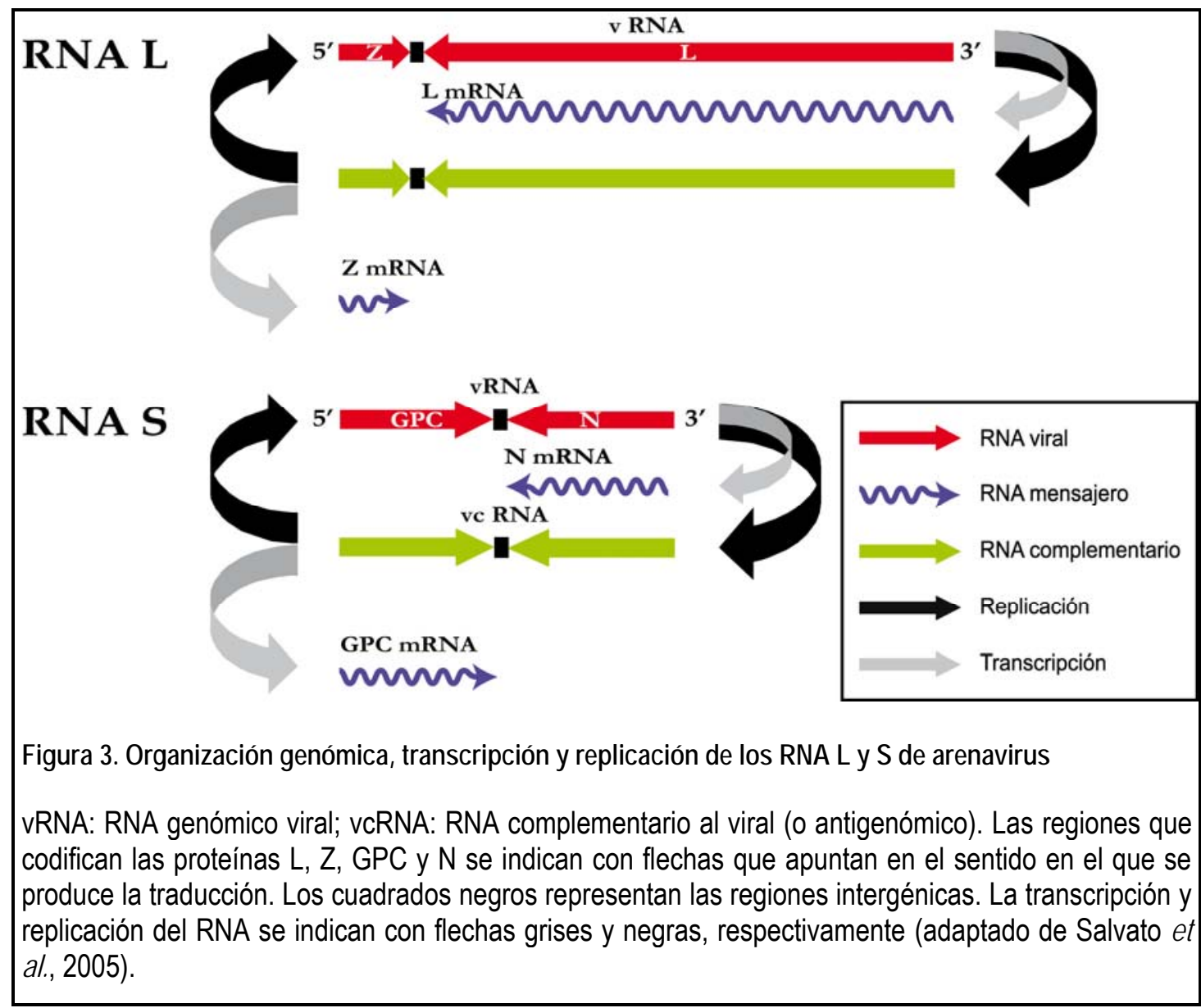

en el citosol (Figura 3). Solamente las moléculas subgenómicas (que contienen un solo marco de lectura abierto u ORF) funcionan como mRNAs y son abordadas por la maquinaria de traducción para sintetizar las proteínas L, Z, N y GPC. Esta última es procesada en el sistema del retículo endoplásmico-aparato de Golgi para producir, como ya se mencionó, los componentes que dan origen a las espículas, G1, G2 y SSP. La proteína Z participa en la regulación de la transcripción y es la proteína de matriz que contribuye a la morfogénesis de las partículas virales (Perez et al., 2003; Perez et al., 2004; Strecker et al., 2003). Durante la brotación se incorporan, en proporciones no equimolares, de las nucleocápsides $L$ y $S$ y cantidades variables de ribosomas (Romanowski y Bishop, 1983). 


\section{Fiebre Hemorrágica Argentina}

La Fiebre Hemorrágica Argentina (FHA), cuyo agente etiológico es el virus Junín, es una enfermedad endémica caracterizada por alteraciones cardiovasculares, hematológicas, renales, inmunológicas y neurológicas. Posee una mortalidad aproximada de entre un 15 y un $30 \%$, siendo este un valor que sufrió variaciones a lo largo de los años (Figura 4).

La FHA es una enfermedad estacional, que presenta un pico máximo en número de casos durante los meses de abril y junio (Weissenbacher et al., 1983).

Los primeros casos registrados aparecieron a mediados de la década del 50 , y desde entonces, se ha informado una gran variación en el número de casos anuales, de entre 300 y 3000 ; aunque en los últimos años se observan alrededor de 80 casos anuales (Figura 5).

Si bien no hay estudios epidemiológicos exhaustivos, existe evidencia, obtenida en estudios sobre trabajadores en situación de riesgo de que la infección puede cursar en forma sub-clínica (de Guerrero et al., 1982; Weissenbacher et al., 1978). Actualmente se estima que el $80 \%$ de las infecciones sigue un curso clínico (Enria et al., 2008).

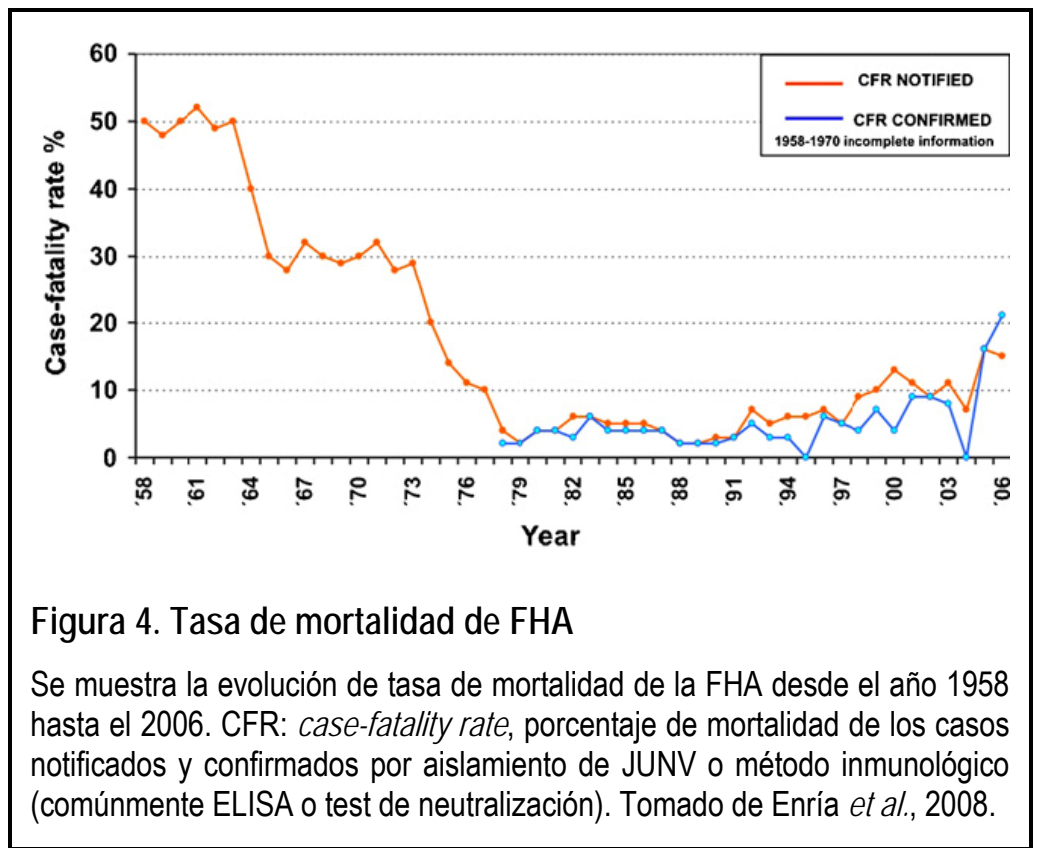




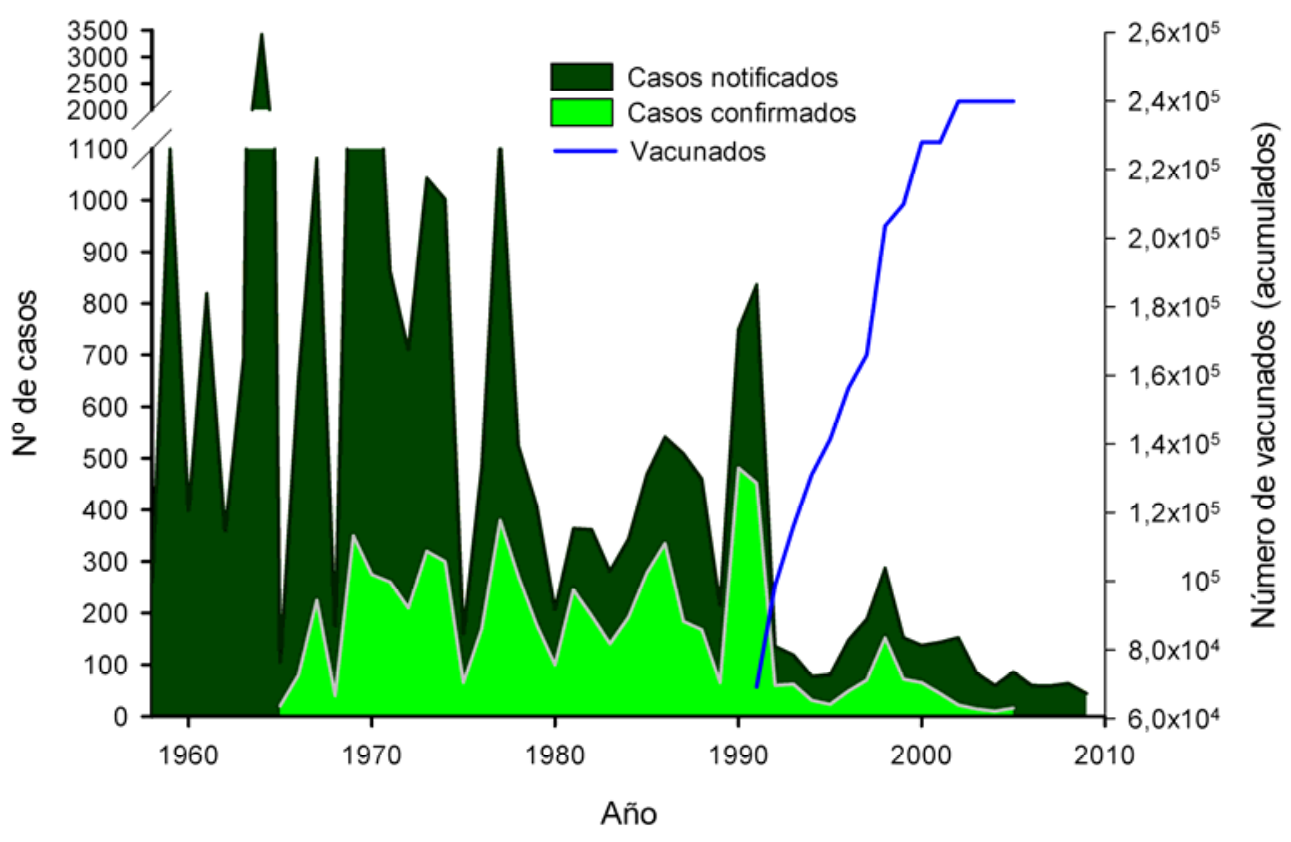

Figura 5. Incidencia de FHA y número de vacunados con Candid \#1

Se muestra los casos de FHA desde su emergencia en 1958 y hasta junio de 2009 según datos oficiales del ministerio de salud de la nación (http://sitios.msal.gov.ar/). Sólo se cuenta con la información de los casos confirmados (serología o aislamiento, INEVH) e individuos vacunados entre los años 1965 y 2005.

El área endémica de la enfermedad ocupaba una superficie de $16.000 \mathrm{~km}^{2}$ en el norte de la provincia de Buenos Aires, entre 1958 y 1962, habiéndose extendido rápidamente hacia las provincias de Córdoba, Santa Fe y La Pampa (Maiztegui y Sabattini, 1977; Mills et al., 1994). Actualmente, el área endémica cubre más de $150,000 \mathrm{~km}^{2}$, en una región con más de 5 millones de habitantes y potencialmente en riesgo (Figura 6) (Enria et al., 2008; Garcia et al., 2000; Maiztegui et al., 1986). Esta región corresponde a la zona agrícolo-ganadera más importante de la Argentina, y la población más expuesta está constituida por trabajadores rurales (Maiztegui, 1975b). Por ello la enfermedad, a

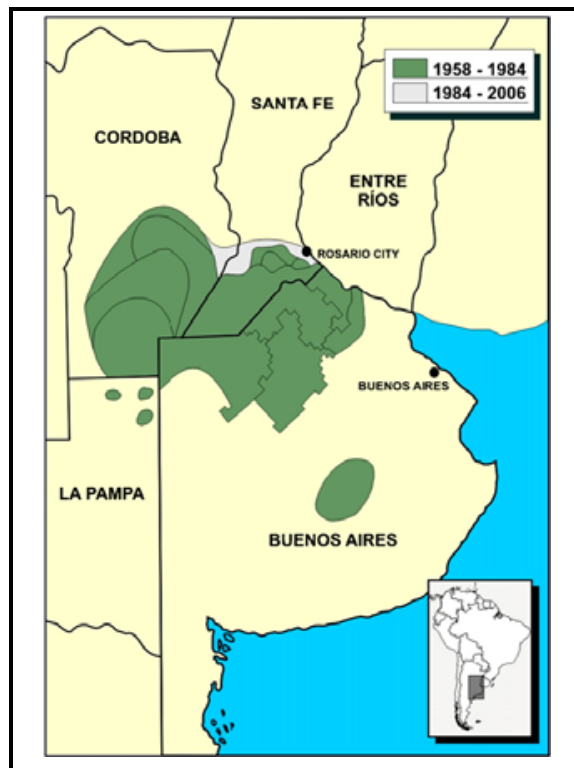

Figura 6. Área endémica de la FHA

Se muestra el área endémica para la FHA en nuestro país $\left(\sim 150.000 \mathrm{~km}^{2}\right)$ con una población potencialmente en riesgo de aproximadamente 5 millones de personas en la actualidad. Imagen de Enria et al., 2008. 
pesar de no poseer una casuística importante, ha tenido un considerable impacto en la salud y en la economía de la Argentina. En consecuencia, se ha estimulado la investigación sobre FHA y su agente etiológico para resolver este problema sanitario (Enria et al., 2008).

La etiología viral de la infección fue establecida en 1958 por dos grupos en forma independiente. Estos grupos aislaron el agente viral a partir de sangre y órganos obtenidos por necropsias en el Hospital Regional de la ciudad de Junín, provincia de Buenos Aires, y de aquí el nombre del agente etiológico (Parodi et al., 1959; Pirosky et al., 1959).

\section{Epidemiología de la fiebre hemorrágica argentina}

En las fiebres hemorrágicas argentina (FHA) y boliviana (FHB) la infección en humanos se produce a través de las mucosas (conjuntival, inhalatoria $u$ orofaríngea) o de lesiones de la piel. Las fuentes y vehículos de virus son aerosoles, polvo u otros materiales contaminados con la orina, la saliva o la sangre de roedores infectados (Arribalzaga, 1955; Johnson et al., 1965; Kenyon et al., 1992; Maiztegui, 1975a; Rugiero et al., 1964a; Rugiero et al., 1964b; Rugiero et al., 1964c). Las semillas, tallos de malezas y rastrojos contaminados con deyecciones y sangre de roedores infectados fueron identificados tempranamente como las fuentes de infección, dando lugar al nombre popular de la FHA: "mal de los rastrojos" (Arribalzaga, 1955; Johnson et al., 1965; Kenyon et al., 1992; Maiztegui, 1975a; Rugiero et al., 1964a; Rugiero et al., 1964b; Rugiero et al., 1964c). El contagio interhumano se demostró en muy pocos casos (Enria et al., 1998).

Los roedores son los reservorios naturales de casi todos los arenavirus (Salazar-Bravo et al., 2002). Todavía es una incógnita cuál fue el camino evolutivo que pudo haber seguido un arenavirus ancestral para pasar de un roedor a un quiróptero frugívoro. Sin embargo, la evidencia creciente de la estrecha relación y la consecuente co-evolución de los arenavirus y sus respectivos reservorios roedores aumenta el escepticismo acerca del verdadero huésped natural de Tacaribe (Abraham et al., 2009; Bowen et al., 1997; Emonet et al., 2009; Gonzalez et al., 2007; Radoshitzky et al., 2008). 
En todo caso, sí se sabe que entre los años 1956 y 1958 este virus circuló en murciélagos y fue aislado de once animales diferentes (Salazar-Bravo et al., 2002). En el caso del virus Junín el reservorio principal es la laucha bimaculada, Calomys musculinus (Sigmodontinae, Muridae), un roedor con hábitos rurales, aunque también ha sido aislado de Calomys laucha, Akodon azarae y Oryzomys flavescens (Buchmeier et al., 2001). Ocasionalmente, se ha encontrado la infección en otros roedores con hábitos urbanos como Mus musculus (Sabattini y Gonzalez, 1967). En la Argentina, además de JUNV, se encuentran otros dos arenavirus: el virus de la coriomeningitis linfocitaria (LCMV, del inglés Lymphocytic ChorioMeningitis Virus) y el virus Oliveros (Buchmeier et al., 2001). El LCMV infecta al ratón común, Mus musculus, lo cual explica su distribución mundial, a diferencia de los demás arenavirus que se encuentran en regiones geográficas relativamente restringidas. En Latinoamérica, además de JUNV, existen otros arenavirus asociados con FH: los virus Machupo y Chapare (Bolivia), el virus Guanarito (Venezuela), y el virus Sabiá (Brasil). En África, el virus Lassa produce una FH severa. En los roedores infectados, el virus sigue un ciclo que asegura su mantenimiento en la naturaleza. En general, se encuentran altos títulos virales en casi todos los órganos y en los fluidos corporales como la sangre $y$, en particular, la saliva del animal. En la mayoría de los arenavirus, los roedores presentan infecciones crónicas inaparentes, con eliminación persistente del virus al medio ambiente (Staneck et al., 1972) (Rawls et al., 1981). De esta manera, se contagian los roedores sanos y, ocasionalmente, se infecta el hombre.

Aunque se detectan casos de FHA durante cualquier época del año, esta enfermedad tiene una distribución estacional que abarca desde marzo hasta julio (Maiztegui, 1975b). Este hecho está relacionado con el número de roedores dentro del área endémica. La población de C. musculinus aumenta considerablemente durante estos meses del año, probablemente debido a un cambio en las condiciones ambientales que favorecen su desarrollo (como por ejemplo la abundancia de alimentos en la época de las cosechas).

Si bien no hay estudios sobre el impacto económico y social, se calcula una incidencia de 140 cada 100.0000 habitantes (total) y 355 cada 100.000 en 
hombres adultos en el área endémica. Esta prevalencia mayor en varones (de hasta cuatro veces con respecto a las mujeres), y en particular, dentro de la población rural, está estrechamente relacionada con los hábitos de sus reservorios y con la relación ocupacional de la exposición. Por ejemplo, los maquinistas de las cosechadoras y sus asistentes muestran una mayor incidencia, probablemente por un mayor contacto con los aerosoles contaminados con material infeccioso (Maiztegui, 1975b). Durante el primer brote de FHA, la enfermedad afectó principalmente a personas que trabajaban en la cosecha de cereales. En los campos sembrados con cereales se encontró una mayor densidad de roedores, lo que aumenta el riesgo, durante la cosecha, para la transmisión del virus entre el roedor y el hombre. Sin embargo, las verdaderas causas de la extensión progresiva del área endémica de FHA aún no se conocen. De hecho, varias especies de Calomys han sido aisladas en diferentes regiones rurales fuera del área endémica, e incluso se demostró que algunos de ellos se encontraban infectados (Mills et al., 1991a; Mills et al., 1991b; Parodi et al., 1961; Weissenbacher et al., 1985).

Si bien en nuestro país los arenavirus producen enfermedad en relación a la actividad productiva, estos virus también son objeto de estudio debido a sus potencialidades como arma biológica. En este sentido, los Centros para el Control y Prevención de Enfermedades (CDC, Centers for Disease Control and Prevention) con sede en Atlanta, EE.UU., han clasificado al JUNV y a otros arenavirus dentro de la categoría A (Tabla 1). Entre las propiedades de estos agentes que favorecerían su uso, se destacan la alta morbilidad y mortalidad, la disponibilidad (natural y de laboratorio), la capacidad de formar aerosoles infectivos y la posibilidad de multiplicarlos en cultivos celulares escalables. Con dichas características, los agentes en esta categoría tienen el mayor potencial para ser usados en atentados bio-terroristas (Rotz et al., 2002). 


\section{Fisiopatología de la infección por arenavirus del nuevo mundo}

La fisiopatología de las enfermedades producidas por los arenavirus sudamericanos, Junín, Machupo y Guanarito (FHV, fiebre hemorrágica Venezolana), es muy similar, diferenciándose en este aspecto de la fiebre producida por el virus de Lassa (ver más adelante), un arenavirus originario de África. El conocimiento actual sobre la patogénesis de la FHA o de la FHB, proviene principalmente de la experimentación en ratones lactantes y en cobayos (Bruno et al., 1968; Coto et al., 1972). Sin embargo, muchas de las alteraciones fisiológicas y patológicas observadas en estos animales luego de la inoculación con los virus Junín o Machupo, no se correlacionan con las manifestaciones de la enfermedad en el hombre. Estas limitaciones fueron superadas en FHA, usando macaco Rhesus como modelo de la infección del hombre con el virus Junín. Además, distintas cepas aisladas de pacientes con diferentes cuadros clínicos de FHA, reprodujeron la enfermedad con las mismas manifestaciones clínicas en los macacos, indicando que las respuestas biológicas diferentes estaban especificadas por el virus utilizado (Green et al., 1987). Se ha demostrado que en la fase aguda de la infección, el virus Junín se replica activamente en linfomonocitos de sangre periférica, sugiriendo que éste es el sitio primario de replicación viral (Ambrosio et al., 1986). Aunque aún no se han realizado estudios definitivos, la evolución de la enfermedad parece estar relacionada con el título del virus en sangre o en tejidos. Estudios de microscopía electrónica mostraron inclusiones citoplásmicas y un daño celular inespecífico en todos los órganos examinados en casos mortales. Los estudios de inmunofluorescencia sugieren que los daños celulares podrían estar relacionados con antígenos virales pero no con inmunoglobulinas o fracciones del complemento. En estudios se reveló la activación del sistema de complemento, pero no existe evidencia de la formación del complejo inmune (de Bracco et al., 1978). Probablemente, el daño celular sea causado directamente por la replicación viral más que por la respuesta inmune (Maiztegui et al., 1975). En ese sentido, se ha encontrado que la presencia de la nucleoproteína viral en el citoplasma de células en cultivo 
mimetiza el efecto citopático producido por la infección con el virus Junín (Rivera Pomar et al., 1991).

En la fiebre de Lassa, A pesar de los diferentes grados de hemorragias, hay suficientes similitudes entre el curso de la enfermedad en FHA, FHB y la fiebre de Lassa, como para pensar que los caminos patofisiológicos de las tres enfermedades están relacionados. La función de los órganos, excepto para el sistema endotelial, permanece intacta. El periodo crítico de shock es corto, durando apenas entre 24 a 48 h. El daño hepático es escaso, produciendo una hepatitis moderada (Mando, 1977) y la función renal está bien mantenida. La hemorragia es más prominente en FHA y FHB que en la fiebre de Lassa, pero no es la causa del shock y de la muerte. Sin embargo, la ruptura capilar es significativa, produciendo una pérdida de proteínas y de volumen intravascular, mucho más pronunciada que la pérdida de eritrocitos. De hecho, el progreso de la enfermedad se ve asociado con una proteinuria elevada y una deshidratación junto con hemo-concentración. Las observaciones clínicas sugieren que una disfunción endotelial vascular, y la subsiguiente falla circulatoria, ocurre en las tres enfermedades, sin que exista una clara evidencia de replicación viral en el endotelio con el correspondiente daño o ruptura endotelial (Maiztegui et al., 1975).

\section{Manifestaciones clínicas de la enfermedad}

El período de incubación es usualmente de 6 a 14 días. Se reconocen tres fases clínicas durante la enfermedad: prodrómica, neurológica-hemorrágica, y de convalecencia (Enria et al., 2004).

\section{Fase prodrómica}

Se extiende durante la primera semana desde el comienzo de los síntomas. Éstos son insidiosos y asemejan los de la gripe común, con escalofríos, malestar, anorexia, dolor de cabeza, mialgia centralizada particularmente en la zona baja de la espalda e hipertermia moderada $\left(38-39^{\circ} \mathrm{C}\right)$. Otros síntomas comunes son dolor retro-orbital, náuseas o vómitos, dolor epigástrico, fotofobia, mareo, constipación o diarrea moderada. El examen físico del paciente revela enrojecimiento de la 
cara, cuello y pecho superior, congestión conjuntival y edema periorbital. La encía aparece congestionada y puede sangrar espontáneamente o bajo presión suave. Sobre el paladar blando, se puede encontrar prácticamente siempre una erupción compuesta por petequias y pequeñas vesículas. Típicamente, los pacientes presentan petequias cutáneas en la región axilar, debajo del pecho y en los brazos. Los ganglios linfáticos latero-cervicales se presentan inflamados. Generalmente, no se detectan signos de anormalidades pulmonares. Frecuentemente, se detecta bradicardia moderada e hipotensión ortostática. Síntomas como Hepatomegalia, esplenomegalia o ictericia son muy raros. Al final de esta fase el paciente puede sentirse irritable, letárgico, y con un sutil temblor en las manos y la lengua. También se presentan ataxia moderada, hiperestesia cutánea, y una disminución en el reflejo tendinoso profundo y tonicidad muscular. En las mujeres, la presencia de metrorragias es característica.

\section{Fase neurológica-hemorrágica}

Aproximadamente el $20-30 \%$ de los casos con FHA entran en esta fase de 8 a 12 días después del comienzo de los síntomas presentando hemorragias severas o manifestaciones neurológicas, shock e infecciones bacterianas superpuestas. Entre los signos hemorrágicos se incluyen hematemesis, melena, hemoptisis, epistaxis, hematomas, metrorragias y hematuria. Comienzo de confusión mental, marcada ataxia, irritabilidad creciente, temblores son los signos neurológicos iniciales acompañados posteriormente por delirios, convulsión generalizada y coma. Infecciones bacterianas superpuestas, como neumonía y septicemia pueden complicar la enfermedad durante este periodo. Falla renal aguda son infrecuentes, pero puede aparecer en esta fase en casos terminales, usualmente después de prolongados periodos de shock como consecuencia de la necrosis tubular aguda. 


\section{Fase convaleciente}

En casos de supervivencia se prolonga durante uno a tres meses. Los pacientes experimentan astenia, irritabilidad, cambios de memoria y pérdida de cabello. Alrededor del $10 \%$ de los casos tratados con plasma inmune desarrollan un síndrome neurológico tardío (o late neurological syndrome, LNS). Este síndrome comienza después de un periodo libre de síntomas, y se caracteriza por síntomas febriles, signos cerebelosos y parálisis de pares craneales (Enria, 2005; Enria et al., 2004). No se han registrado casos de pacientes de FHA con LNS que se hayan recobrado sin un tratamiento específico (Enria et al., 1985; Maiztegui et al., 1979).

\section{Diagnóstico clínico y de laboratorio}

El diagnóstico de FHA es primariamente establecido por examen clínico, análisis generales de laboratorio bioquímico y anamnesis del paciente (permanencia en el área endémica en las últimas tres semanas) (Harrison et al., 1999). Los síntomas y signos iniciales de la FHA son similares a los de muchas otras enfermedades infecciosas. Sin embargo, la velocidad de eritrosedimentación, que es normal o esta disminuida, y la leucopenia permiten descartar la mayoría de las infecciones bacterianas. Además, el recuento de plaquetas es por debajo de 100.000 y los tiempos de sangría y de retracción de coágulo están concordantemente prolongados. También se ha descripto la presencia de un inhibidor de la agregación de plaquetas circulante (Cummins et al., 1990) junto con niveles disminuidos de los factores de coagulación II, V, VII, VIII y X y de fibrinógeno. A pesar de ello, las alteraciones en las funciones de coagulación son menores. En FHA se han observado, además altos niveles de interferón alfa en pacientes con una enfermedad severa, llegando hasta $64.000 \mathrm{Ul} / \mathrm{ml}$ (Levis et al., 1984), y una disminución en el complemento. Los niveles de interferón en los pacientes con FHA se relacionan con la severidad de la enfermedad y con su progreso (Levis et al., 1985). Contrariamente, los títulos virales en suero son bajos, pero la infección es aparentemente pantrópica (Weissenbacher et al., 1975). También se puede detectar proteinuria, y el sedimento urinario contiene cilindros hialinos granulares y eritrocitos. La elevación de aspartato 
transaminasa, creatina fosfoquinasa, y lactato-deshidrogenas son comunes pero moderados. Creatinina y urea en suero son generalmente normales, pero se incrementan en casos severos en correlación con la deshidratación y shock. De la fase aguda de la enfermedad, el fluido cerebroespinal es normal, incluso en pacientes con manifestaciones neurológicas severas. Sin embargo, el fluido cerebroespinal en pacientes con LNS muestra un incremento moderado en el numero de células y la presencia de anticuerpos contra el virus Junín en títulos que exceden la relación 1:40 comparado con los valores detectados en el suero (Enria et al., 2004) (Enria, 2005).

\section{Terapéutica}

La respuesta inmune contra el virus Junín puede ser muy efectiva en la eliminación del virus durante la enfermedad aguda, y además, puede ser suficiente para proteger contra futuras infecciones. Los anticuerpos detectados en pacientes que comienzan a recuperarse después de una infección aguda son principalmente anticuerpos neutralizantes (de Bracco et al., 1978). En ese sentido, la eficacia terapéutica del tratamiento de los pacientes de FHA con plasma inmune (plasma de convalecientes de FHA) está directamente relacionada al título de anticuerpos neutralizantes en el plasma suministrado (Enria et al., 1984). Actualmente, se recomienda una dosis de al menos 3000 unidades terapéuticas por $\mathrm{kg}$ de peso corporal (Enria et al., 1984). Por otra parte, aunque se ha mostrado alguna evidencia en humanos de respuesta inmune mediada por células, su rol en la eliminación del virus y en la protección subsiguiente es desconocido. En la década del 70 se realizaron importantes avances en el tratamiento de la FHA. Los resultados de los estudios originales sobre la utilización de la administración pasiva de anticuerpos como tratamiento para la infección de virus Machupo en primates, sugirieron que esta terapia podría tener éxito en humanos para el tratamiento de FHA o de FHB (Eddy et al., 1975). Poco tiempo después, un ensayo realizado sobre un muestreo estadístico de pacientes de FHA en el Instituto Nacional de Estudios sobre Virosis Humanas en Pergamino, estableció la eficacia de la administración de plasma de la fase convaleciente como tratamiento para la FHA. Esta terapia redujo drásticamente la tasa de mortalidad de $30 \%$ hasta menos de un $1 \%$ 
solo cuando fue aplicada previamente al octavo día después del comienzo de la infección (Maiztegui et al., 1979). Esta forma de tratamiento, neutraliza la viremia, acorta la duración del período febril, disminuye la intensidad de la mayoría de las alteraciones y reduce la incidencia de las infecciones bacterianas agregadas. Hasta el momento, la administración de plasma inmune, obtenido de pacientes que han sobrevivido a la infección por virus Junín se ha convertido en la única terapia efectiva contra la FHA. Sin embargo, esta mejora no se logró sin un costo, ya que $10 \%$ de los pacientes tratados con plasma inmune desarrollaron el síndrome neurológico tardío (Ambrosio et al., 1986). Este síndrome, no ha sido observado en pacientes no tratados, y, hasta el momento, no ha podido detectarse la presencia de virus Junín en preparaciones de líquido cefalorraquídeo de los pacientes afectados. El síndrome neurológico tardío comienza entre cuatro y siete semanas después del comienzo de la enfermedad aguda y termina en menos de una semana más. Este síndrome se caracteriza por fiebre, cefalea, ataxia, temblores y esta asociado con una pleocitosis moderada y la presencia de anticuerpos contra el virus Junín en el líquido cefalorraquídeo (Enria et al., 1986). El cuadro neurológico es, en general, benigno, pero puede provocar secuelas, y en algunos casos raros, hasta la muerte del paciente. El título de los anticuerpos neutralizantes contra el virus Junín produce un pico más tardío, aunque de mayor valor, en el caso de los pacientes con el síndrome neurológico tardío, comparado con el que se obtiene para los pacientes tratados que no desarrollan el síndrome o con los pacientes no tratados (Weissenbacher et al., 1987). No parece existir ninguna correlación entre el día de la administración de la terapia o la dosis de anticuerpos neutralizantes suministrada, y la aparición del síndrome neurológico tardío. Además, la terapia conlleva otro riesgo que consiste en la posible transmisión al paciente de algún agente infeccioso transportado por sangre. Esto hace imprescindible el ensayo del plasma utilizado para la detección de agentes infecciosos, tales como los virus que producen hepatitis, el HIV y el Trypanosoma cruzi. Por otra parte, la terapia depende de una provisión limitada del plasma que donan voluntariamente los convalecientes de FHA. Previamente a su utilización, se debe obtener el título de anticuerpos neutralizantes presentes en el plasma donado. Una 
última complicación es que desde el comienzo de la aplicación masiva de la terapia, el título de anticuerpos neutralizantes detectados en los individuos receptores del plasma inmune está disminuyendo en los últimos años (Enria et al., 2008).

Por otra parte, la administración adicional de ribavirina, un agente antiviral de amplio espectro, podría optimizar aún más dicho tratamiento, permitiendo la reducción de la dosis necesaria de anticuerpos neutralizantes (Enria et al., 2008; Enria y Maiztegui, 1994).

\section{Confirmación etiológica}

La FHA es una enfermedad de notificación obligatoria en nuestro país (Ley 15.465), cuyo diagnóstico se basa en datos clínicos y de laboratorio. En este contexto, parámetros como recuento plaquetario menor a $100.000 / \mathrm{mm}^{3}$ y glóbulos blancos por debajo de $2.500 / \mathrm{mm}^{3}$ se han utilizado como criterio para la detección de posibles enfermos en áreas endémicas (Harrison et al., 1999).

El diagnóstico etiológico y de confirmación de la FHA puede establecerse mediante un inmunoensayo o ELISA (enzyme-linked immunosorbent assay) (Peters y Oldstone, 2002) o por RT-PCR (reverse transcriptase-polymerase chain reaction). Este último fue desarrollado previamente en nuestro laboratorio en colaboración con el Instituto Nacional de Enfermedades Virales Humanas (INEVH) de Pergamino (Lozano et al., 1995; Lozano et al., 1993) y es el único método de diagnóstico de laboratorio específico aplicable en etapas tempranas de la enfermedad (Lozano et al., 1995). Por su parte, los ensayos inmunológicos pueden confirmar la etiología, seguir la evolución del paciente, detectar infecciones previas no diagnosticadas y contribuir en programas de vigilancia epidemiológica en roedores capturados para la evaluación y el control de esta zoonosis. Debido a su sencillez, sensibilidad, objetividad y bajo costo, el ELISA es el método de rutina para la confirmación etiológica en pacientes convalecientes y para la vigilancia de la zoonosis (Morales et al., 2002; Riera et al., 1997). Pese a ello, su utilidad queda restringida a fines epidemiológicos, ya que la presencia de anticuerpos es detectada tardíamente durante la convalecencia. En efecto, 
aunque la conversión serológica ocurre, en general, después del primer mes, su detección se utiliza como un ensayo etiológico definitivo, recién a los 6090 días después de la internación del paciente, sólo con el fin de confirmar el diagnóstico etiológico de FHA. El ensayo se realiza por las técnicas de ELISA (Garcia Franco et al., 1988) o test de neutralización (Barrera Oro et al., 1990). La técnica de inmunofluorescencia indirecta, también muy utilizada, es análoga a la desarrollada para FHB (Peters et al., 1973). La técnica de fijación de complemento es muy poco utilizada en la actualidad (Casals, 1977).

La mayor desventaja de los métodos inmunológicos actualmente empleados, radica en que la producción de los antígenos $(\mathrm{Ag})$ utilizados se realiza infectando cultivos celulares con JUNV. Esto implica la restricción a laboratorios equipados con un nivel de bio-seguridad 3 o 4 (BSL-3/4) y a la variabilidad que pueda existir entre los Ag producidos por distintos laboratorios. Por otra parte, las cepas atenuadas de JUNV, que pueden manipularse con menores medidas de seguridad (BSL-2), se replican dando títulos bajos. Por esta razón, sería de gran valor contar con un método de diagnóstico que no implique la manipulación del virus patógeno en su desarrollo y que emplee $\mathrm{Ag}$ producidos mediante técnicas de DNA recombinante.

\section{Vacunación}

Hace más de una década, se introdujo una vacuna a virus atenuado, Candid \#1, que resultó efectiva (Enria et al., 2008; Maiztegui et al., 1998). En la Figura 5 se observa la correlación entre la vacunación a partir del año 1991 y la disminución en la incidencia de la enfermedad.

La vacuna fue desarrollada mediante un proyecto de colaboración entre el Ministerio de Salud Pública de la República Argentina y los laboratorios de USAMRIID en Maryland, Estados Unidos. Esta es una vacuna a virus vivos de virulencia atenuada (Ambrosio et al., 2006). La vacunación consiste en la administración de una cepa de virus Junín de virulencia atenuada, llamada Candid \#1, para provocar la respuesta inmune protectora en los pacientes. 
La cepa vacunal fue derivada de la misma cepa original de la que 20 años antes se obtuvo la cepa atenuada XJ-Cl3 (Weissenbacher et al., 1987). La cepa atenuada vacunal mostró no poseer efectos adversos en primates sin evidencia de persistencia viral. Esta vacuna, que ha pasado exitosamente una serie de pruebas clínicas en Estados Unidos y en Argentina, incluyendo un estudio realizado con 6000 voluntarios, es un adelanto para la protección de individuos de muy alto riesgo de contraer la enfermedad. De hecho la vacunación es una protección importante tanto para los trabajadores rurales en el área endémica como para el personal del sistema de salud que trabaja en estrecho contacto con el virus. Sin embargo, la alta frecuencia de mutación de los virus cuyo genoma esta constituido por RNA (Holland et al., 1982), es un argumento a ser tenido en cuenta en la evaluación del riesgo que implica el use de una vacuna a virus vivos, toda vez que no se conocen fehacientemente los determinantes de la atenuación de la virulencia a nivel molecular. Sin embargo, existen indicios de que mutaciones puntuales en la RNA polimerasa, L, podrían ser los determinantes de la atenuación (Goni et al., 2006). Por otra parte, y al igual que otras vacunas a virus atenuados, presenta ciertas desventajas al no poder administrarse a individuos inmunocomprometidos y gestantes. A ello se agrega el riesgo latente de reversión de la atenuación. De hecho, durante el desarrollo de la vacuna Candid \#1, se observó que durante el re-aislamiento de virus en macacos Rhesus vacunados, el pasaje in-vivo generó variantes con índices de letalidad de entre 10 y 1000 veces el valor del atenuado control (Enría y Barrera Oro, 2002). A ello deben sumarse, además, la alta frecuencia de recombinación y reasociación de los virus con genoma segmentado (Vezza et al., 1980) y la formación de viriones con genomas poliploides (Romanowski y Bishop, 1983) . 

Objetivos 



\section{Contexto}

La importancia del estudio de los arenavirus resulta no solo de su condición de patógenos humanos sino también de su potencial uso como modelos experimentales para estudiar la interacción virus-hospedador. En nuestro país, el virus Junín es el agente etiológico de la fiebre hemorrágica argentina (FHA), una enfermedad endémica que pone en riesgo a cinco millones de habitantes, principalmente trabajadores rurales de la zona agrícolo-ganadera más importante del país. En consecuencia, esta enfermedad tiene un impacto considerable en la salud de la población y a su vez en la economía de la Argentina. Como se mencionó previamente, durante la última década se ha aplicado una vacuna a virus atenuado que resultó efectiva. Sin embargo, los riesgos asociados a su uso, tanto por la manipulación viral para la producción de la vacuna como la posible reversión de la atenuación en la cepa vacunal, ponen de manifiesto la necesidad de desarrollar nuevas estrategias preventivas. Sumado a esto, los métodos inmunológicos actualmente empleados para el seguimiento epidemiológico de la FHA también requieren la producción de los antígenos $(\mathrm{Ag})$ a partir de cultivos celulares infectados con la cepa virulenta y la utilización de laboratorios con un nivel de seguridad adecuado para tal fin. En consecuencia, la utilización de un método de diagnóstico que no implique la manipulación del virus patógeno en su desarrollo y que, en cambio, emplee Ag virales producidos mediante técnicas de DNA recombinante, representaría un gran avance en el estudio, control y prevención de la FHA. Con el fin de contribuir al desarrollo de tales técnicas y conocimientos los objetivos de este trabajo de tesis doctoral son:

\section{Objetivos generales de la investigación}

- Desarrollo de ensayos diagnósticos de fiebre hemorrágica argentina basados en antígenos recombinantes.

- Evaluación de proteínas virales como candidatos vacunales mediante la fusión genética a adyuvantes naturales. 


\section{Objetivos particulares de la investigación}

- Clonado, expresión y purificación de antígenos recombinantes.

- Desarrollo y validación de un método ELISA basado en antígenos recombinantes.

- Caracterización de anticuerpos monoclonales contra $\mathrm{N}$ de arenavirus.

- Evaluación de la eficacia de anticuerpos monoclonales para el diagnóstico de fiebres hemorrágicas producidas por arenavirus.

- Clonación, expresión y purificación de proteínas virales fusionadas a la subunidad B de la toxina colérica y evaluación como candidatos vacunales. 
Capítulo I 



\section{Ensayo de diagnóstico basado en la proteína recombinante $\mathbf{N}$ del virus Junín}

\section{Resumen}

Debido a su morbilidad y alta tasa de mortalidad en casos sin tratamiento, la FHA debe ser notificada obligatoriamente en nuestro país. Para la vigilancia epidemiológica es necesario contar con métodos diagnósticos seguros y precisos. Los ensayos actuales están basados en Ag preparados a partir de cultivos celulares infectados con el virus. El riesgo biológico asociado a la manipulación de grandes cantidades de virus restringe la producción a laboratorios equipados con la contención biológica apropiada. En este capítulo se describe el desarrollo y validación de un ELISA basado en $\mathrm{Ag}$ recombinantes producidos en células de insecto. Ocho variables del ensayo fueron optimizadas aplicando el método de Taguchi para el diseño experimental (disposición L18, 7 factores de 3 niveles y 1 factor de 2 niveles). El área bajo la curva ROC (receiver operating characteristics) fue de 0,966 , lo que muestra la alta eficiencia del ensayo al discriminar las muestras positivas de las negativas. Teniendo en cuenta los beneficios asociados a la bio-seguridad, rendimiento de $\mathrm{Ag}$ en el cultivo celular y alto rendimiento general del ensayo, se espera que se convierta en una herramienta alternativa al ELISA actual para el diagnóstico etiológico y en estudios de vigilancia epidemiológica.

\section{Introducción}

\section{Baculovirus como sistema de expresión de proteínas}

La familia Baculoviridae está constituida por virus a DNA, envueltos y que infectan principalmente insectos del orden Lepidoptera (Adams y McClintock, 1991). Su permanencia en el ambiente en su ciclo natural se facilita por la protección de los viriones en cuerpos de inclusión, llamados poliedros 
(género Nucleopolyhedrovirus). Éstos están formados por una proteína mayoritaria (poliedrina) cuya expresión ocurre a niveles muy altos en etapas tardías de la infección. En cultivos celulares, estos genes no son esenciales, por lo que pueden ser reemplazados por genes heterólogos bajo el control del promotor de poliedrina. De esta manera, pueden obtenerse altos niveles de expresión de las proteínas recombinantes, alcanzando entre el 25 y $50 \%$ de la masa total de proteínas (O'Reilly et al., 1992). Asimismo, el sistema baculovirus-células de insecto tiene la ventaja de ser un sistema eucariótico seguro, sencillo y eficaz. Entre las ventajas se incluyen los altos niveles de expresión proteica, expresión de proteínas grandes, clivaje eficiente de péptidos señal, modificaciones post-traduccionales, capacidad de expresar simultáneamente varios genes y la propiedad de ser un sistema escalable (Fath-Goodin et al., 2006).

Debido a su sencillez, alta sensibilidad, objetividad y bajo costo, el ELISA es el sistema más utilizado en la detección de anticuerpos en diagnóstico confirmatorio (retrospectivo) y en estudios seroepidemiológicos (Morales et al., 2002; Riera et al., 1997).

La proteína $\mathrm{N}$ de los arenavirus es la más abundante y conservada entre las proteínas estructurales tanto en células infectadas como en viriones (Buchmeier et al., 2007) y es comúnmente el blanco seleccionado en ELISA para la detección de antígenos virales (Saijo et al., 2007). Asimismo, se ha observado que las nucleoproteínas de arenavirus son las proteínas más conservadas entre cepas de la misma especie o, hasta cierto punto, entre diferentes especies de arenavirus (Bui et al., 2007; Gonzalez et al., 1996). Por lo tanto, $\mathrm{N}$ posee características aptas para su utilización en ensayos diagnósticos, tanto para la detección de anticuerpos contra $\mathrm{N}$ en sueros de pacientes convalecientes como en el desarrollo de anticuerpos monoclonales para la detección de Ag virales. 


\section{Resultados y discusión}

En estudios previos, se ha propuesto el uso de proteínas $\mathrm{N}$ recombinantes de arenavirus del viejo mundo como Ag para ensayos diagnósticos tanto con sueros humanos como animales (Barber et al., 1987; Barber et al., 1990; Gunther et al., 2001; Homberger et al., 1995; Lukashevich et al., 1993; Lloyd et al., 1989; Saijo et al., 2007; Ter Meulen et al., 1998). Sin embargo, el ELISA acá descripto es el primero desarrollado para el diagnóstico de una fiebre hemorrágica provocada por un arenavirus del nuevo mundo y basado enteramente en una proteína viral recombinante.

Para la expresión de la proteína $\mathrm{N}$ se eligió el sistema baculovirus-células de insecto, en función de las consideraciones adelantadas en la sección anterior. Además, a priori, se esperaban niveles menores de reactividad cruzada que si se utilizase la misma proteína, pero expresada en bacterias, lo que, en consecuencia, demandaría una mayor purificación del $\mathrm{Ag}$ recombinante y posiblemente una menor sensibilidad debido al mayor background.

El gen $\mathrm{N}$ del JUNV (cepa MC2 de patogenicidad moderada y aislada de roedor) fue reconstruido a partir de dos clones de una biblioteca de cDNA (Ghiringhelli, 2002). Luego, fue clonado en los vectores de transferencia pAcUW2B (Weyer et al., 1990) y pAcRP25 (Merryweather et al., 1990). Estos vectores de transferencia fueron empleados para obtener los baculovirus recombinantes AcJUN-N+ (polh+) y AcJUN-N (polh-) (Ghiringhelli, 2002).

Se obtuvieron altos niveles de expresión de la proteína $\mathrm{N}$ en células de insecto infectadas con los baculovirus recombinantes en las condiciones empleadas (aproximadamente el $43 \%$ de la proteínas totales según estimación densitométrica) (Figura $7 \mathrm{C}$ ). La identidad de $\mathrm{N}$ fue demostrada mediante western blot (panel B) con un anticuerpo monoclonal ya descripto (Sanchez et al., 1989). 


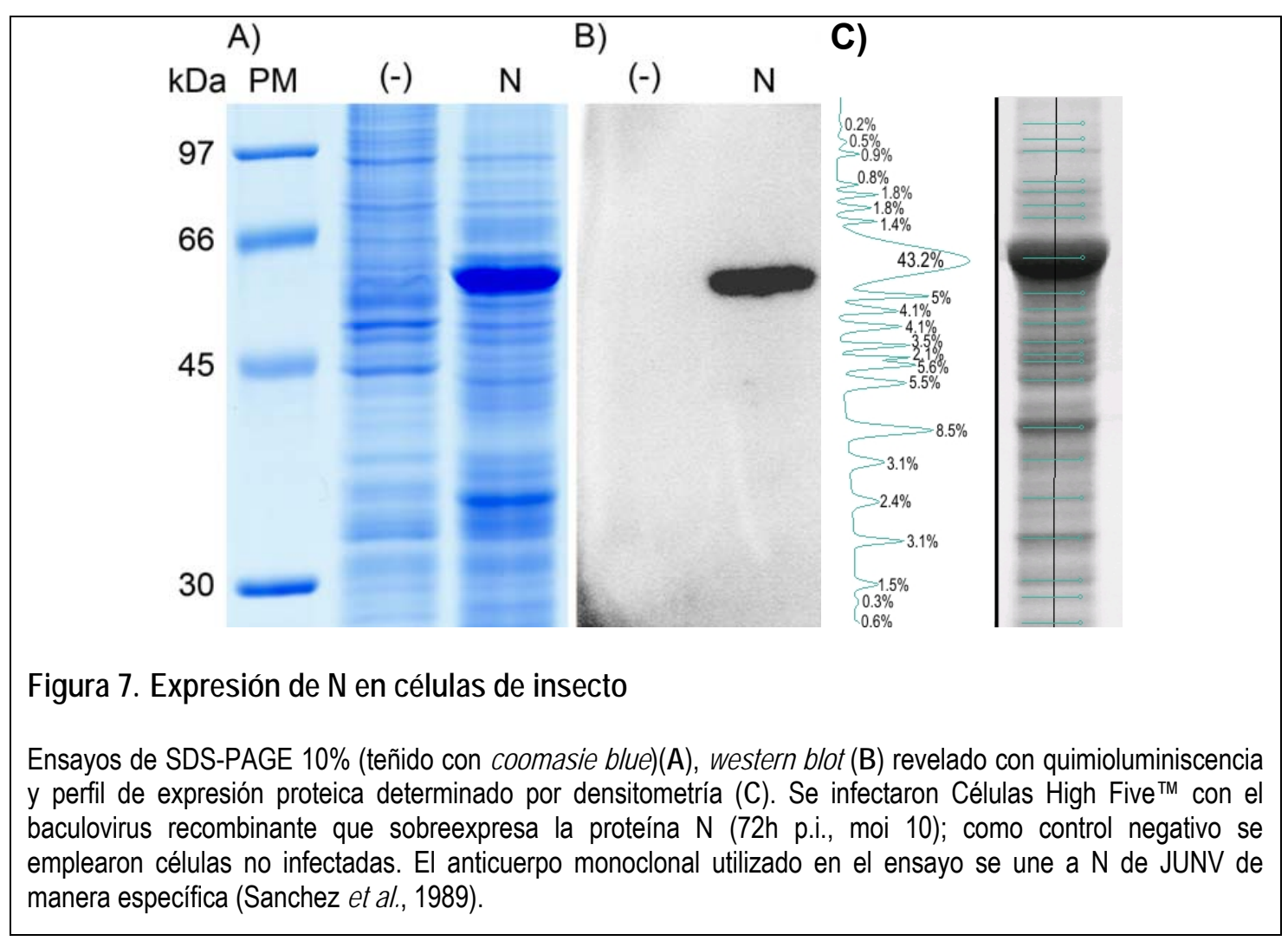

Se realizaron ensayos de cinética de expresión con el fin de establecer las mejores condiciones para la sobreexpresión de $\mathrm{N}(24,48,72$ y 96 h postinfección (p.i.). Además, se evaluaron distintas multiplicidades de infección (moi) 0,1, 1 y 10, líneas celulares de insecto, Sf9 o High Five ${ }^{\mathrm{TM}}$, y el tipo de baculovirus utilizado, polh+o polh-, es decir, con y sin poliedrina (Figura 8 y Figura 9).

Los rendimientos más altos fueron observados a las $72 \mathrm{~h}$ p.i. en células High Five $^{\mathrm{TM}}$ infectadas con una moi de 10 ufp/célula (ufp, unidades formadoras de placa). No se observaron diferencias entre los baculovirus polh ${ }^{+}$y polh. Sin embargo, se eligió el virus AcJUN-N, que no expresa poliedrina, para emplearlo en el IgG-ELISA. Dicha elección se hizo teniendo en cuenta que la poliedrina expresada en altos niveles en el virus AcJUN-N+ podría competir en la adsorción a la superficie del well en el ELISA. Sin embargo, y de ser necesario, AcJUN-N+ podría utilizarse para la producción de la proteína recombinante a una escala mayor y en larvas de insecto, con una importante reducción de los costos. 


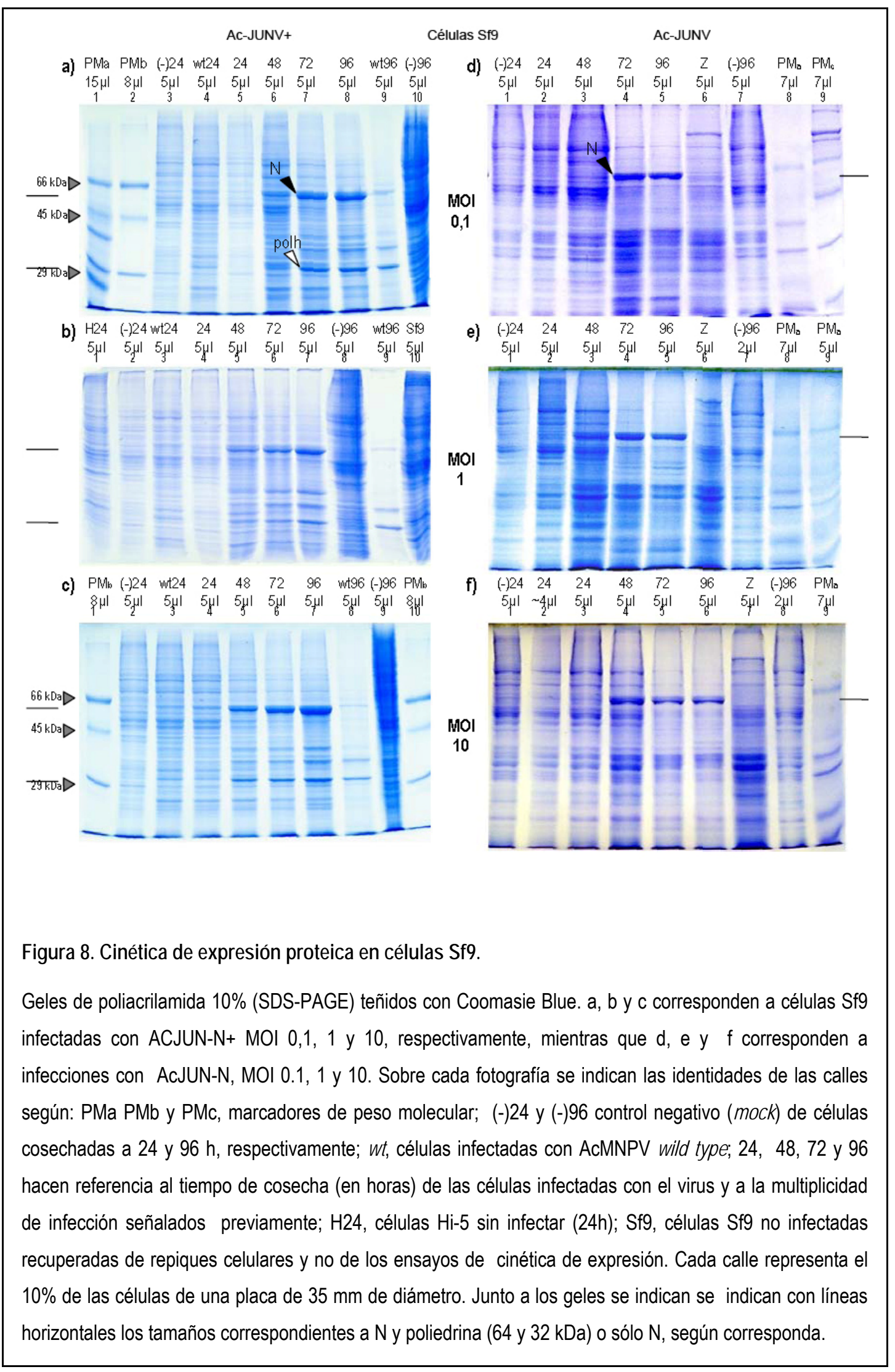




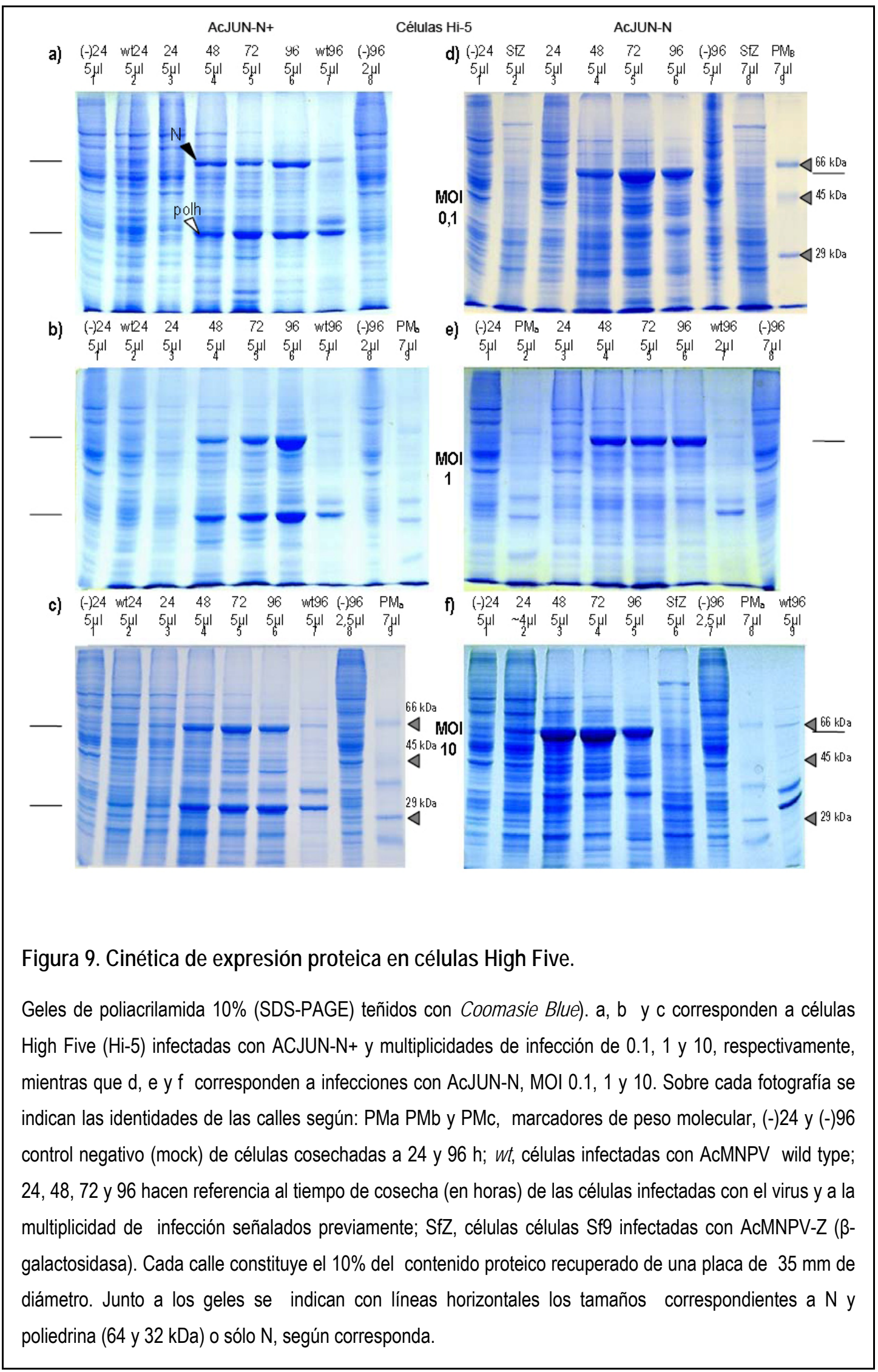


La proteína recombinante $\mathrm{N}(\mathrm{rN})$ se mostró altamente insoluble, como ya había sido observado al expresarla en bacterias (Tortorici et al., 2001). Esta característica fue aprovechada para hacer una purificación parcial de la proteína. La mayoría de las proteínas celulares fueron solubilizadas en una solución $2 \mathrm{M}$ urea, mientras que $\mathrm{N}$ permaneció insoluble. Luego de este procedimiento (ver Expresión y purificación parcial de antígenos para ELISA), se utilizó una solución urea 10 M para su solubilización.

\section{Optimización del IgG-ELISA}

En un ensayo multifactorial como el ELISA, las numerosas variables tienden a generar un protocolo distinto prácticamente para cada ensayo desarrollado. Con el fin de simplificar la optimización del ensayo, se empleó el método de Taguchi (Taguchi, 1993). En un estudio factorial completo, es decir evaluando cada una de las combinaciones posibles, el análisis de la misma cantidad de niveles y factores hubiera demandado un total de 4.374 experimentos (wells) y la misma cantidad para el estudio del background. Se adoptó una disposición L18, la cual permite estudiar 18 experimentos, es decir, 18 combinaciones de factores (variables) y niveles (valores de cada variable). De esta manera es posible estudiar 7 niveles de 3 factores y 1 nivel de 2 factores. Sumado a esto, se hizo el análisis del background, lo que dio un total de 36 experimentos (wells), distribuidos de manera aleatoria en las placas, pero limitados por el tiempo de incubación (factor I). Es decir, los wells que tuvieran el mismo nivel para el factor I fueron incluidos en la misma placa. Los resultados se detallan en la Tabla 2. Se eligieron las condiciones con los mejores cocientes, aún cuando la incidencia de ese factor fuese despreciable. No se aplicó este criterio en el caso de la dilución del anticuerpo anti-lgG humana, en el que se optó por el nivel de la mayor dilución. Se tomó esta decisión para economizar uno de los reactivos más costosos del ELISA y en vista de la disminución mínima en el desempeño del ensayo, a juzgar por la incidencia de este factor. El protocolo resultante fue el descripto en Materiales y Métodos (IgG-ELISA). 
Tabla 2. Condiciones óptimas y ANOVA para el IgG-ELISA

\begin{tabular}{|c|c|c|c|c|c|c|c|c|c|c|c|c|}
\hline \multirow[b]{4}{*}{ Factor(a) } & \multicolumn{4}{|c|}{ Señal Positiva (+) } & \multicolumn{4}{|c|}{ Señal del Background (B) } & \multicolumn{4}{|c|}{ Cociente (+)/(B) } \\
\hline & \multicolumn{3}{|c|}{ Totales de Taguchi } & \multirow[b]{2}{*}{$\% \mathrm{~F}$} & \multicolumn{3}{|c|}{ Totales de Taguchi } & \multirow[b]{2}{*}{$\% \mathrm{~F}$} & Total & s de Ta & uchi & \multirow[b]{2}{*}{$\% \mathrm{~F}$} \\
\hline & & Nivel & & & & Nivel & & & & Nivel & & \\
\hline & 1 & 2 & 3 & (ANOVA) & 1 & 2 & 3 & (ANOVA) & 1 & 2 & 3 & (ANOVA) \\
\hline $\mathrm{T}$ & 48.105 & 48.619 & - & & -43.315 & -41.586 & - & & 4.941 & 7.091 & - & \\
\hline N & 47.136 & 48.591 & 49.359 & & -42.654 & -41.763 & -42.933 & & 4.558 & 7.056 & 6.435 & \\
\hline U & 48.742 & 48.582 & 47.762 & & -46.336 & -40.617 & -40.396 & 31.07 & 2.502 & 8.069 & 7.478 & 31.16 \\
\hline A & 50.317 & 48.987 & 45.782 & 7.54 & -44.256 & -42.602 & -40.492 & 9.75 & 6.217 & 6.492 & 5.340 & \\
\hline S & 55.046 & 47.145 & 42.896 & 52.76 & -46.309 & -41.771 & -39.270 & 34.88 & 8.770 & 5.519 & 3.760 & 21.54 \\
\hline । & 43.803 & 47.660 & 53.624 & 33.97 & -41.184 & -41.002 & -45.165 & 15.17 & 2.663 & 6.730 & 8.656 & 31.19 \\
\hline D & 46.863 & 48.369 & 49.854 & & -41.661 & -42.472 & -43.217 & & 5.336 & 5.968 & 6.745 & \\
\hline le & 48.237 & 48.073 & 48.777 & & -42.349 & -41.410 & -43.591 & & 6.076 & 6.675 & 5.298 & \\
\hline
\end{tabular}

Las condiciones óptimas están resaltadas con negrita. El porcentaje $F(\% F)$ proviene del ANOVA e indica el porcentaje que representa cada factor del total de cocientes $F$. De éstos, sólo se muestran los valores significativos. (a) T: concentración de tween 20 (en soluciones de lavado ý dilución de anticuerpos). N: conc. de N (coating). U: concentración de urea (coating). A: dil. anti-IgG humanas. S: dil. streptavidina/HRP. I: tiempo de incubación (con anticuerpos). D: tiempo de revelado (cromógeno). le: error (control interno).

Dado que el objetivo principal del ensayo es obtener el mayor cociente posible entre las muestras y el background, se diseñó y probó una nueva fórmula para evaluar los resultados de la optimización con el método de Taguchi. Los resultados estuvieron en concordancia con aquellos obtenidos en forma independiente, tanto para la señal positiva como para el background de acuerdo con la incidencia de cada factor y según el ANOVA (Tabla 2). Esto demostró la aplicabilidad de dicha fórmula para interpretar rápidamente los resultados de la optimización un ELISA con este método.

En síntesis, la implementación del método de Taguchi permitió la rápida optimización del ensayo (dos días) con un fundamento estadístico (ANOVA para la incidencia de cada factor) y un mínimo número de experimentos (108 wells, lo que incluye el estudio del background y los correspondientes triplicados). Sorprendentemente, y según nuestro conocimiento, el método de Taguchi ha sido aplicado previamente para la optimización de ELISA una vez.

El ensayo resultante mostró una variabilidad intra- e inter-ensayo de 4,9\% (CV x 100) y $11,6 \%$, respectivamente.

La Figura 10 muestra la reactividad de sueros positivos para FHA y LCM en el ELISA optimizado con la proteína recombinante. Existe reactividad 

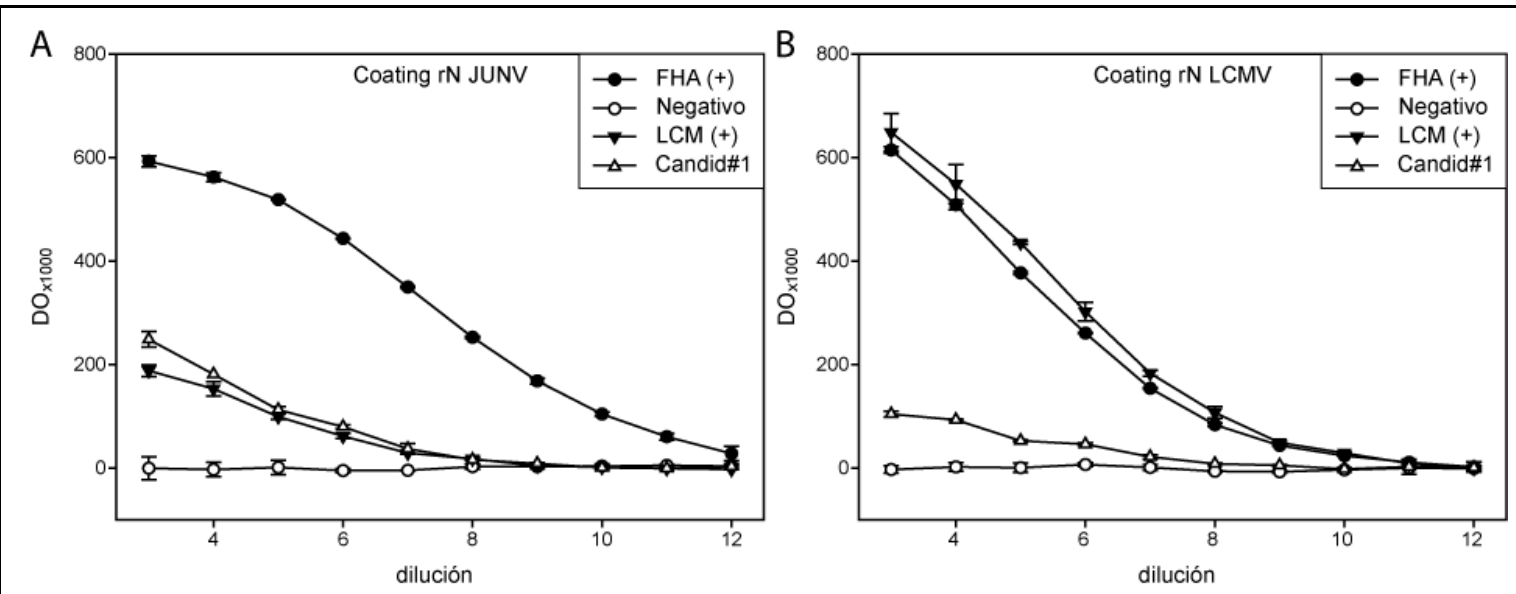

Figura 10. Reactividad de sueros positivos para arenavirus frente a proteínas $\mathrm{rN}$

Reactividad de sueros en el lgG-ELISA basado en la proteína $\mathrm{N}$ recombinante. A: placa sensibilizada con la proteína $\mathrm{N}$ de Ac-JUN-NP; B: placa sensibilizada con N de LCMV producida en paralelo con otro baculovirus recombinante (Matsuura et al., 1986). Diluciones seriadas 1:2 de los sueros a partir de una inicial 1:10 (se muestra a partir de la tercera dilución).

cruzada entre ambos arenavirus como ha sido probado con un suero hiperinmune de conejo (Saijo et al., 2007).

El suero elegido como positivo para FHA en la figura es el que mostró el mayor grado de reactividad cruzada (panel B). Esto probablemente refleje el hecho de que ambos arenavirus coexisten en el área endémica de la FHA (Ambrosio et al., 1994; Ambrosio et al., 2006). Sin embargo, el cociente medio de reactividad JUNV/LCMV (a una dilución 1/400) para los 36 sueros positivos fue de 6.1 .

En la misma figura se muestra la reactividad frente a ambos Ag de un suero correspondiente a una persona que no había sufrido la enfermedad y que fue vacunada (cepa Candid \# 1, INEVH, Pergamino, Argentina) (Figura 10 B).

\section{Evaluación como ensayo diagnóstico}

Con el fin de determinar la precisión del ensayo, es decir, la habilidad de discernir entre muestras positivas y negativas, se empleó un ensayo basado en curvas ROC (no paramétricas). El gráfico ROC es un gráfico de sensibilidad (probabilidad de verdadero positivo) versus 1 - especificidad (probabilidad de un falso positivo). De esta manera, un ensayo con una 


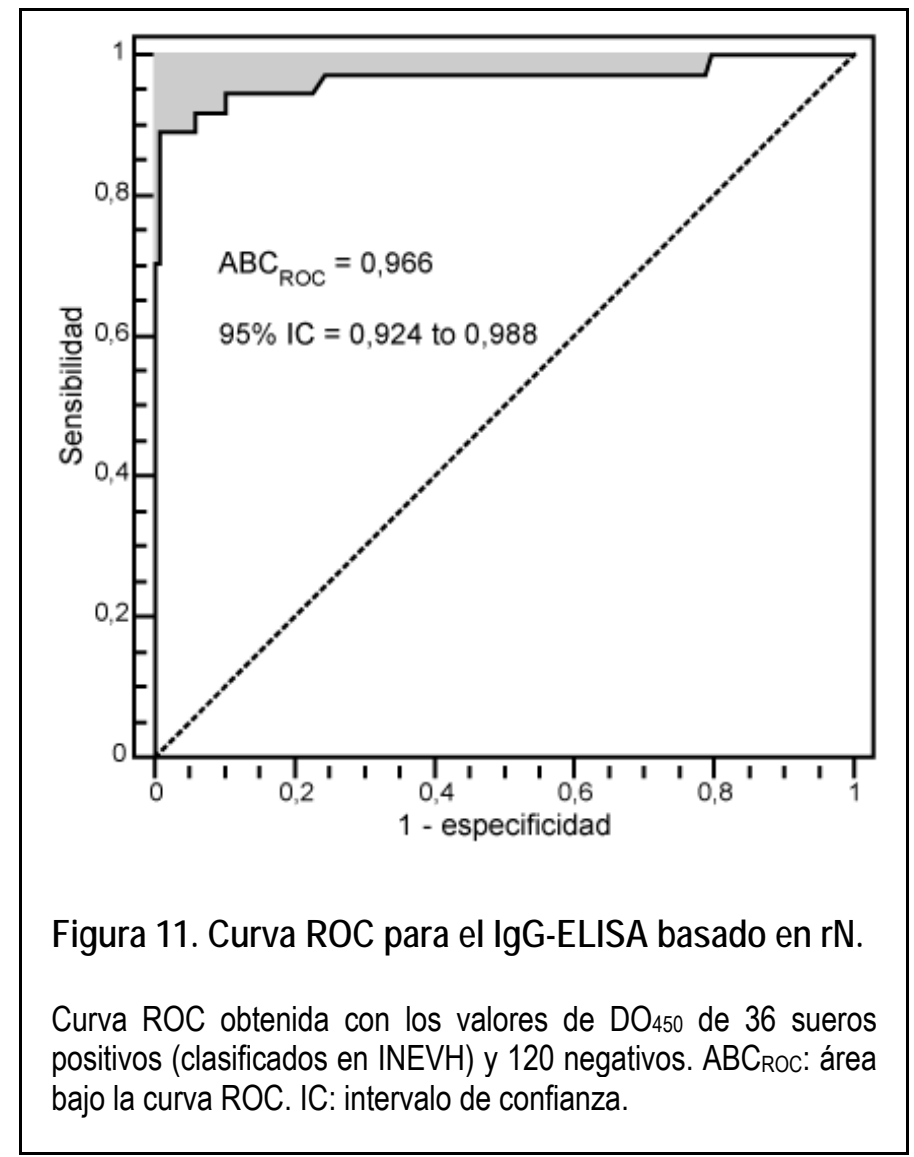

perfecta capacidad de discriminación, esto es, sin superposición entre muestras positivas y negativas, tiene una curva ROC que pasa por el punto superior y a la izquierda y con un área bajo la curva $(A B C)$ de 1 . Por el contrario, un ensayo incapaz de discriminar las muestras tendrá una curva ROC con un ángulo de $45^{\circ}$ y empezando en la esquina inferior izquierda y con un área de 0,5 (Obuchowski et al., 2004; Zweig y Campbell, 1993). En este estudio se incluyeron como positivas todas las muestras cuya reactividad había sido determinada previamente (en el INEVH, Pergamino) ya sea por ELISA basado en el Ag viral (células Vero E6 infectadas con Junín $\mathrm{XJCl}_{3}$ ) o por NT (test de neutralización). Esto y el hecho de sólo conocer la reactividad de cada muestra y no su título, ayuda a evitar la llamada desviación por verificación (selección de las muestras fácilmente diagnosticables).

Se evaluaron 36 sueros positivos y 120 controles. El área bajo la curva ROC $\left(A B C_{R O C}\right)$ fue de $0,966(95 \% \underline{I C}=0,924$ a 0,988), lo que indica que el test tiene una excelente precisión (Figura 11). El área es estadísticamente significativa $(P=0,0001)$. Un área de 0,966 significa que una muestra 


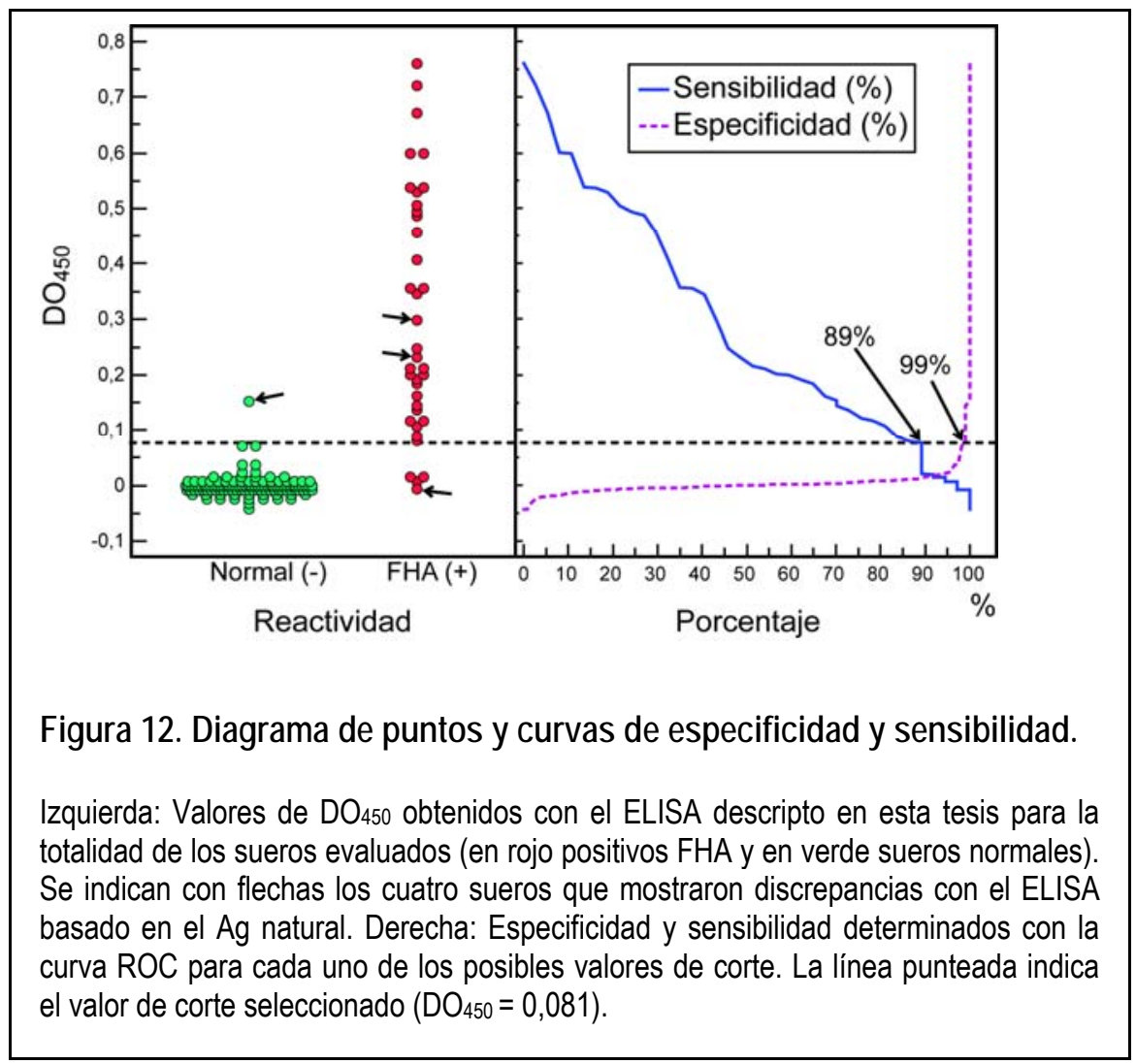

seleccionada aleatoriamente del grupo de los enfermos, tiene un valor en el test de laboratorio superior al de uno seleccionado del grupo de los saludables en el 96,6\% de los casos (Zweig y Campbell, 1993). Se obtuvo un $A B C_{R O C}$ similar utilizando una dilución de suero de 1:10 (datos no mostrados), pero se seleccionó la dilución mayor para ahorrar suero.

Luego de haber determinado que el test tiene una alta precisión, se debería seleccionar un valor de corte que permita obtener altos valores de sensibilidad y especificidad. Este valor de corte (COV por las siglas en inglés de cut-off value) depende de la futura aplicación del IgG-ELISA. En este caso, el ensayo sería empleado para la confirmación de la etiología en pacientes convalecientes, lo que implica que una alta especificidad es lo más relevante. Por el contrario, hay ensayos que requieren la máxima sensibilidad, por ejemplo un ensayo de RT-PCR desarrollado en nuestro laboratorio con el fin de detectar el virus en la fase aguda y permitir la administración de plasma inmune (Lozano et al., 1995; Lozano et al., 1993). En el panel izquierdo de la Figura 12 se muestran los valores de $\mathrm{DO}_{450}$ obtenidos para todos los sueros ensayados. A la derecha, están graficadas las curvas de sensibilidad y especificidad obtenidas de la tabla ROC 
(utilizada para la construcción del gráfico ROC, no mostrada), para cada uno de los posibles COV. Finalmente, se seleccionó el COV con el máximo valor de especificidad y sensibilidad (máxima verosimilitud positiva), $\mathrm{DO}_{450} \geq$ 0,081 . Para dicho valor, se obtiene una especificidad del $99,16 \%$ y una sensibilidad del 89,19\% (IC del 95\%: 95,4-99,9\% y 74,6-96,9\%, respectivamente). La alta especificidad obtenida para dicho COV se ajusta a los requerimientos para este ensayo.

De las 36 muestras consideradas positivas (previamente), 28 fueron estudiadas por ELISA basado en el Ag natural (infección con JUNV). De éstas, 5 habían sido clasificadas como dudosas en la institución de origen (INEVH). Esta clasificación reciben las muestras cuyo título (determinado por la inversa de la última dilución positiva) es igual o cercana al COV (S. Levis, comunicación personal). De las restantes 23 , sólo 4 mostraron discrepancias con el IgG-ELISA desarrollado en el presente estudio y se indican con flechas en la Figura 12. Como consecuencia, se debería realizar una comparación directa entre ambos ensayos antes de aplicarlo a campo, pero basada en muestras fehacientemente clasificadas como positivas 0 negativas (por ejemplo, mediante seroconversión). Esto es particularmente importante cuando se carece de un buen "gold standard" para el diagnóstico, es decir, un método de referencia irrefutable. Esta determinación de la reactividad frente a la verdad es más difícil de llevar a la práctica, pero brinda información mucho más relevante y válida (Zweig y Campbell, 1993). En particular, podrían por ejemplo utilizarse positivos únicamente determinados por aislamiento del virus a partir de monocitos de sangre periférica, método reportado con una eficiencia cercana al 100\% (Ambrosio et al., 1990). 
Capítulo II 



\section{Mapeo de anticuerpos monoclonales y evaluación en ELISA de captura}

\section{Resumen}

Los virus Junín, Machupo, Guanarito, Sabiá y Chapare son miembros del linaje $B$ de los arenavirus del nuevo mundo, y además, son los agentes etiológicos de fiebres hemorrágicas en Sudamérica. En este capítulo se evaluó la reactividad de 3 anticuerpos monoclonales ( $\mathrm{mAb}$, del inglés, monoclonal antibody) anti-N de JUNV, C6-9, C11-12 y E4-2. La especificidad de los mAb fue evaluada por ELISA, western blot y un ensayo de mapeo de epitopes mediante el bloqueo con péptidos. Estos mAb también fueron usados para desarrollar un ELISA de captura de antígeno. Se demostró que con el uso del mAb C6-9 es posible detectar antígenos de JUNV de manera específica. Por otra parte, con los mAb C11-12 o E-4-2, fue posible detectar los antígenos de todos los arenavirus sudamericanos (patogénicos) estudiados. La aplicación combinada de estos ELISA de captura de antígeno podría utilizarse para el diagnóstico en la etapa aguda de las fiebres hemorrágicas provocadas por cualquiera de los arenavirus sudamericanos. 


\section{Introducción}

Los arenavirus son relativamente estables en cuanto a su secuencia aminoacídica, la cual varía entre un 90 y $95 \%$ entre cepas del mismo virus o entre el 44 y $63 \%$ entre proteínas homólogas de las distintas especies (Sevilla et al., 2002). Sin embargo, en un estudio de 333 secuencias de arenavirus patogénicos, se observó que $\mathrm{N}$ posee el grado más alto de conservación, sobre todo concentrado en la región entre los aminoácidos 1 y 310 (Bui et al., 2007).

Entre los arenavirus sudamericanos, JUNV, Machupo (MACV), Guanarito (GTOV), Sabiá (SABV) y Chapare (CHPV) son miembros del linaje B de los arenavirus del nuevo mundo (NW-B, ver Tabla 1) y todos ellos provocan fiebres hemorrágicas en humanos. Esto sugiere que el fenotipo altamente patogénico puede derivar de un ancestro viral común (Bowen et al., 1996b). CHPV fue recientemente aislado y caracterizado a partir de un caso fatal de $\mathrm{FH}$ en Bolivia (Delgado et al., 2008). Estudios filogenéticos indican que JUNV está más relacionado con MACV que con SABV o CHPV, mientras que SABV y CHPV están más estrechamente relacionados entre sí que con cualquier otro arenavirus (Cajimat et al., 2008; Delgado et al., 2008).

En general, se considera que la utilización de mAb específicos de antígenos virales en ELISA de captura es útil para el diagnóstico de fiebres hemorrágicas en la fase aguda mediante la detección de antígenos en sangre y otros tejidos homogeneizados (Saijo et al., 2007). Con JUNV esto ha sido probado en animales, tanto en modelos experimentales como en ensayos de vigilancia epidemiológica, y se cree que podría ser útil para la fase aguda de todas las FH sudamericanas (Buchmeier et al., 2007; Mills et al., 1994; Mills et al., 1991b; Mills et al., 1992). 


\section{Resultados}

\section{Reactividad de anticuerpos monoclonales frente a nucleopro- teínas de arenavirus.}

En colaboración con el grupo del Dr. Shigeru Morikawa (Department of Virology, National Institute of Infectious Diseases, Tokyo) se desarrollaron anticuerpos monoclonales contra la proteína $\mathrm{N}$ de JUNV expresada en el sistema baculovirus-células de insecto detallado en el capítulo anterior.

Mediante ensayos de ELISA, se analizó la reactividad de los mAb con distintas proteínas $\mathrm{N}$ de arenavirus patogénicos sudamericanos. El mAb C69 reaccionó con $\mathrm{N}$ de JUNV, pero no mostró reactividad contra los demás arenavirus (Figura 13). Por el contrario, el mAb C11-12 reconoció con el

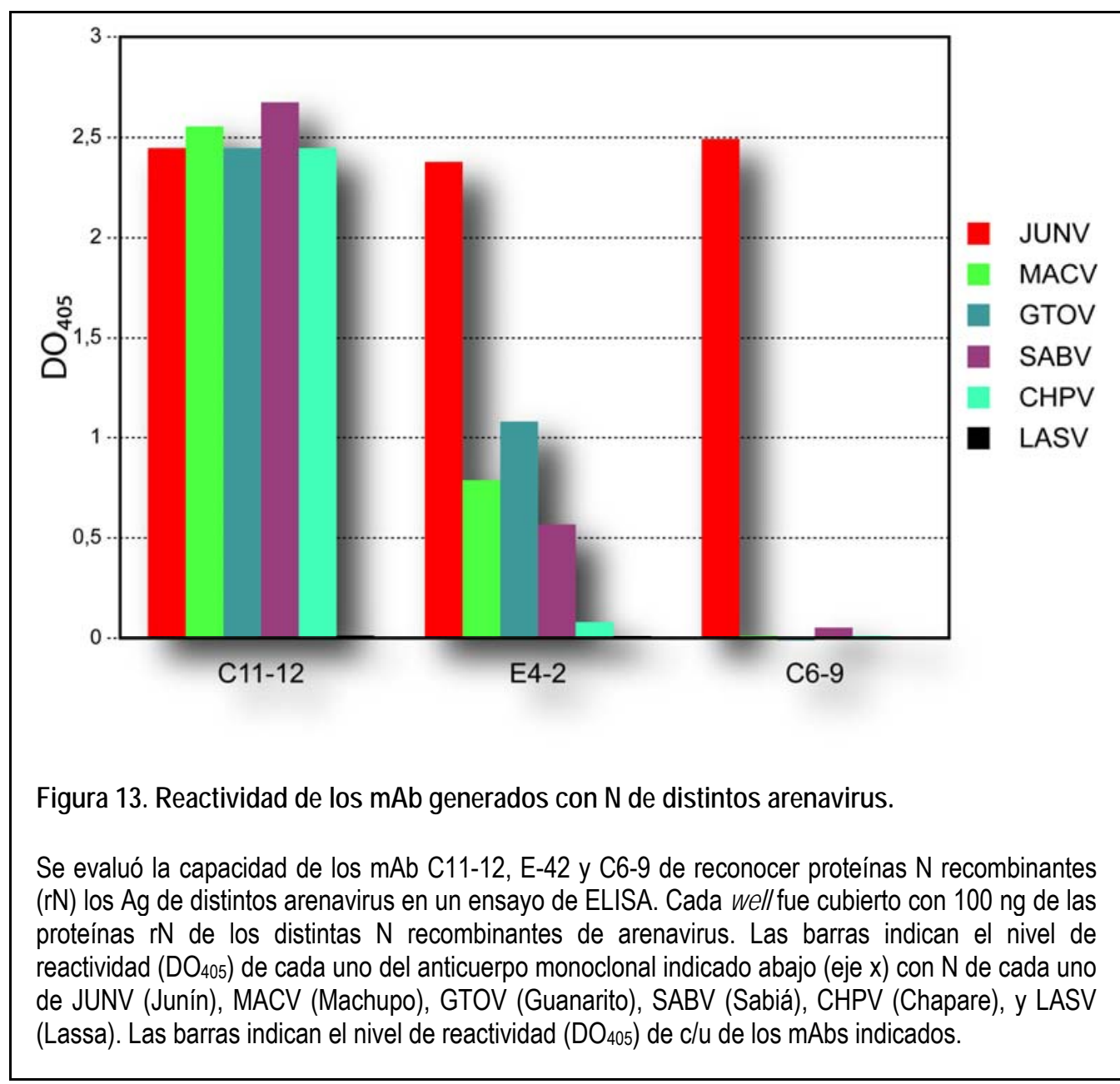


mismo nivel de reactividad todas las proteínas $\mathrm{N}$ recombinantes de los arenavirus sudamericanos JUNV, GTOV, MACV, SABV, y CHPV, pero sin mostrar reactividad con el arenavirus africano, LASV. En una situación intermedia, E4-2 reaccionó con $\mathrm{N}$ de JUNV, pero en menor medida con GTOV, MACV y SABV, y muy débilmente con CHPV.

\section{Desarrollo de ELISA de captura de Ag.}

Con los mAb C11-12, E-42 y C6-9 se desarrollaron ensayos de ELISA de captura de antígeno (Ag-ELISA) y se determinó su especificidad y sensibilidad, en relación a las nucleoproteínas de los otros arenavirus sudamericanos. Éstas fueron sintetizadas y clonadas por el grupo del Dr. Shigeru Morikawa (ver Materiales y Métodos). El Ag-ELISA basado en el mAb C6-9 detectó específicamente $\mathrm{N}$ de JUNV, el límite fue de $62.5 \mathrm{ng} / \mathrm{well}$, y no pudo detectar la proteína homóloga de los otros arenavirus sudamericanos estudiados (Figura $14 \mathrm{~A}$ ). Por el contrario, los ELISA fueron más sensibles cuando el anticuerpo de captura empleado fue el mAb C11-12 y E4-2, siendo capaces de detectar hasta 7,82 y 3,91 ng/well, respectivamente. Con el fin de establecer el grado de especificidad, se emplearon proteínas recombinantes de los distintos arenavirus sudamericanos. Cuando se empleó los mAb también se detectó $\mathrm{N}$ de los otros arenavirus sudamericanos: GTOV, MACV, SABV, y CHPV (Figura 14 B y C). En ninguno de los casos fue posible detectar $\mathrm{N}$ de LASV. 


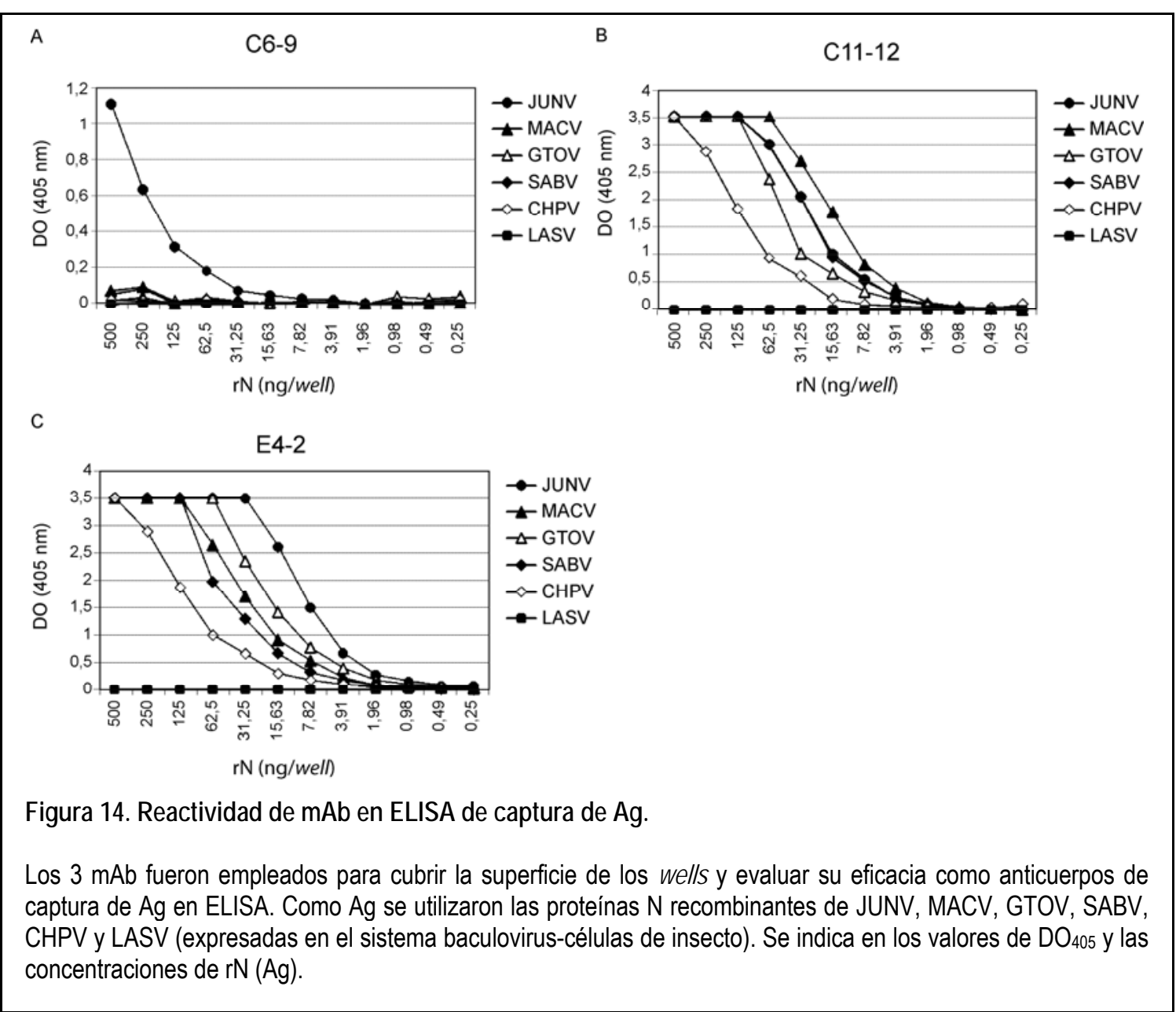

\section{Mapeo de los epitopes reconocidos por los anticuerpos monoclonales}

Para mapear los epitopes de $\mathrm{N}$ de JUNV que son reconocidos por los mAb, se expresaron en E. coli proteínas de fusión con GST (glutation Stransferasa) que contenían diferentes fragmentos del ORF de JUNV. La reactividad de los distintos $\mathrm{mAb}$ ante estas proteínas recombinantes se evaluó por western blot (Figura $15 \mathrm{~A}$ ). Como puede apreciarse en la Figura 15 B, el mAb C6-9 reconoció GST-JUNV-N1-564 (N completa) y GSTJUNV-N384-564. El mAb C11-12 detectó las GST-JUNV-N1-564, 1-235 y 159. El mAb E4-2 reaccionó con GST-JUNV-N1-235 y 54-117. 
A)
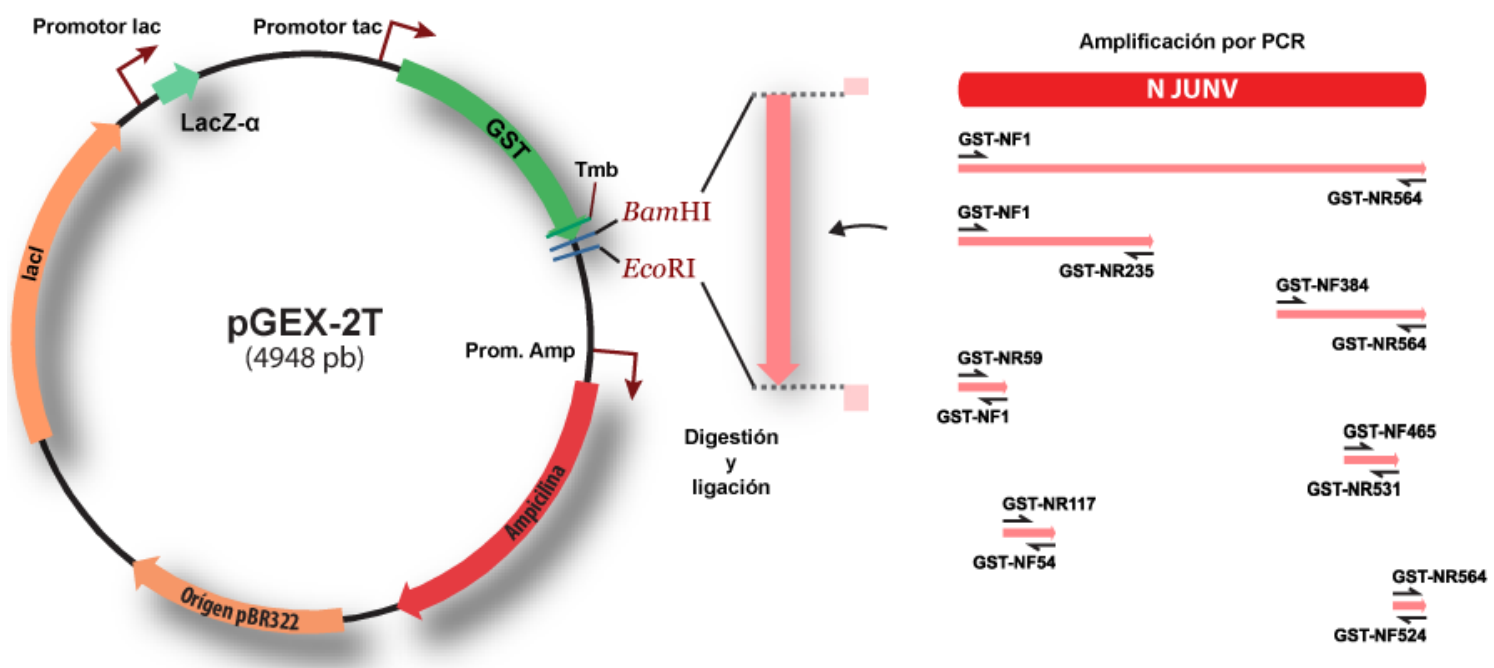

B)

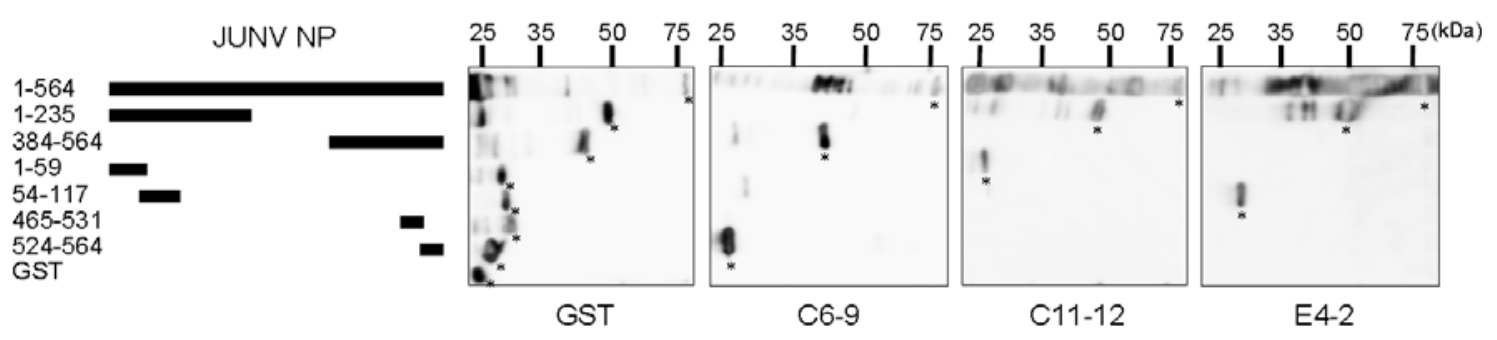

Figura 15. Reactividad de mAb C6-9, C11-12 y E4-2 con fragmentos de N de JUNV

Panel A: Esquema de la estrategia utilizada para clonar los distintos fragmentos de $\mathrm{N}$ fusionados a GST con el vector pGEX-2T. Los primers empleados para amplificar los distintos fragmentos incorporaron sitios BamHI y EcoRI. Panel B: A la izquierda, se indican los fragmentos de $\mathrm{N}$ (fusionados a GST). A la derecha, western blots de los fragmentos de $\mathrm{N}$ reconocidos por los distintos mAb estudiados. El sentido de la corrida en el SDS-PAGE (10\%) fue de derecha a izquierda (los tamaños moleculares de los marcadores se muestran en la parte superior de cada western blot). Se utilizó un anticuerpo anti-GST como control. Se indican con asteriscos las bandas que se consideraron positivas para cada anticuerpo.

Con el fin de determinar en forma más precisa la posición de los epitopes reconocidos en $\mathrm{N}$, se realizó un ensayo de bloqueo de epitopes en ELISA empleando péptidos sintéticos (Figura 16). 
A

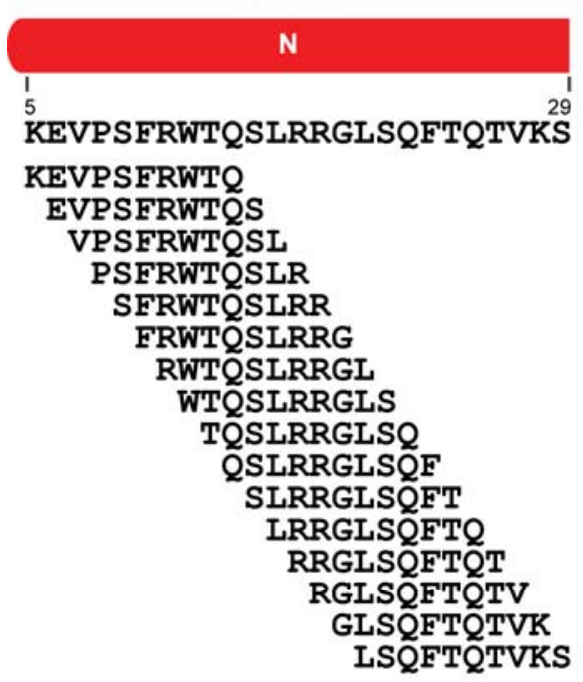

C

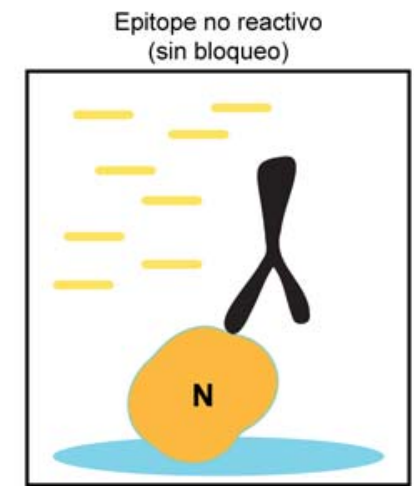

B $\quad$ C6-9

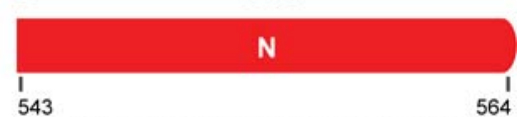

EEELTPLLPPSLLFLPKAAYAL

EEELTPLLPP

EELTPLLPPS

ELTPLLPPSL

LTPLLPPSLL

TPLLPPSLLF

PLLPPSLLFL

LLPPSLLFLP

LPPSLLFLPK

PPSLLFLPKA

PSLLFLPKAA

SLLFLPKAAY

LLFLPKAAYA

LFLPKAAYAI

Epitope reactivo

(bloqueo)

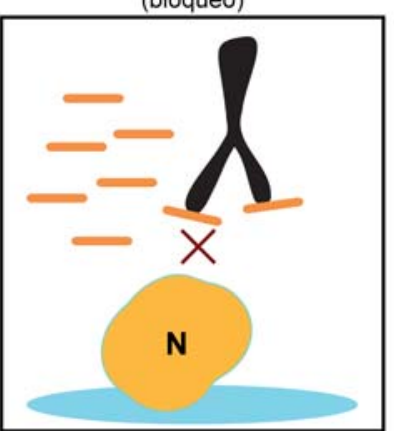

Figura 16. Ensayo de bloqueo de mAb en ELISA.

Los mAb, C11-12 y C6-9 fueron mapeados mediante un ensayo de bloqueo con decapéptidos sintéticos. En A y B se indican las secuencias aminoacídicas de los decapétptidos utilizados y la región que abarcan dentro de la proteína $\mathrm{N}$. En $\mathrm{C}$ se muestra un esquema del ensayo, en el que proteína $\mathrm{N}$ recombinantes es adsorbida a la superficie de los wells. En el caso de que el péptido no es capaz de bloquear la interacción con $\mathrm{N}$ (izquierda) el mAb se unirá y dará señal positiva. Por el contrario, el decapéptido que compite por la unión bloquea la interacción entre el mAb y N (ver Materiales y Métodos). 


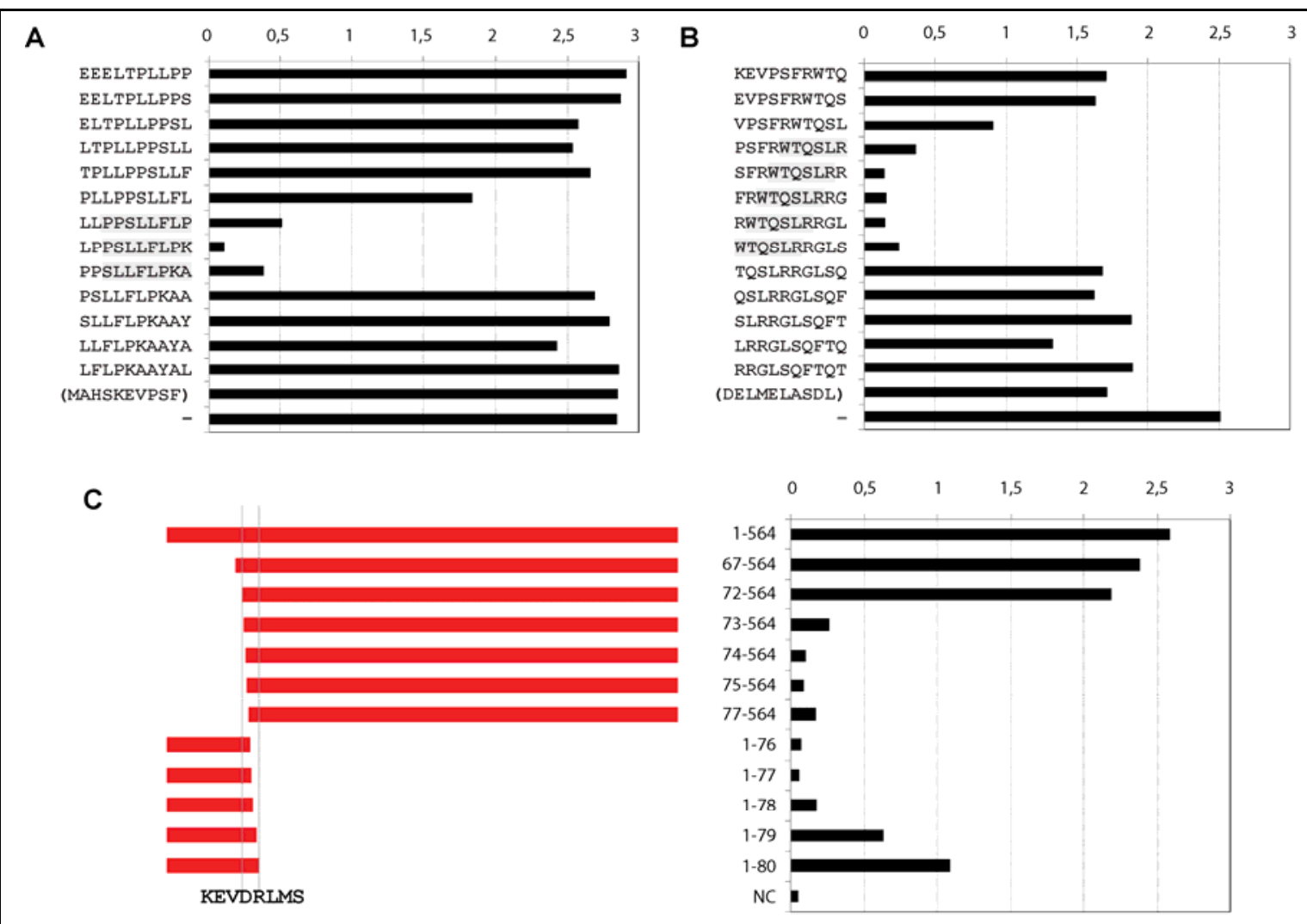

Figura 17. Determinación de los epitopes de $\mathrm{N}$ reconocidos por los mAb

Los epitopes de N de JUNV reconocidos por los mAb C6-9 (A), C11-12 (B), y E4-2 (C). (A, B) La determinación del epitope de $\mathrm{N}$ reconocido por estos $\mathrm{mAb}$ se hizo mediante el bloqueo de la interacción en ELISA por péptidos sintéticos (10 aa). La secuencia aminoacídica y la posición de los péptidos se muestra en el eje y. En el eje x se muestra el nivel de reactividad $\left(\mathrm{DO}_{405}\right)$. Los péptidos sintéticos del aa 1 al 10 y del 97 al 106 se usaron como controles negativos para los mAb C6-9 y C11-12, respectivamente. Las barras negras reflejan los valores de $\mathrm{DO}_{405}$. En gris está resaltada la secuencia que reconoce cada uno de los mAb. Con sombreado gris se resalta la región reconocida por cada anticuerpo. El mAb C6-9 reconoció el péptido PPSLLFLF (posición 551 a 558) mientras que el C11-12 reaccionó con el péptido WTQSLR de la posición 12 a 17. (C) Reactividad del mAb E4-2 con fragmentos de $\mathrm{N}$ fusionados a GST en ELISA. A la izquierda se esquematizan los fragmentos de N. A la derecha, se muestras los valores de $\mathrm{DO}_{405}$ y las posiciones aminoacídicas de los fragmentos de N. GST fue usada como control (sin fragmentos de N). El mAb E4-2 reconoció el péptido KEVDRLMS (aa 72 -79).

En la Figura 17 A se puede apreciar que un péptido con la secuencia PPSLLFLP (posición 551 a 558) fue capaz de bloquear la reacción entre el mAb C6-9 y N de JUNV. De manera similar, péptidos con la secuencia aminoacídica WTQSLR (residuos 12 a 17) impidieron la unión del C11-12 a $\mathrm{N}$ de JUNV (Figura 17 B). La unión del mAb E4-2 a N no pudo ser bloqueada por este ensayo por lo que se recurrió a una serie de proteínas $\mathrm{N}$ truncadas y fusionadas a GST y se estudió la unión del anticuerpo por ELISA. La reactividad con cada uno de los fragmentos fue normalizada utilizando la 


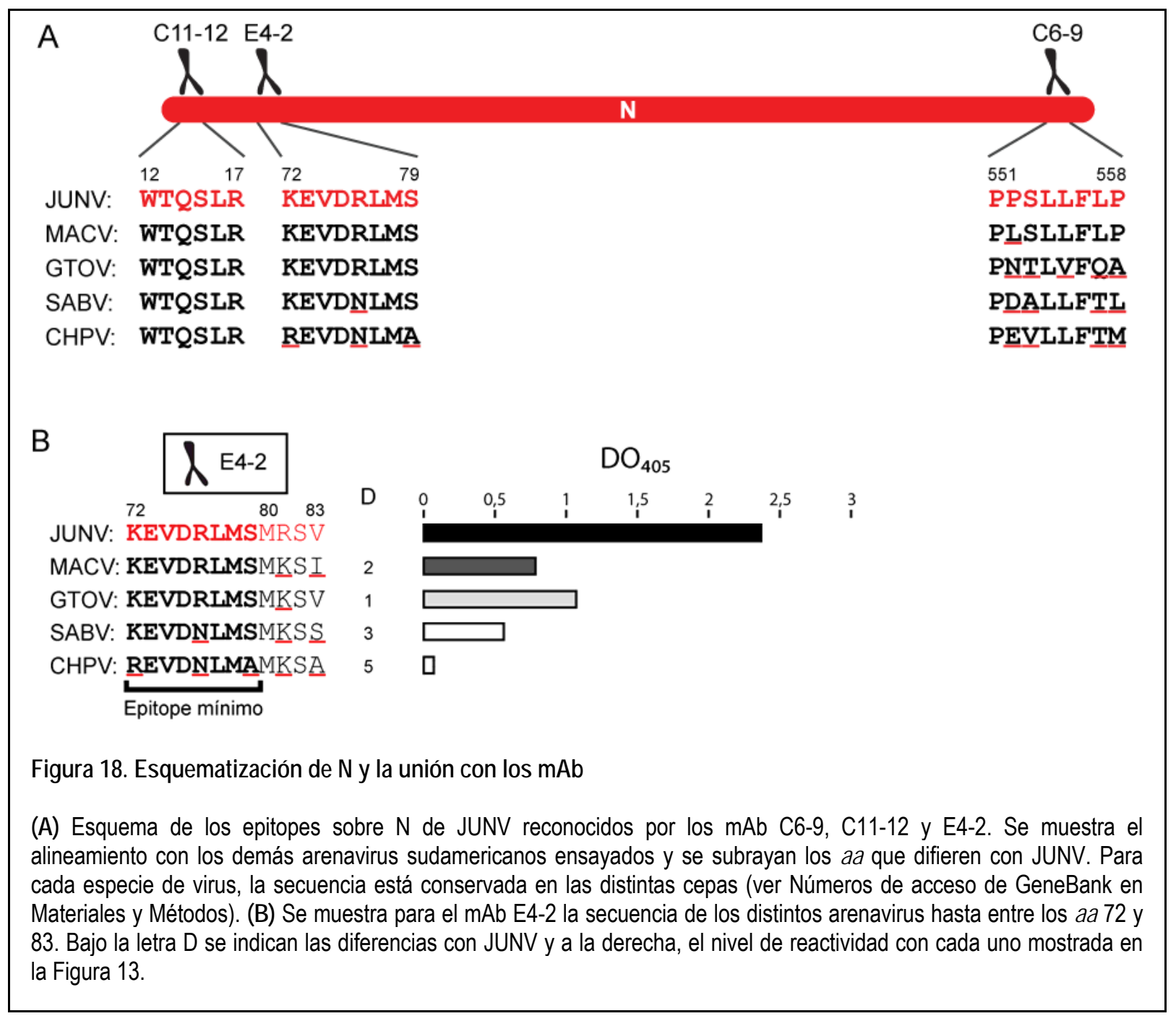

reactividad de un anticuerpo monoclonal anti-GST (cociente de los valores de $\mathrm{DO}_{405}$ ). El mAb E4-2 reconoce el péptido KEVDRLMS (posición 72 a 79) (Figura $17 \mathrm{C}$ ).

En la Figura 18 se esquematiza la proteína $\mathrm{N}$ y las regiones reconocidas por los distintos mAb. 


\section{Discusión}

La detección de antígenos o genoma viral es esencial para el diagnóstico temprano en pacientes con $\mathrm{FH}$ causadas por arenavirus sudamericanos. Esto es crítico ya que el tratamiento con plasma inmune sólo resulta efectivo si se administra durante un período limitado de la fase aguda de la enfermedad. Con este fin se desarrollaron métodos de RT-PCR y TaqMan PCR para la detección de los genomas de JUNV, MACV y GTOV (Lozano et al., 1995; Lozano et al., 1993; Vieth et al., 2005). El análisis serológico también es útil para el diagnóstico de algunas FH (Garcia Franco et al., 1988; Morales et al., 2002; Riera et al., 1997; Saijo et al., 2007). Un AgELISA con una mezcla de mAb anti-JUNV (Sanchez et al., 1989) fue aplicado para estudios epidemiológicos en roedores en nuestro país (Mills et al., 1991c). Esos mismos mAb mostraron reactividad cruzada con MACV y otros arenavirus no patogénicos (Sanchez et al., 1989). En este trabajo, los nuevos mAb anti-JUNV fueron evaluados como anticuerpo de captura de $\mathrm{Ag}$ en ELISA. Los mAb (C6-9, C11- 12 y E4-2) reaccionaron con $\mathrm{N}$ de JUNV expresada con el sistema baculovirus-células de insecto (Figura 13). A su vez, los 3 mAb sirvieron en el Ag-ELISA para detectar $N$ de JUNV (Figura 14). Esto sugiere que estos ELISA podrían ser útiles para el diagnóstico de FHA.

El mAb C11-12 detectó $\mathrm{N}$ de todos los arenavirus sudamericanos evaluados (Figura 14 B). Por otra parte, el ELISA con el mAb E4-2 mostró una mayor reactividad con $\mathrm{N}$ de JUNV que con el resto de los arenavirus sudamericanos. El epitope mínimo reconocido por el mAb E4-2 fue el octapéptido con la secuencia ${ }_{(72)} \mathrm{KEVDRLMS}_{(79)}$. Sin embargo, la proteína de fusión que contiene el fragmento de N 1-80 no exhibe el mismo nivel de reactividad que poseen los fragmentos $72-564,67-564$ y 1-564. Por otra parte, el fragmento 1-80 de N-GST tiene mayor reactividad que el 1-79. Esto deja abierta la posibilidad que la zona de reconocimiento pueda extenderse más allá de la posición 80 .

Si bien no se pudieron expresar en E. coli fragmentos mayores al 1-80 (tal vez por su toxicidad), esto no puede ser totalmente descartado. Los 
alineamientos de secuencias aminoacídicas de las proteínas $\mathrm{N}$ de los diferentes arenavirus que muestran reactividad con el mAb E4-2 apoyan esta posibilidad. En particular, se observaron diferencias respecto de JUNV de 1 aa para GTOV, 2 aa para MACV, 3 aa para SABV y 5 para CHPV (Figura 18 $B)$. Estas diferencias se correlacionan bien con los niveles variables de reactividad observados con el $\mathrm{mAb} E 4-2$ frente a las distintas $\mathrm{N}$.

El Ag-ELISA basado en el monoclonal C11-12 también detectó los Ag de todos los otros arenavirus sudamericanos patogénicos. Estos resultados sugieren que el mAb $\mathrm{C} 11-12$ podría ser útil en la detección de $\mathrm{Ag}$ de todos los arenavirus sudamericanos mediante Ag-ELISA. Además, la secuencia aminoacídica del epitope reconocido (WTQSLR), está conservado en todos los arenavirus patogénicos sudamericanos que figuran en GeneBank hasta el momento. Dado que la región $\mathrm{N}$-terminal de las $\mathrm{N}$ reconocidas por los mAb C11-12 y E4-2 (aa 1 a 80) está relativamente conservada entre las $\mathrm{N}$ de los arenavirus sudamericanos, se puede considerar que el Ag-ELISA basado en estos dos anticuerpos podría ser útil para detectar la mayoría de los aislamientos. De esta forma, no sólo sería útil para el diagnóstico de la FHA, si no también para el diagnóstico de las fiebres hemorrágicas boliviana $(\mathrm{FHB})$, venezolana $(\mathrm{FHV})$, brasileña y podría ser útil para nuevas $\mathrm{FH}$ emergentes como la causada por CHPV. Por otra parte, el Ag-ELISA basado en el mAb C6-9 sólo detecta Ag de JUNV, tanto por IgG-ELISA como por AgELISA. El epitope (PPSLLFLP) reconocido por el mAb C6-9 está conservado entre los aislamientos de JUNV depositados hasta la fecha en GeneBank, pero es diferente en los demás arenavirus sudamericanos. Sin embargo, la única diferencia con MACV radica en la prolina 552, por lo que se puede inferir que esta prolina es crítica en la reacción entre el mAb C6-9 y N de JUNV. De esta forma, el Ag-ELISA basado en este mAb podría detectar todos los aislamientos de JUNV. Si se tiene en cuenta que los síntomas de la FHA son indistinguibles de las $\mathrm{FH}$ provocadas por otros arenavirus, el AgELISA basado en el mAb C6-9 podría ser una herramienta de diagnóstico muy útil para FHA.

En general se acepta que un Ag-ELISA es una herramienta útil para la detección de Ag virales en sangre o muestras de otros tejidos de pacientes 
en la fase aguda de la enfermedad, sobre todo cuando la viremia tiene altos niveles, como en el caso de la fiebre de Lassa. Debido a que la viremia en la FHA es menor, la posibilidad de detectar antígenos virales en la etapa aguda debe ser verificada. La secuencia aminoacídica de los epitopes reconocidos por los mAb E4-2 y C6-9 es distinta en la región correspondiente de LASV. Por el contrario, la secuencia mínima reconocida por el mAb C11-12 (WTQSLR) es igual en N de JUNV y LASV y, pese a ello, el anticuerpo no reacciona con $\mathrm{N}$ de LASV. Sin embargo, los aa 8 y 11 (fuera de la zona mínima 12-17) son prolina y arginina en las $\mathrm{N}$ de los arenavirus sudamericanos, mientras que son lisina/arginina y leucina en LASV, respectivamente. De esta forma, es posible que algunos aa fuera del área mínima de reconocimiento del mAb C11-12 puedan afectar su interacción con $\mathrm{N}$ de LASV.

La RT-PCR es un método más sensible que el ELISA de captura de antígeno para la detección de virus en muestras de pacientes. Un método aún más sensible, basado en real time RT-PCR, fue recientemente publicado para la detección de arenavirus sudamericanos (Vieth et al., 2005). Sin embargo, nuevos arenavirus o distintas cepas a las que se tuvo en cuenta al momento de diseñar los primers limita la posibilidad de detección. Por el contrario, el Ag-ELISA desarrollado en este trabajo reconoce epitopes altamente conservados. Incluso, y pese a tratarse de anticuerpos monoclonales, pueden detectarse antígenos con mutaciones (como se vio con las distintas especies estudiadas en este trabajo). Por otra parte, la disponibilidad de equipos de real time PCR es mucho menor que el equipo necesario para llevar a cabo un ELISA. Todo esto sugiere que este Ag-ELISA puede ser útil para el diagnóstico en pacientes sospechosos, confirmación retrospectiva de la etiología y estudios epidemiológicos. 
Capítulo II I 



\section{Expresión de proteínas quiméricas recombinantes entre CTB y proteínas del virus Junín}

\section{Resumen}

En varios estudios recientes se demostró que la subunidad B de la toxina colérica posee potentes y diversas propiedades inmuno-moduladoras (Freytag y Clements, 2005; Gong et al., 2005; Partidos et al., 2004). Entre las aplicaciones biotecnológicas que ello brinda, se destaca la posibilidad de utilizar quimeras de CTB como inmunógeno en mucosas (Singh et al., 2006; Tochikubo et al., 1998; Yasuda et al., 2003), una de las principales vías de infección por arenavirus (aerosoles).

En este capítulo se describe la clonación de diversos genes de JUNV y la expresión en bacterias como proteínas de fusión a CTB. Finalmente, se evaluó la capacidad protectora de la proteína quimérica CTB-Z en un desafío de cobayos con JUNV. Si bien no se observó protección específica, el estudio permitió evaluar la utilidad del modelo y abrió la posibilidad de estudios posteriores con otras proteínas virales con mejores perspectivas como posible componente de una vacuna a subunidad. 


\section{Introducción}

\section{Toxina colérica y su utilidad como adyuvante}

Las mucosas, constituyen una de las principales barreras contra el ingreso de patógenos al cuerpo humano. En el caso de las FH provocadas por arenavirus se cree que junto con las abrasiones en la piel, constituyen la principal vía de ingreso. Por esto, es importante la búsqueda de vacunas capaces de estimular la respuesta inmune en estos sitios. Las enterotoxinas sensibles al calor de tipo I y II producidas por E. coli y la toxina colérica producida por Vibrio cholerae han sido estudiadas ampliamente como adyuvantes de mucosas (Harandi et al., 2003). Estas toxinas pertenecen a la superfamilia de toxinas del tipo $\mathrm{AB}_{5}$ y se relacionan tanto por su estructura como por su función (Spangler, 1992). Se las denomina así porque están formadas por 2 subunidades en una relación 1:5 (Figura 19). La subunidad $\mathrm{A}$, un heterodímero unido por un puente disulfuro, está asociada de forma no covalente a un homopentámero formado por las subunidades $\mathrm{B}$ (Merritt et al., 1994; Vanden Broeck et al., 2007). Brevemente, la toxina se une en la superficie epitelial al gangliósido GM1 a través de la subunidad B. A continuación, la toxina es internalizada en vesículas y transportada al Golgi, donde se separa la subunidad A por reducción de un puente disulfuro. En el citosol, la subunidad A produce la ADP-ribosilación irreversible de una proteína $G_{S a}$, y como consecuencia, elimina su actividad inhibitoria sobre la adenilato ciclasa. De esta manera, aumenta la concentración de AMP cíclico y en consecuencia la salida de iones cloruro y agua al lumen intestinal, provocando la diarrea característica (Vanden Broeck et al., 2007). 


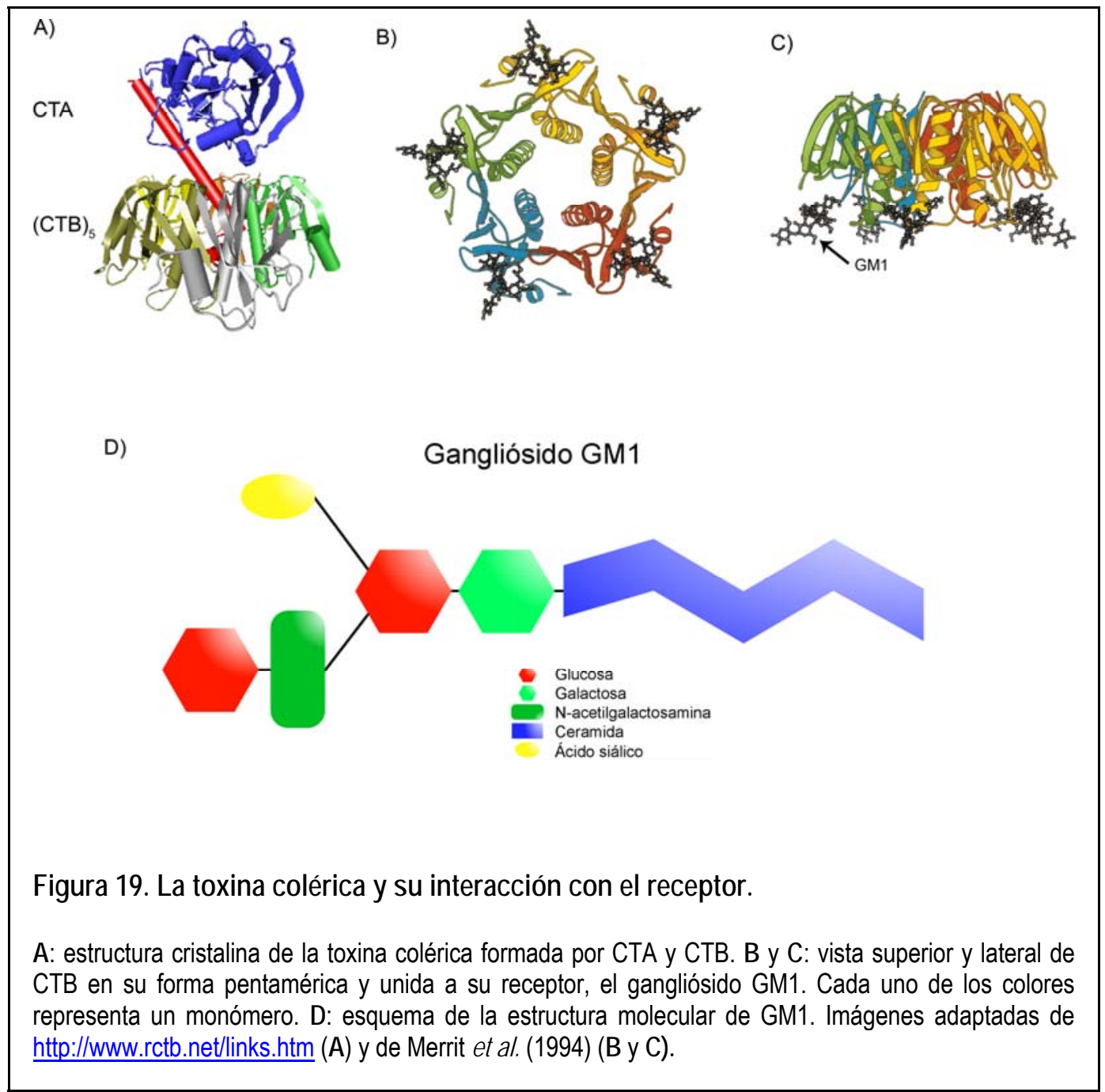

Se ha demostrado que CTB es un potente inmuno-estimulador y que la expresión de polipéptidos de fusión con CTB permite la reducción de hasta 10.000 veces la dosis de inmunógeno necesaria para lograr una determinada respuesta inmune (George-Chandy et al., 2001). El mecanismo por el cual CTB es eficaz como adyuvante no está bien definido, pero se sabe que está asociado con la fuerte unión de CTB con su receptor, GM1. Este gangliósido está presente en la mayoría de los tipos celulares, incluyendo células presentadoras de antígenos. Tanto en el caso de la toxina colérica como en el de las toxinas sensibles al calor de tipo I, la unión al receptor GM1 es esencial para su actividad inmuno-moduladora (Guidry et al., 1997; Rodighiero et al., 2001). 


\section{Estrategia general para la clonación de proteínas de JUNV fusionadas a CTB}

La estrategia utilizada fue básicamente la descripta por Arêas et al. (2004) y está basada en un vector de expresión llamado pAEctxB (Figura 20). En la generación de dicho vector, el gen que codifica la proteína CTB, $\operatorname{ctxB}$, fue modificado para asegurar que los codones empleados fuesen compatibles con los utilizados con mayor frecuencia por E. coli, L. casei y S. typhimurium (Arêas et al., 2002). El ORF manipulado genéticamente, fue luego clonado en el vector de expresión pAE (Ramos et al., 2004) e incluye dos sitios consecutivos Mlul y Hindlll. El vector resultante permite expresar, bajo el control de un promotor T7, proteínas fusionadas al C-terminal de CTB. A su vez, las proteínas expresadas tienen 6 residuos de histidina en el extremo $\mathrm{N}$ terminal, lo que facilita su purificación por cromatografía de afinidad por ión metálico inmovilizado (IMAC, por las siglas en inglés). Este trabajo se hizo en el marco de una colaboración con el Dr. Paulo Lee Ho, del Laboratorio de Biotecnología Molecular, Instituto Butantan, SP, Brasil.

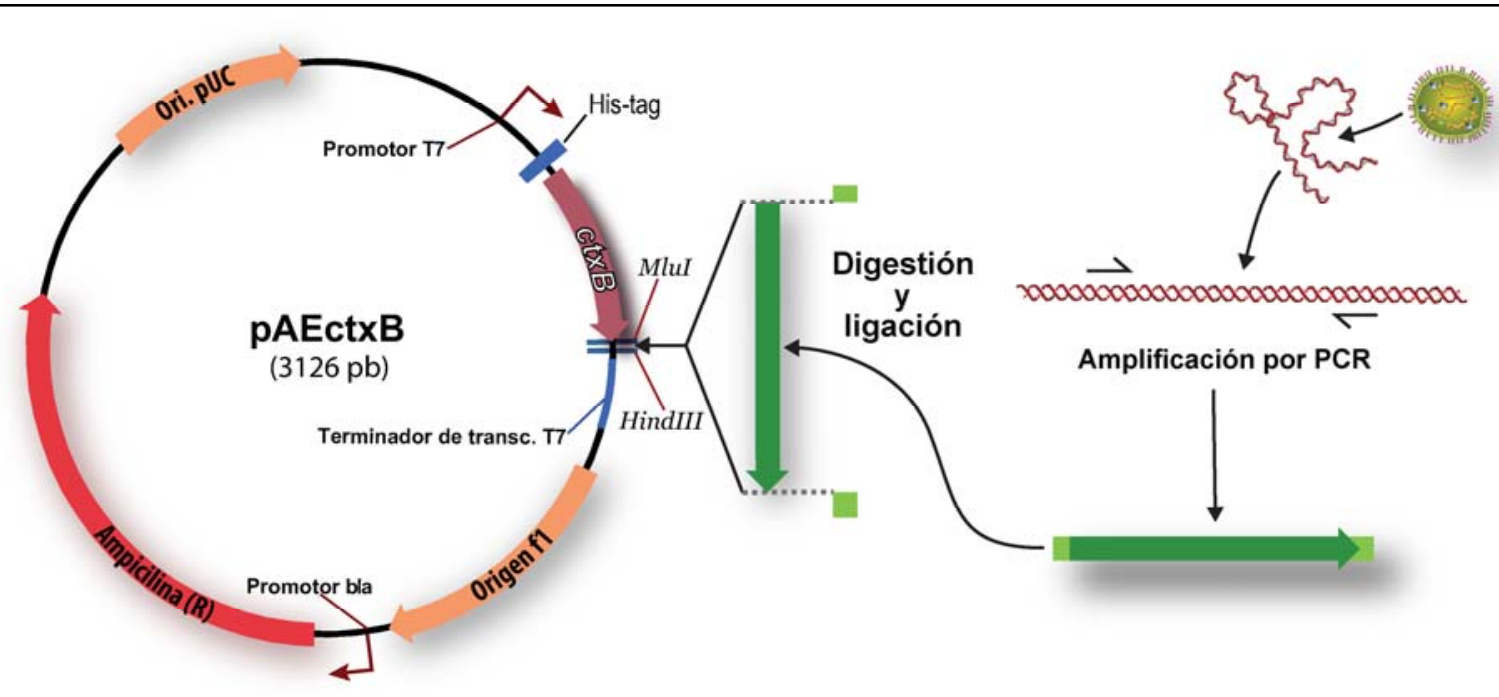

Figura 20. Estrategia de clonado en el vector pAEctxB.

Estructura del plásmido de expresión pAEctxB. Se indican los promotores $T 7$ y bla que permiten la expresión de las proteínas heterólogas (fusionada a CTB) y de la $\beta$-lactamasa (resistencia al antibiótico ampicilina). Se indican los sitios de clonado Mlul y Hindlll empleados para clonar los distintos ORF de JUNV. 


\section{Modelos}

Los modelos animales capaces de reproducir los síntomas de las fiebres hemorrágicas virales en humanos son esenciales para el desarrollo de vacunas y de drogas anti-virales. Si bien los modelos de primates no humanos son los más fidedignos, los modelos de roedores son más accesibles y pueden reproducir ciertas características de estas enfermedades, y por lo tanto, han sido frecuentemente usados para estudios de FH (Tabla 3) (Gowen y Holbrook, 2008). El cobayo, Cavia porcellus, es el roedor más utilizado para el estudio de la FHA (Enria et al., 2008; Gowen y Holbrook, 2008) y fue usado en ensayos pre-clínicos de la actual vacuna contra JUNV (Ambrosio et al., 2005). Recientemente, se caracterizó la respuesta de cobayos a dos cepas del virus Junín y se demostró que gran parte de los síntomas característicos de la enfermedad en humanos están presentes en este modelo (Tabla 4) (Liang et al., 2009; Yun et al., 2008). En síntesis, el cobayo es un modelo conveniente para evaluar las propiedades protectoras de candidatos vacunales en un desafío con JUNV.

Tabla 3. Modelos animales para el estudio de FH producidas por arenavirus.

\begin{tabular}{cccc}
\hline Virus & Modelo de & Modelo animal & Nombre científico \\
\hline LASV & Fiebre de Lassa & Macaco Rhesus & Macaca mulatta \\
LCMV & Fiebre de Lassa & Macaco Rhesus & Macaca mulatta \\
LASV & Fiebre de Lassa & Mono tití & Callithrix jacchus \\
LASV & Fiebre de Lassa & Cobayo & Cavia porcellus \\
PICV & Fiebre de Lassa & Cobayo & Cavia porcellus \\
PICV & Fiebre de Lassa & Hámster & Mesocricetus auratus \\
PIRV & Fiebre de Lassa & Hámster & Mesocricetus auratus \\
JUNV & FHA & Macaco Rhesus & Macaca mulatta \\
JUNV & FHA & Mono tití & Callithrix jacchus \\
JUNV & FHA & Cobayo & Cavia porcellus \\
GTOV & FH venezolana & Cobayo & Cavia porcellus \\
MACV & FH boliviana & Macaco Rhesus & Macaca mulatta \\
MACV & FH boliviana & Mono verde africano & Chlorocebus sabaeus \\
\hline
\end{tabular}

Adaptado de Gowen et al. (2008). 
Tabla 4. Síntomas de la enfermedad en humanos y cobayos.

\begin{tabular}{|c|c|c|c|}
\hline Característica & Síntoma & Humano $^{+}$ & Cobayo \\
\hline \multicolumn{4}{|c|}{$\begin{array}{l}\text { Fase de la enfermedad } \\
\text { Aguda }\end{array}$} \\
\hline & Fiebre & + & + \\
\hline & Mialgia & + & Desconocido \\
\hline & Malestar & + & Desconocido \\
\hline & Mareos & + & Desconocido \\
\hline & Temblores & + & + \\
\hline & Petequias & + & - \\
\hline \multicolumn{4}{|l|}{ Severa } \\
\hline & Shock & + & + \\
\hline & Hemorragia en mucosas & + & + \\
\hline & Coma & + & + \\
\hline & Convulsión & + & + \\
\hline & Muerte & + & + \\
\hline \multicolumn{4}{|l|}{ Hematología } \\
\hline & Leucopenia & + & Desconocido \\
\hline & Trombocitopenia & + & + \\
\hline \multicolumn{4}{|l|}{ Clínica } \\
\hline \multirow[t]{3}{*}{ Bioquímica } & Proteinuria & + & Desconocido \\
\hline & $\mathrm{AST}^{*}$ elevada & + & + \\
\hline & Hipercolesterolemia & Desconocido & Desconocido \\
\hline
\end{tabular}

*aspartato aminotransferasa. + Los síntomas en humanos provienen de Harrison et. al (1999). Tabla adaptada de Yun et al. (2008). 


\section{Resultados y discusión}

\section{Clonado de genes virales fusionados a ctxB}

Siguiendo la estrategia general esquematizada en la Figura 20, los ORF de JUNV y el gen de EGFP (enhanced green fluorescent protein) fueron amplificados con primers diseñados para incorporar sitios Hindlll y Mlul en los extremos (Tabla 5). De esta manera, fueron clonados en el vector pAEctxB, GPC, G1, G2, Z y N de JUNV y EGFP (Figura 21 y Figura 22). En las figuras se esquematizan las zonas de inserción de los ORF para las distintas construcciones, así como también una representación de los primers utilizados para el clonado y screening de colonias transformantes (por Colony PCR). Estas construcciones fueron, además, corroboradas por digestión con las enzimas empleadas en el clonado y, posteriormente, por secuenciación.

Dado que el gen de GPC de JUNV presenta un sitio Hindlll interno, se realizó una digestión parcial con esta enzima y completa con Mlul para clonar el ORF completo (Figura 21). Una digestión parcial con dicha enzima, permitió clonar el inserto deseado.

Uno de los clones resultantes fue secuenciado y puede verse que mantuvo su integridad y el marco de lectura en fase (Figura 23).

Tabla 5. Amplificación de genes virales por PCR para el clonado en pAEctxB

\begin{tabular}{llllc}
\hline ORF & \multicolumn{1}{c}{ DNA molde } & \multicolumn{2}{c}{ Primers* } & Producto $(\mathrm{pb})$ \\
\hline $\mathrm{N}$ & pcDNA3-N & N-Mlul F & N-HindlII R & 1719 \\
$\mathrm{Z}$ & pcDNA3.1-Z & Z-Mlul F & Z-HindlII R & 309 \\
GPC & pBacPAK9-GPC & GPC-Mlul F & GPC-HindIII R & 1482 \\
G1 & pBacPAK9-GPC & G2 F Kpn-Mlu & G1 R Xho-Hind & 613 \\
G2 & pBacPAK9-GPC & G2 F Kpn-Mlu & G2 R Xho-Hind & 741 \\
EGFP & pEGFP-N3 & EGFP Mlul F & EGFP HindIII R & 760 \\
\hline
\end{tabular}

* Las secuencias nucleotídicas de cada uno se detallan en la sección Materiales y Métodos (bajo el título Primers). 
A)
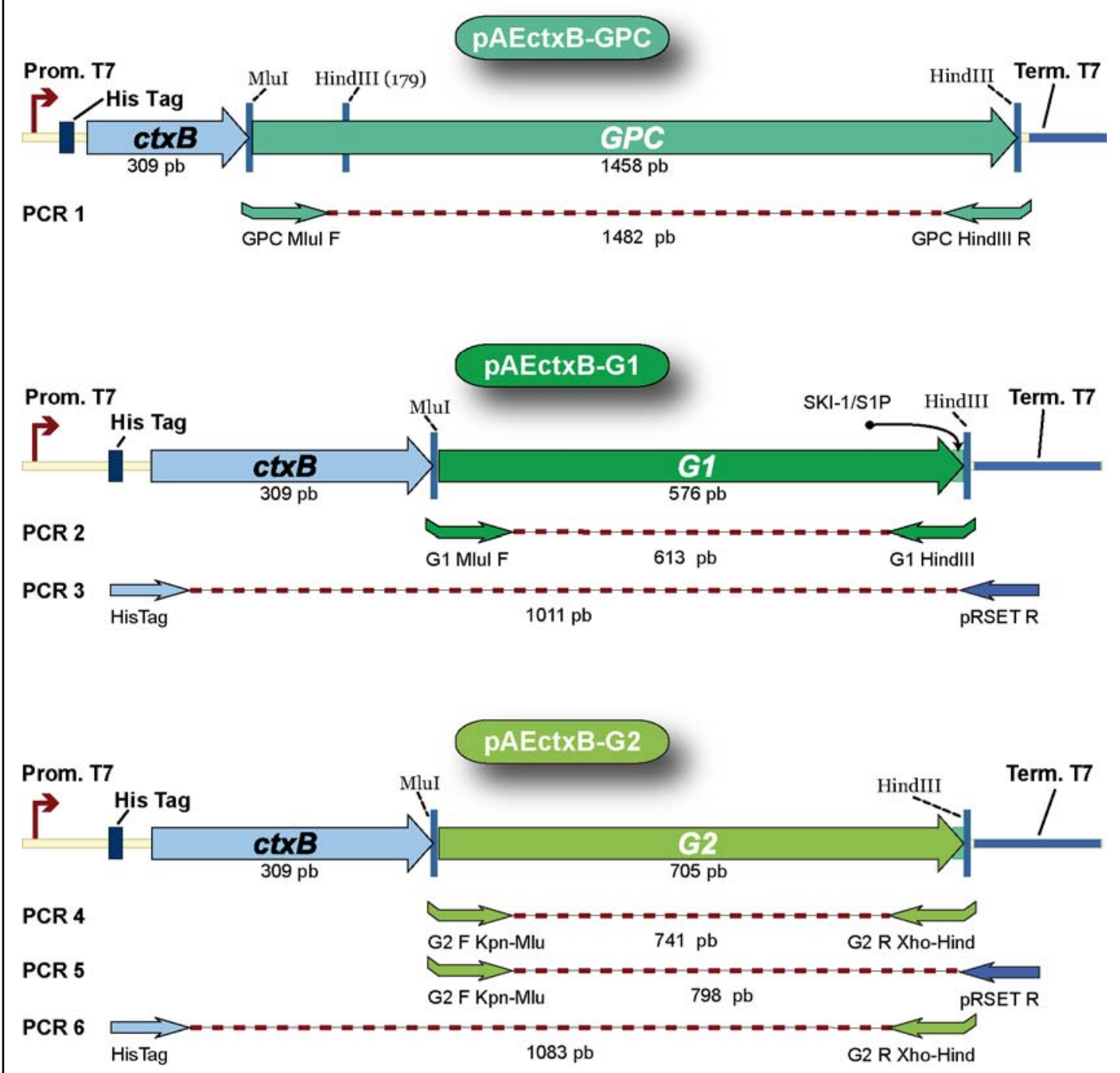

B)
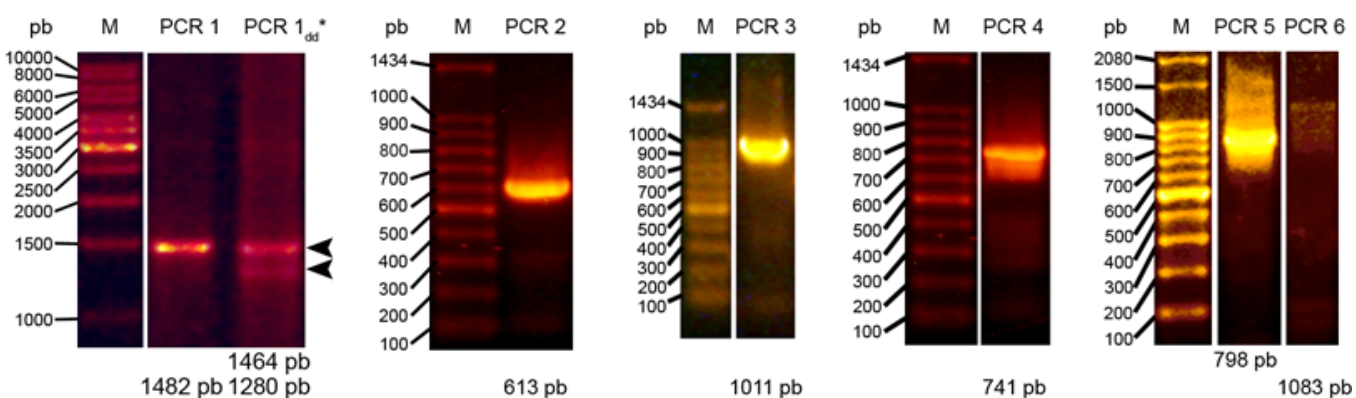

Figura 21. Generación de los vectores pAEctxB-GPC, G1 y G2

(A) Esquematización de la zona de clonado de los vectores pAEctxB-GPC, G1 y G2. Debajo de cada uno se muestran los primers utilizados para la amplificación del ORF (que incorporan los sitios Mlul y HindllI) así como los utilizados en las etapas de screening de colonias transformantes. Los primers para clonar $\mathrm{G} 1$ abarcaron la región inmediatamente posterior al péptido señal estable y los 4 codones que determinan el sitio de corte para la proteasa SKI1/S1P, antes de G2. La relación entre el tamaño de ctxB y los respectivos ORF clonados para cada vector se encuentra a escala (y no la relación entre GPC, G1 y G2). (B) Se muestran un ejemplo de cada uno los productos de PCR obtenidos con los primers indicados en A. * Se muestra las dos bandas producto de la doble digestión con Mlul y los dos sitios Hindlll. 
A)
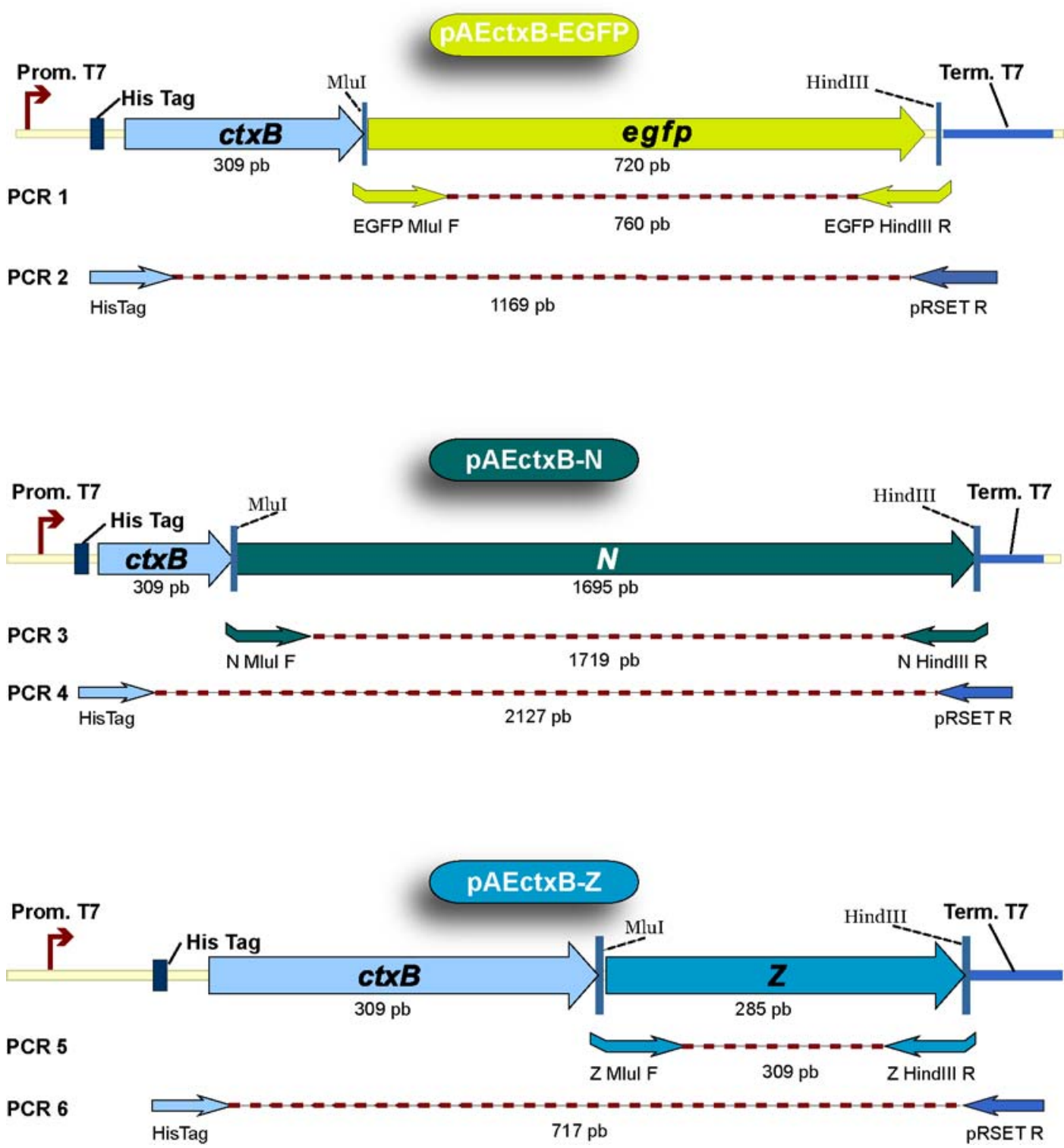

B)
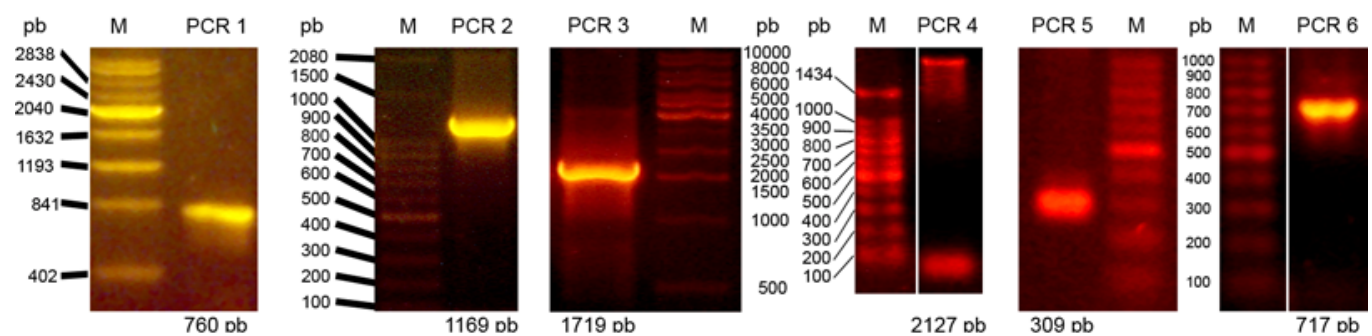

Figura 22. Generación de los vectores pAEctxB-EGFP, N y Z.

(A) Esquematización de la zona de clonado de los vectores pAEctxB-EGFP, pAEctxB-N y pAEctxB-Z. Debajo de cada uno se muestran los primers utilizados para la amplificación del ORF (que incorporan los sitios Mlul y HindllI) así como los utilizados en las etapas de screening de colonias transformantes. La relación entre el tamaño de ctxB y los respectivos ORF clonados para cada vector se encuentra a escala. (B) Se muestran un ejemplo de cada uno los productos de PCR obtenidos con los primers indicados en $\mathbf{A}$. 
El gen $\mathrm{N}$ también contiene un sitio HindllI interno, pero a diferencia de GPC, esta secuencia se encuentra mucho más cerca del extremo 5'. Esto permitió diseñar un primer más extenso (ver N-MlulF en Primers) de manera tal de eliminar ese sitio de restricción. En el primer se introdujo la mutación silenciosa CCA $\rightarrow$ CCG en el codón que codifica prolina (pos. 8) (Figura 23). El nuevo codón fue elegido teniendo en cuenta la frecuencia de uso de codones de E. coli (Nakamura et al., 2000), la cual muestra que el codón CCG codifica el $52,5 \%$ de las prolinas, si se tienen en cuenta los 4290 ORF de esa bacteria, y el $71,9 \%$, si sólo se toman los genes con altos niveles de expresión (clase II).

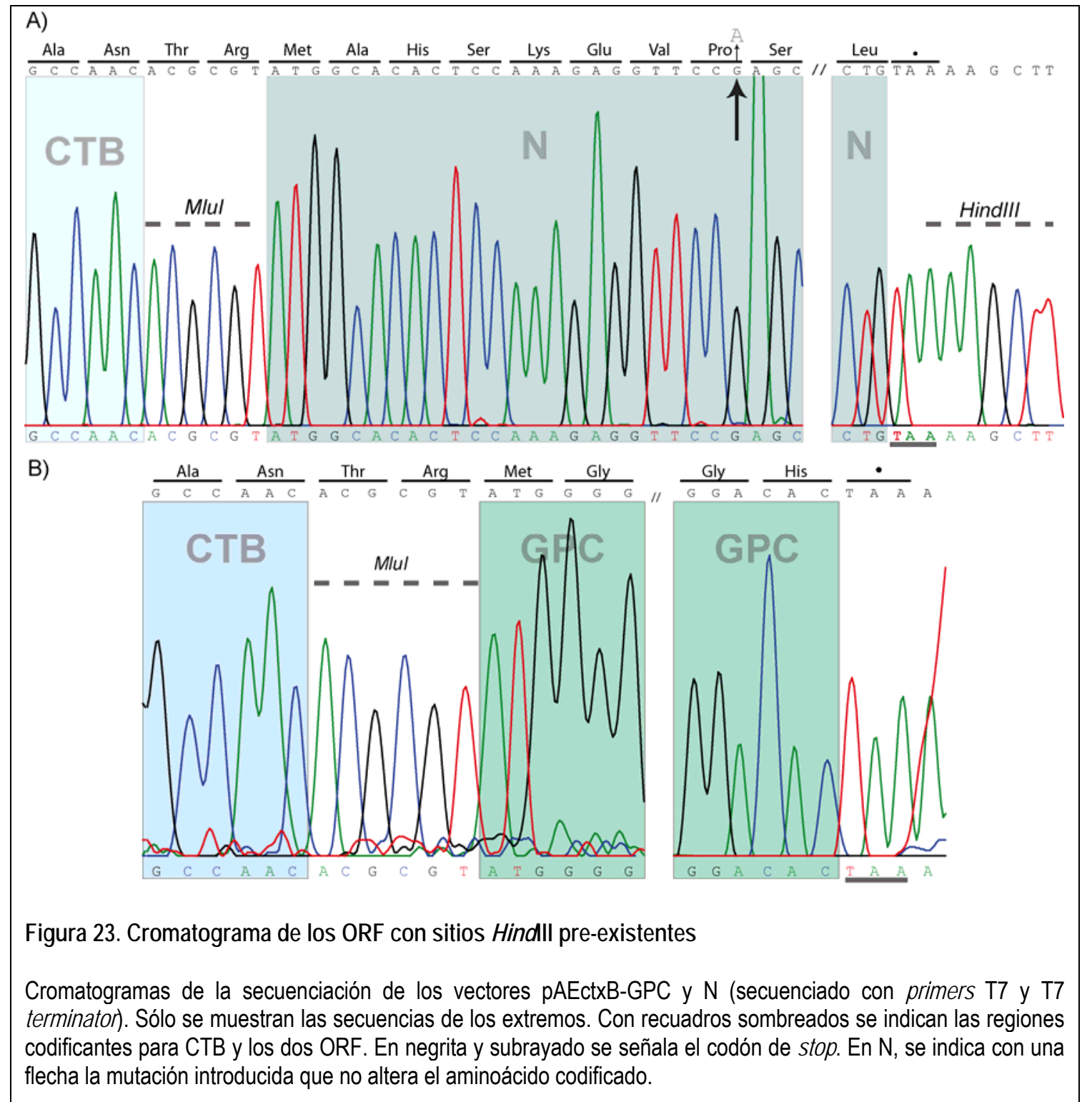




\section{Expresión y antigenicidad de proteínas virales fusionadas a CTB}

Con el fin de evaluar la expresión de las proteínas recombinantes, se transformaron bacterias BL21-SI (salt inducible) con los plásmidos pAEctxBZ/N/GPC/G1/G2 y EGFP. Dichas bacterias derivan de la cepa (GJ1158) y tienen integrada en el cromosoma una copia de la RNA polimerasa del fago T7, bajo el control de un promotor inducible por sal (Bhandari y Gowrishankar, 1997). Dicho promotor es un elemento regulador del operón proU, el cual responde a variaciones de osmolaridad (Gowrishankar y Manna, 1996). De esta manera, la sobreexpresión de los productos fusionados a CTB fue ensayada a escala pequeña (ver Expresión en pequeña escala). Tanto CTB-Z, CTB-N, CTB-G1 como CTB-EGFP fueron sobreexpresadas con bacterias BL21 (SI) inducidas con cloruro de sodio. Únicamente en los casos de CTB-G2 y CTB-GPC no se observó sobreexpresión y tampoco fue posible detectarlas por western blot, incluso después de haber intentado una purificación por cromatografía de afinidad de cultivos en escala mayor (hasta un litro). El resto de las proteínas recombinantes fue reconocida por un anticuerpo policlonal anti-CTB (Arêas et al., 2002). En la Figura 24 se observan los resultados de dicho ensayo, en el que fueron reconocidas CTB-Z, CTB-N, CTB-EGFP y CTB-G1. En el caso

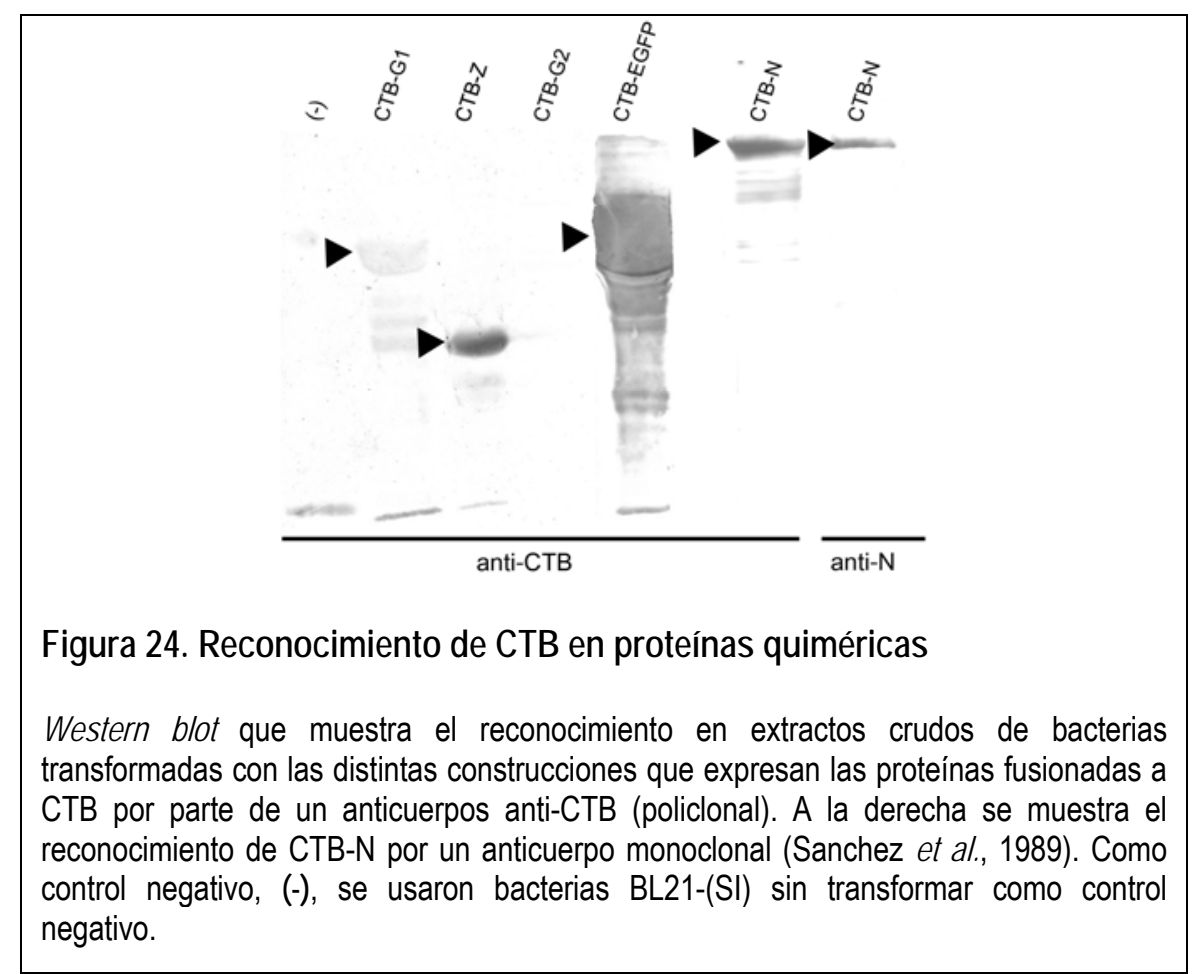




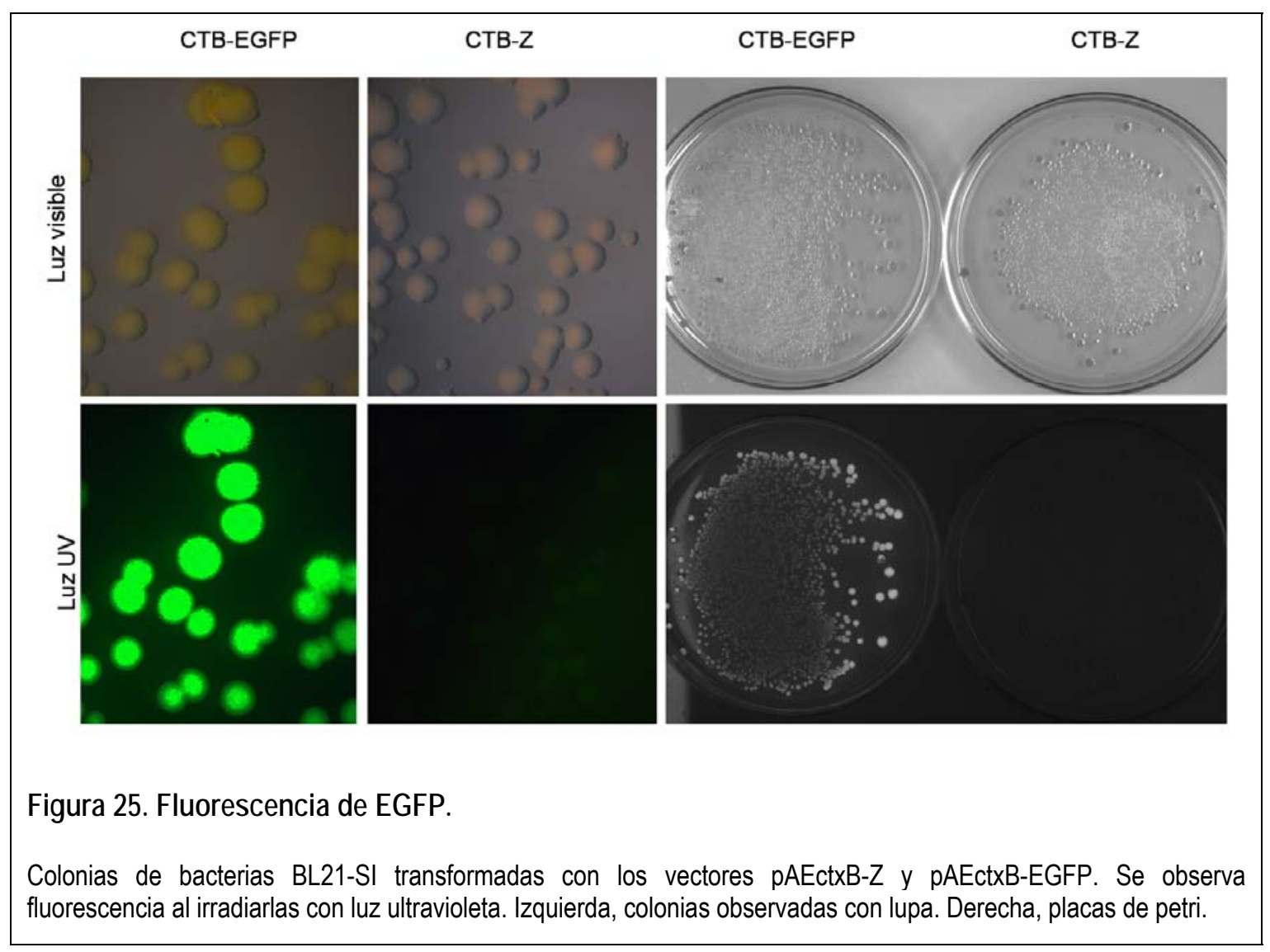

particular de la proteína quimérica CTB-N, se pudo demostrar su reactividad a mAb anti-N y anticuerpos policlonales anti-CTB (Figura 24). De esta manera, se mostró fehacientemente que se trata de una proteína quimérica y antigénicamente indistinguible de la viral.

Las bacterias transformadas con CTB-EGFP mostraron un intenso color verde y fue posible observar la fluorescencia al irradiarlas con luz UV (Figura 25).

\section{Purificación por IMAC}

Los distintos clones fueron utilizados para inducir la expresión de las proteínas recombinantes en cultivos de hasta un litro. Luego fueron purificadas por IMAC en condiciones desnaturalizantes, con cloruro de guanidinio y urea como agentes caotrópicos (Figura 27). 


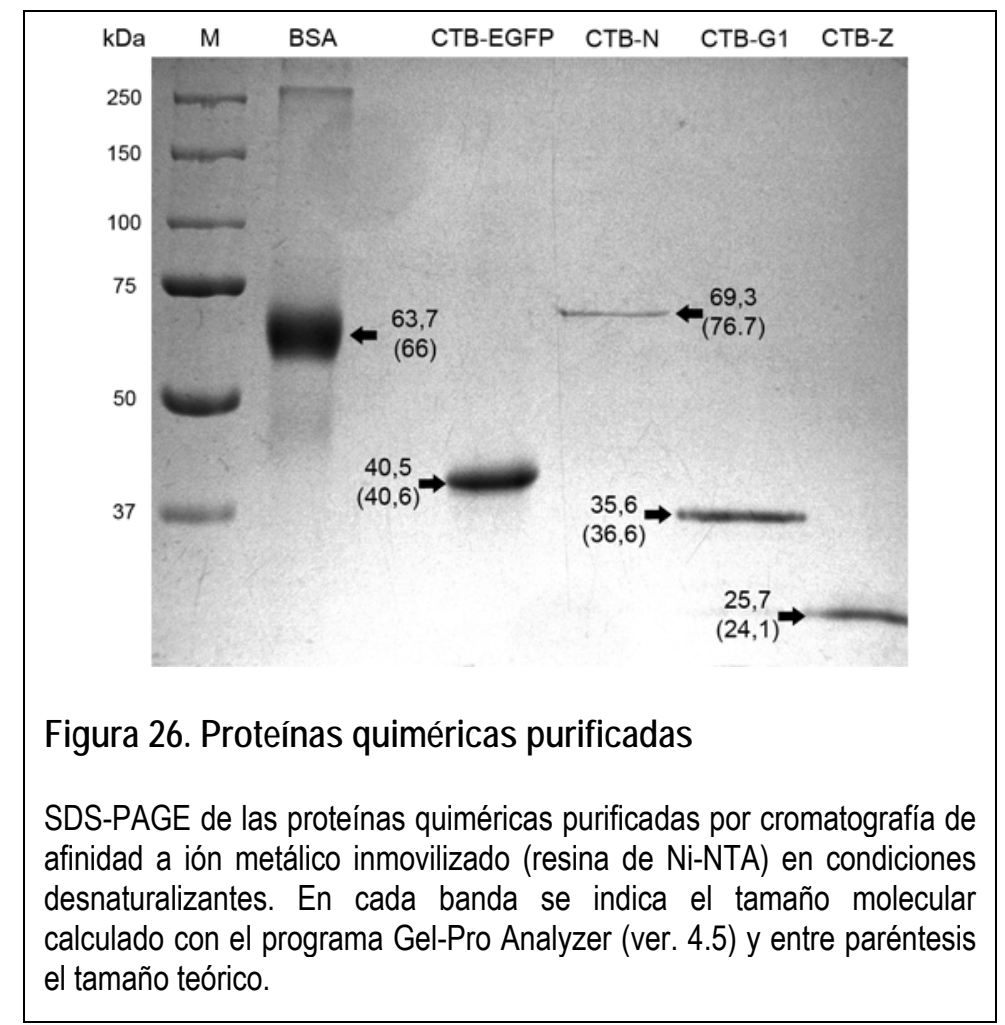

\section{Recuperación de la conformación nativa}

Frecuentemente, las proteínas recombinantes sobreexpresadas en bacterias se acumulan formando cuerpos de inclusión.

Dos de las estrategias principales para producir proteínas eucariotas activas son la modificación de las condiciones de cultivo para obtener proteína soluble y la recuperación de proteína activa a partir de cuerpos de inclusión mediante el re-plegamiento o refolding (Sahdev et al., 2008). Para los cuatro casos, CTB-G1, CTB-N, CTB-Z y CTB-EGFP se hicieron modificaciones en las condiciones de cultivo, incluyendo la inducción de la expresión a temperaturas menores a $37^{\circ} \mathrm{C}\left(16^{\circ} \mathrm{C}\right.$ y $\left.30^{\circ} \mathrm{C}\right)$ y la limitación en oxígeno, con el fin de disminuir la velocidad de síntesis y mejorar las chances de obtener proteínas solubles, pero en todos los casos se detectó la proteína recombinante en la fracción insoluble (cuerpos de inclusión). Pese a que las proteínas no fueron observadas en el sobrenadante mediante SDS-PAGE y tinción con coomasie blue, se intentó su purificación a partir de la fracción soluble mediante cromatografía de afinidad a Ni-NTA en condiciones nativas. Esta estrategia no dio resultados positivos y por ello se recurrió a la segunda opción. Los cuerpos de inclusión fueron solubilizados con un agente 


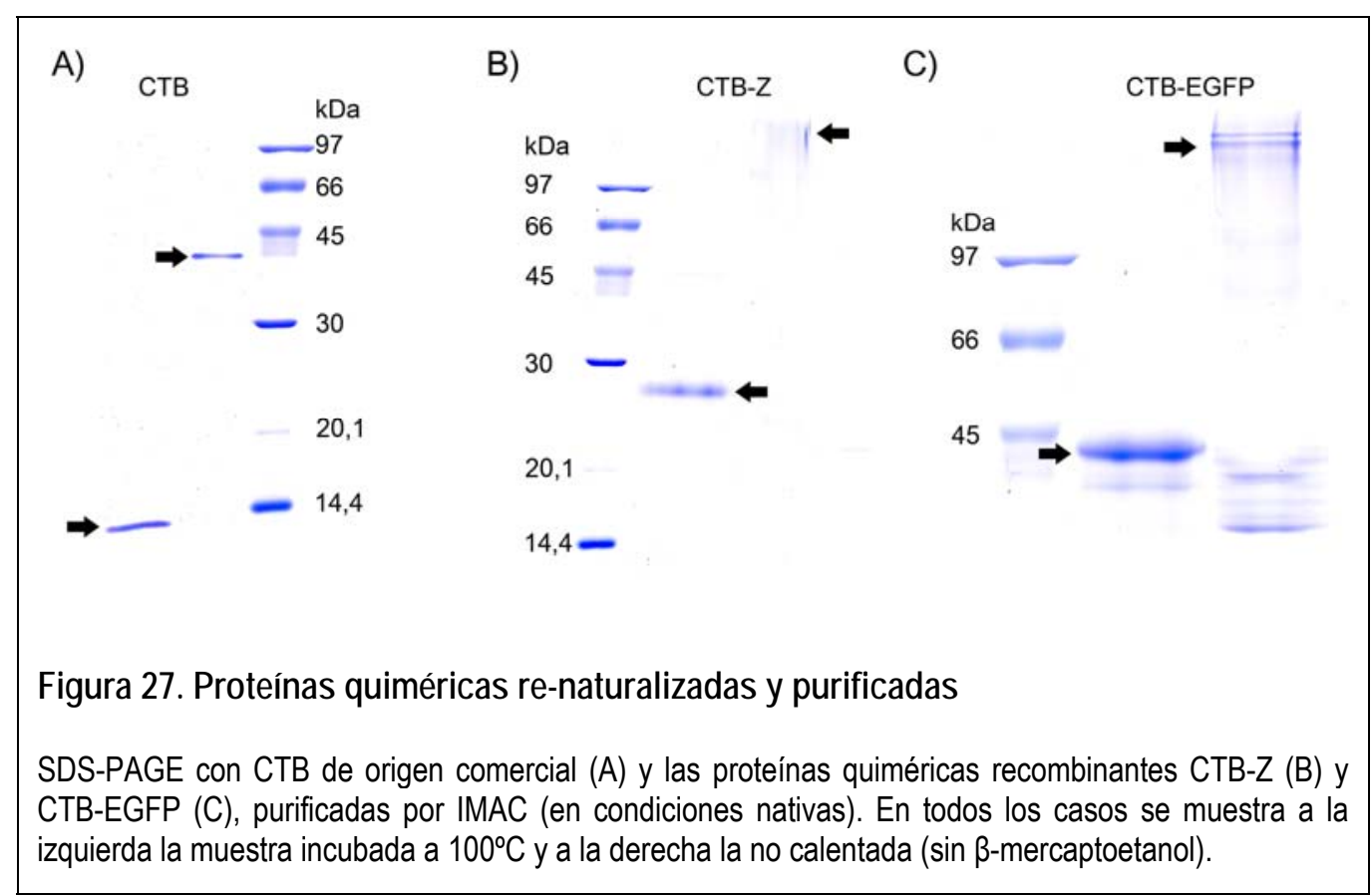

caotrópico (cloruro de guanidinio) y se realizó el re-plegamiento por la técnica de dilución (Clark, 1998). Para esto se utilizaron dispositivos que permitieron descargar gota a gota las proteínas desnaturalizadas en un buffer con un volumen 100 veces mayor ( 30 $\mathrm{ml}$ en $3 \mathrm{I})$. Esta metodología permitió recuperar CTB-Z y CTB-EGFP. En cambio, CTB-N y CTB-G1 volvieron a precipitar durante el procedimiento de dilución y no fue posible recuperarlas en forma soluble. Las proteínas re-plegadas fueron purificadas empleando columnas de Ni-NTA. Como puede verse en la Figura 27, CTB-Z y CTB-EGFP fueron recuperadas exitosamente. Mientras que, CTB-G1 y CTB-N permanecieron insolubles.

Con el fin de verificar la oligomerización de CTB, se hizo un SDS-PAGE con muestras desnaturalizadas y no desnaturalizadas por temperatura, un método utilizado habitualmente (Arêas et al., 2002; Lebens et al., 1996). En las muestras no calentadas a $100^{\circ} \mathrm{C}$, pudo apreciarse una banda de alto peso molecular, que indicaría la formación del pentámero, tanto para CTB-Z como para CTB-EGFP (Figura 27). 


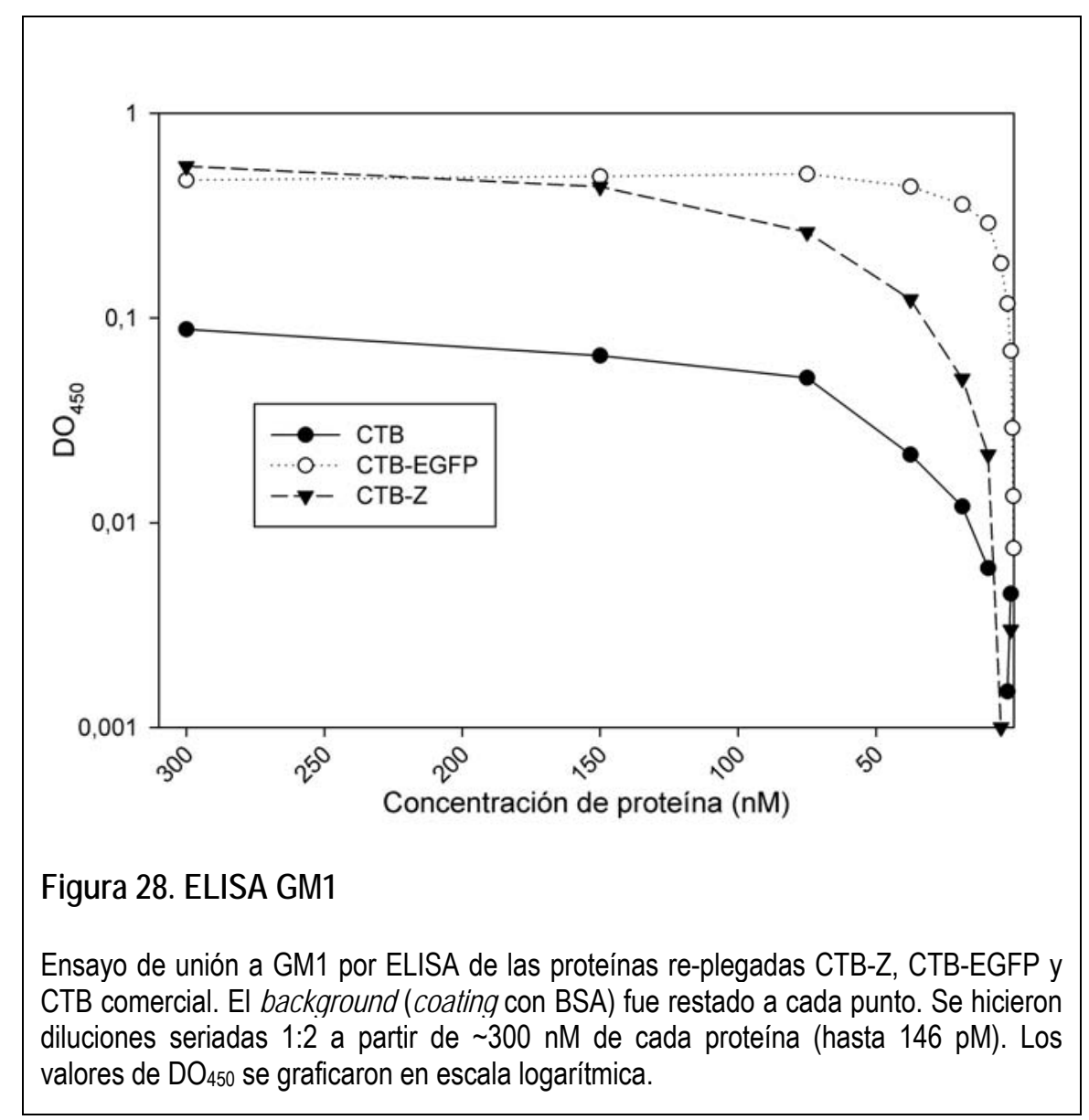

Para comprobar si las proteínas re-plegadas recuperan la capacidad de unión al receptor de CTB, se hizo un ELISA-GM1 (Menezes et al., 2002). La señal observada responde proporcionalmente a la dosis, lo que indica que las proteínas re-plegadas pueden unirse nuevamente a GM1 (Figura 28). A su vez, también confirma que la fusión de $Z$ y EGFP no altera la estructura de CTB y ésta todavía es capaz de formar el pentámero y de unirse a GM1.

A su vez, también se evaluó el efecto de la utilización de glicerol como crioprotector. Las soluciones que incluyeron glicerol no perdieron actividad de unión como sí ocurrió con las que no lo tenían (ambas conservadas $1 \mathrm{~h}$ a $-20^{\circ} \mathrm{C}$ ). Por este motivo, las preparaciones de proteína fueron conservadas con glicerol al $20 \%$. 


\section{Estimación $\mathrm{DL}_{50}$ en cobayos}

Como se mencionó en la Introducción, el modelo animal más utilizado con JUNV es el cobayo. En éste, el desarrollo de la enfermedad y la tasa de mortalidad dependen de la dosis empleada así cómo también de la edad de los animales. De esta manera, antes de hacer un desafío con el virus es necesario conocer la dosis letal $50\left(\mathrm{DL}_{50}\right)$, esto es, la dosis que mata el $50 \%$ de los animales. Para que este número sea estadísticamente significativo, se debe emplear un número grande de animales. Sin embargo, ese valor sólo se aplicará a ese único stock viral y animales en las mismas condiciones sanitarias y de la misma edad. En consecuencia, y por razones bioéticas, se optó por realizar sólo una estimación de la $\mathrm{DL}_{50}$, utilizando un número mínimo de animales (10 en total y 2 por dosis). El ensayo se dio por terminado al $15^{\circ}$ día post-inoculación y mostró una $\mathrm{DL}_{50}$ aproximada de $10^{2}$ ufp/ml (Figura 29). De esta manera, no se obtuvo un valor preciso de $\mathrm{DL}_{50}$

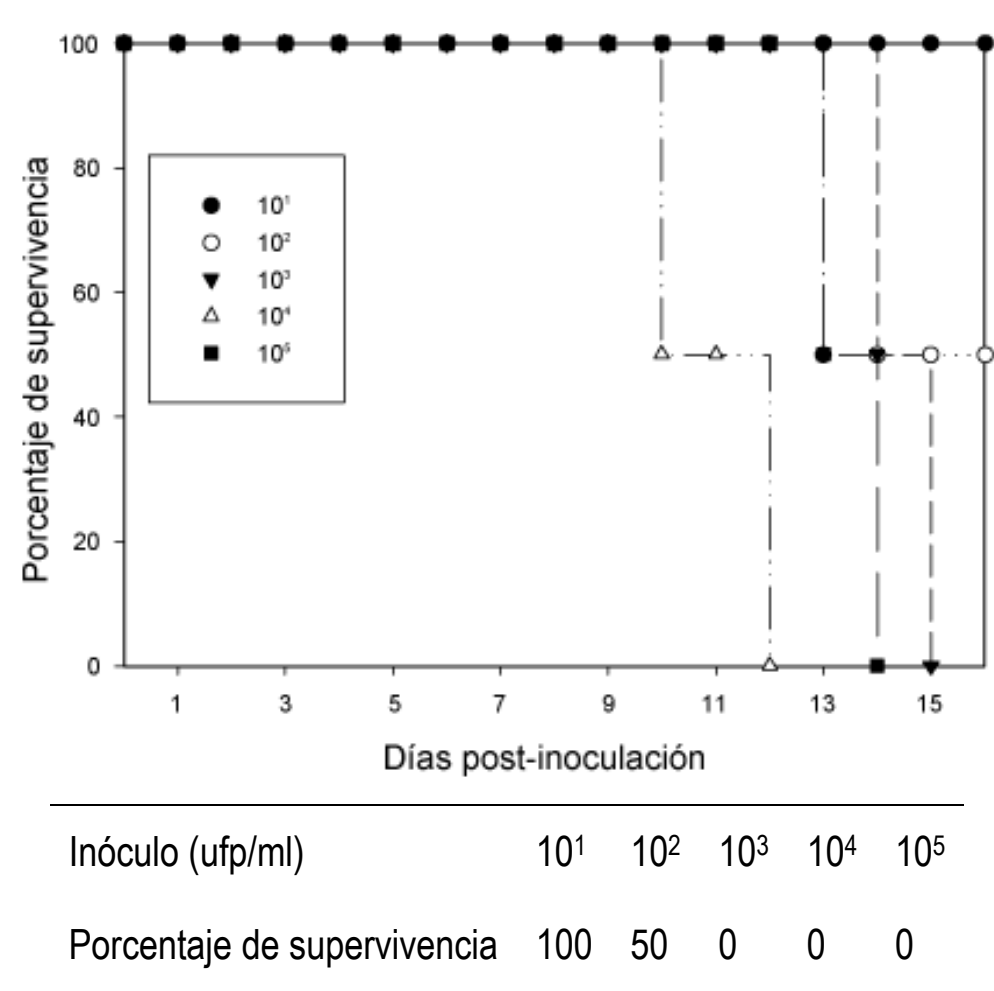

Figura 29. Estimación DL50

Se realizó una estimación de la $\mathrm{DL}_{50}$ en cobayos con la cepa patógena P3441 de JUNV (aislada de un paciente con FHA). Se utilizó un total de 10 animales y 2 para cada dosis. Los animales fueron inoculados por la vía intraperitoneal con dosis de $10^{1}$ a $10^{5} \mathrm{ufp} / \mathrm{ml}$ del virus. La tabla de abajo muestra los porcentajes de supervivencia al día 15. 


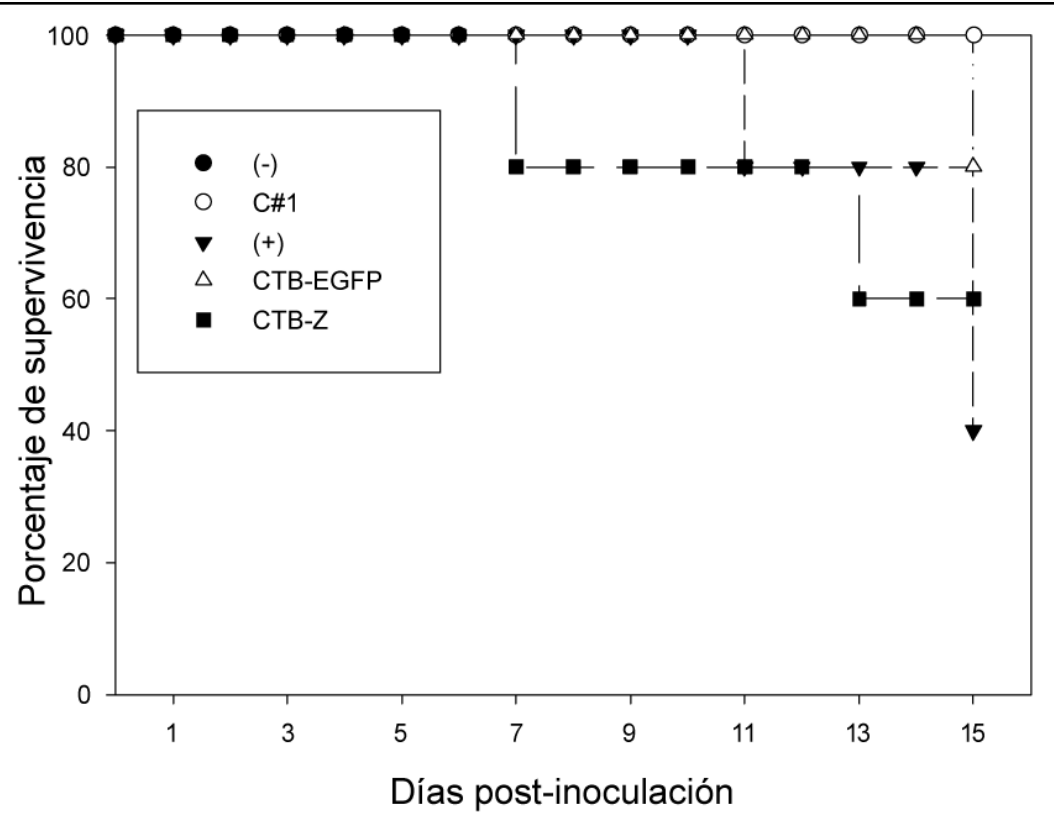

Figura 30. Desafío de cobayos con JUNV.

Cobayos macho adolescentes fueron inmunizados tres veces con las distintas preparaciones de antígeno con al menos dos semanas entre inoculaciones. El desafío se hizo a dos semanas de la última inmunización. Los vacunados con Candid \#1 fueron inoculados un mes antes del desafío. Los animales fueron desafiados por la vía intraperitoneal con una dosis de $50 \mathrm{ufp} / \mathrm{ml}$ del virus P3441 en PBS, excepto el control negativo, (-), que fue inoculado solo con PBS. Tanto (-) como (+) fueron inmunizados sólo con el adyuvante $\left(\mathrm{Al}(\mathrm{OH})_{3}\right)$.

pero sí una estimación, y lo que es más importante, se validó el modelo con la cepa viral y de cobayo utilizados (P3441 y Hartley, respectivamente).

\section{Desafío}

Con el fin de evaluar la posible capacidad protectora de CTB-Z, se realizó un desafío de cobayos con una cepa virulenta de JUNV. A tal fin, cinco grupos de cinco cobayos cada uno fueron inmunizados con las distintas formulaciones y controles. Estos incluyeron CTB-Z y CTB-EGFP con hidróxido de aluminio como adyuvante.

Por otra parte, un grupo fue inmunizado con Candid \#1 (control de vacunación), mientras que, otros dos grupos simplemente fueron inmunizados con el adyuvante y sin antígeno. Estos últimos dos grupos fueron luego utilizados en el desafío como controles (+) y (-), ambos no inmunizados, pero inoculados con virus y mock (sólo PBS), respectivamente. 
Tabla 6. Supervivencia de cobayos desafiados con JUNV

\begin{tabular}{ccc} 
Vivos & $\%$ & $\boldsymbol{p}$ \\
\hline $2 / 5$ & 40 & - \\
$5 / 5$ & 100 & 0,083
\end{tabular}

$\begin{array}{lccc}\text { Candid \#1 } & 5 / 5 & 100 & 0,083 \\ \text { CTB-EGFP } & 4 / 5 & 80 & 0,238 \\ \text { CTB-Z } & 3 / 4 & 75 & 0,396 \\ \text { *Valor } p \text { unilateral en el test exacto de Fisher para cada grupo vs. (+). }\end{array}$

Los animales fueron desafiados con $500 \mu$ de una suspensión viral de JUNV P3441 con 50 ufp/ml. Dicha concentración se adoptó teniendo en mente que el sólo se cuenta con una estimación de la $\mathrm{DL}_{50}$. En tal sentido, un inóculo viral (título) muy alto podría subestimar la capacidad protectora de CTB-Z.

El gráfico de la Figura 30 muestra la evolución de los distintos grupos a lo largo del tiempo que duró el ensayo. Uno de los animales inmunizados con CTB-Z murió al $7^{\circ}$ día post-inoculación. Dado que las muertes se esperan a fines de la segunda semana, ésta fue clasificada como inespecífica y descartada para el análisis. Cada uno de los tratamientos fue comparado con el grupo (+), el cual fue inmunizado sólo con el adyuvante $\left(\mathrm{Al}(\mathrm{OH})_{3}\right)$ y PBS y desafiado con el virus. Debido al número reducido de animales y a que se trata de una tabla dicotómica, los datos fueron analizados con el test exacto de Fisher. Éste es un ensayo de significancia empleado en tablas de contingencia (por ejemplo, vivo o muerto) en las que el número de muestras es bajo. En la Tabla 6 se pueden ver los porcentajes de sobrevida para cada grupo, así como también, los valores $p$ para el test de Fisher.

Hubo diferencia significativa entre el control (+) y el (-) y los vacunados con Candid \#1; no la hubo con respecto a CTB-Z o CTB-EGFP. Esto indica que $Z$ no brindó protección en un desafío con JUNV patógeno o que, al menos, la diferencia no fue lo suficientemente grande como para ser detectada con el número de animales utilizado (el poder del test, el cual refleja la probabilidad de rechazar la hipótesis nula cuando ésta es falsa). Por otra parte, se podría 
inferir un cierto grado de protección inespecífica, tanto para CTB-EGFP como para CTB-Z. Si bien este ensayo fue sólo exploratorio y una confirmación requeriría un número mayor de animales, este tipo de respuesta a CTB ha sido observada para otras enfermedades y modelos animales (Matsuo et al., 2000; Pascale et al., 1999; Tamura et al., 1996). Por otra parte, hasta el momento no hay reportes de que $Z$ tenga actividad protectora, como sí la hay para las glicoproteínas y $\mathrm{N}$ de arenavirus (FisherHoch et al., 2000; Lopez et al., 2000; Rodriguez-Carreno et al., 2005). No obstante, el ensayo permitió corroborar la utilidad del modelo, así como también, la validez del uso de CTB. 

Conclusiones generales y proyecciones futuras 

Los arenavirus son agentes causantes de enfermedades emergentes, principalmente como resultado de la expansión de la actividad productiva agrícola del ser humano.

En trabajos reciente mente publicados sobre la evolución de esta familia viral y sus reservorios se asegura que es altamente probable la aparición de nuevas infecciones emergentes causadas por arenavirus aún desconocidos (Charrel y de Lamballerie, 2009; Emonet et al., 2009). Esto es particularmente apreciable si se tiene en cuenta que los roedores son los mamíferos más exitosos (40\% de las especies de mamíferos) y con mayor cantidad de especies en la actualidad (Myers, 2009), y que los arenavirus existen como cuasiespecies gracias a la alta tasa de mutación característica de los virus cuyo genoma es de RNA (Sevilla et al., 2002).

Si bien los datos actuales muestran una incidencia cada vez menor de FHA, no es posible pensar en la completa erradicación de la enfermedad, por tratarse de una zoonosis transmitida por un roedor muy abundante y distribuido por todo nuestro país. En tal sentido, la única fiebre hemorrágica que pudo ser controlada mediante el control del roedor es la FHB y esto gracias a las características suburbanas de su reservorio (Calomys callosus) (Johnson et al., 1967; Salazar-Bravo et al., 2002).

Por su parte, la vacuna Candid \#1 mostró una alta eficacia y protección prolongada en el tiempo, con anticuerpos detectables hasta 10 años después de la vacunación (Enría y Barrera Oro, 2002). Sin embargo, el área endémica actual incluye regiones altamente pobladas como la ciudad de 
Rosario, lo que obliga a considerar la vacunación en forma masiva (Enria et al., 2008). El hecho de no sólo vacunar a trabajadores rurales de entre 15 y 34 años como hasta ahora, si no también al resto de la población, podría acentuar las características negativas de una vacuna a virus atenuado, como la posibilidad de reversión de la atenuación. Por ese motivo es importante contar con alternativas, que puedan ser utilizadas también en mujeres gestantes y en individuos inmunodeprimidos.

En otro orden de cosas, si bien se considera a los aerosoles como la principal fuente de infección, muy poco se sabe sobre la inmunidad de mucosas asociada a infecciones por arenavirus (Whitton, 2002). En este contexto, se clonaron genes del virus Junín en vectores plasmídicos que permiten su expresión como productos de fusión con la subunidad B de la toxina colérica. Esta última actúa como transportador de otras proteínas (en ese caso las proteínas quiméricas de JUNV) y tiene actividad adyuvante, provocando respuestas inmunológicas tanto sistémicas como en mucosas (Holmgren et al., 2005; Lycke, 2005; Silva et al., 2008; Vanden Broeck et al., 2007).

En esta etapa, se logró expresar exitosamente CTB-N, CTB-G1 y CTB-Z. A su vez, también se clonó y logró la expresión de CTB-EGFP, para su utilización como control. De todas las proteínas recombinantes producidas, solamente pudieron ser re-plegadas por el método de dilución las proteínas CTB-Z y CTB-EGFP y por esta razón fueron las primeras en ser utilizadas (EGFP como control) para evaluar su posible capacidad de protección de cobayos en un desafío con JUNV. Si bien los resultados no fueron alentadores, este primer ensayo permitió evaluar el modelo para futuros 
experimentos. Actualmente se está llevando a cabo un nuevo ensayo para estudiar las propiedades de CTB-G1 y CTB-N (se encuentra en las etapas de inmunización de los animales). A diferencia de $Z$, existen antecedentes de que estos dos candidatos vacunales podrían brindar protección (Lopez et al., 2000; Rodriguez-Carreno et al., 2005).

Como producto colateral de este trabajo se cuenta con CTB-EGFP; su capacidad de unión a GM1 y la fluorescencia que emite, la muestran como un reactivo útil para futuros experimentos. Entre ellos, podrá utilizarse para la marcación fluorescente de lipid rafts en membranas celulares.

La expansión de las infecciones por JUNV a zonas en las que no se presentaban casos de FHA aumenta la necesidad de disponer en forma local de ensayos diagnósticos estandarizados. Actualmente las muestras clínicas son enviadas al INEVH (Pergamino) y esta centralización limita la capacidad de respuesta rápida ya que ese instituto también concentra los diagnósticos confirmatorios de dengue y hantavirus.

En este trabajo se desarrolló un sistema de IgG ELISA altamente específico basado en la nucleoproteína del JUNV expresada en células de insecto infectadas con un baculovirus recombinante. En vista de los altos rendimientos de antígeno en el cultivo celular (más económico) y los beneficios asociados a la bio-seguridad del sistema, se espera que este ensayo se convierta en una alternativa útil al actual ELISA para la confirmación de la etiología en el diagnóstico clínico o en estudios seroepidemiológicos. A su vez, este ensayo puede adaptarse fácilmente 
para el seguimiento de la zoonosis en poblaciones de roedores (vigilancia epidemiológica).

Por otra parte, se desarrolló una serie de ELISA de captura de antígeno basados en anticuerpos monoclonales (mAb) contra $\mathrm{N}$ de JUNV, que cuando se hicieron con el mAb C6-9 mostraron un reconocimiento específico de Ag de JUNV. Por otra parte, el uso de los mAb C11-12 y E4-2 permitió detectar, además de $\mathrm{Ag}$ de JUNV, Ag de todos los arenavirus sudamericanos patogénicos ensayados. El uso combinado de estos Ag-ELISA podría ser útil para el diagnóstico y la diferenciación de las $\mathrm{FH}$ provocadas por infecciones con los arenavirus sudamericanos. 


\section{Bibliografía}



Abraham, J., Kwong, J. A., Albarino, C. G., Lu, J. G., Radoshitzky, S. R., Salazar-Bravo, J., Farzan, M., Spiropoulou, C. F. y Choe, H. (2009). Host-species transferrin receptor 1 orthologs are cellular receptors for nonpathogenic new world clade B arenaviruses. PLoS Pathog 5, e1000358.

Adams, J. R. y McClintock, J. T. (1991). Nuclear polyhedrosis viruses of insects. In Atlas of Invertebrate Viruses, pp. 87-204. Edited by J. R. Adams y J. R. Bonami. Boca Raton, FL, USA: CRC Press.

Ambrosio, A. M., Enria, D. A. y Maiztegui, J. I. (1986). Junin virus isolation from lympho-mononuclear cells of patients with Argentine hemorrhagic fever. Intervirology 25, 97-102.

Ambrosio, A. M., Feuillade, M. R., Gamboa, G. S. y Maiztegui, J. I. (1994). Prevalence of lymphocytic choriomeningitis virus infection in a human population of Argentina. Am J Trop Med Hyg 50, 381-386.

Ambrosio, A. M., Riera, L. M., Saavedra, M. C. y Sabattini, M. S. (2006). Immune response to vaccination against Argentine hemorrhagic Fever in an area where different arenaviruses coexist. Viral Immunol 19, 196-201.

Ambrosio, A. M., Riera, L. M., Saavedra, M. C. y Sottosanti, M. J. (2005). [Preclinical assay of candid \#1 vaccine against Argentine Hemorrhagic Fever made in Argentina]. 0025-7680 65, 329-332.

Ambrosio, M., Vallejos, A., Saavedra, C. y Maiztegui, J. I. (1990). Junin virus replication in peripheral blood mononuclear cells of patients with Argentine haemorrhagic fever. Acta Virol 34, 58-63.

Anon, M. C., Grau, O., Segovia, Z. M. y Franzefernandez, M. T. (1976). RNA composition of Junin virus. J Virol 18, 833-838.

Arêas, A. P., Oliveira, M. L., Ramos, C. R., Sbrogio-Almeida, M. E., Raw, I. y Ho, P. L. (2002). Synthesis of cholera toxin B subunit gene: cloning and expression of a functional 6XHis-tagged protein in Escherichia coli. Protein Expression Purif 25, 481-487.

Armstrong, C. y Lillie, R. D. (1934). Experimental lymphocytic choriomeningitis of monkeys and mice produced by a virus encountered in studies of 1933 St. louis encephalitis epidemic. Public Health Rep, 9.

Arribalzaga, R. A. (1955). Una nueva enfermedad epidémica a germen desconocido: hipertermia nefrotóxica, leucopénica y enantemática. Dia Med, 1204-1210.

Auperin, D. D., Romanowski, V., Galinski, M. S. y Bishop, H. L. (1984). Sequencing studies of Pichinde arenavirus S RNA indicate a novel coding strategy, an ambisense viral S RNA. JVirol, 987-904.

Barber, G. N., Clegg, J. C. y Chamberlain, J. (1987). Expression of Lassa virus nucleocapsid protein segments in bacteria: purification of high-level expression products and their application in antibody detection. Gene 56, 137-144.

Barber, G. N., Clegg, J. C. y Lloyd, G. (1990). Expression of the Lassa virus nucleocapsid protein in insect cells infected with a recombinant baculovirus: application to diagnostic assays for Lassa virus infection. J Gen Virol 71 ( Pt 1), $19-28$.

Barrera Oro, J. G., McKee, K. T., Jr., Spisso, J., Mahlandt, B. G. y Maiztegui, J. I. (1990). A refined complement-enhanced neutralization test for detecting antibodies to Junin virus. J Virol Methods 29, 71-80. 
Bhandari, P. y Gowrishankar, J. (1997). An Escherichia coli host strain useful for efficient overproduction of cloned gene products with $\mathrm{NaCl}$ as the inducer. $J$ Bacteriol 179, 4403-4406.

Bowen, M. D., Ksiazek, T. G., Rollin, P. E., Pinheiro, F. P., Goldsmith, C. S., Zaki, S. R., Nichol, S. T., Peters, C. J. y TravassosdeRosa, A. P. (1998). Characterization of Cupixi virus, a newly recognized new world group B Arenavirus. Proceedings of the Program and Abstracts of the 47th Annual Meeting of the American Society of Tropical Medicine and Hygiene.

Bowen, M. D., Peters, C. J., Mills, J. N. y Nichol, S. T. (1996a). Oliveros virus: a novel arenavirus from Argentina. Virology 217, 362-366.

Bowen, M. D., Peters, C. J. y Nichol, S. T. (1996b). The phylogeny of New World (Tacaribe complex) arenaviruses. Virology 219, 285-290.

Bowen, M. D., Peters, C. J. y Nichol, S. T. (1997). Phylogenetic analysis of the Arenaviridae: patterns of virus evolution and evidence for cospeciation between arenaviruses and their rodent hosts. MolPhylogenetEvol 8, 301-316.

Bradford, M. M. (1976). A rapid and sensitive method for the quantitation of microgram quantities of protein utilizing the principle of protein-dye binding. Anal Biochem 72, 248-254.

Briese, T., Paweska, J. T., McMullan, L. K., Hutchison, S. K., Street, C., Palacios, G., Khristova, M. L., Weyer, J., Swanepoel, R., Egholm, M., Nichol, S. T. y Lipkin, W. I. (2009). Genetic detection and characterization of Lujo virus, a new hemorrhagic fever-associated arenavirus from southern Africa. PLoS Path 5, e1000455.

Bruno, L. G., Bruno, L. M., Johnson, K. M., Webb, P. A. y Paola, D. d. (1968). Pathogenesis of Junin virus infection in the infant hamster. Anais de Microbiologia 15, 11-33.

Buchmeier, M. J., Bowen, M. D. y Peters, C. J. (2001). Arenaviridae: The Viruses and Their Replication. In Fields - Virology 4th edn, pp. 1334-1361. Edited by B. N. Fields, P. M. Howley, D. E. Griffin, R. A. Lamb, M. A. Martin, B. Roizman, S. E. Straus y D. M. Knipe. Philadelphia: Lippincott Williams \& Wilkins.

Buchmeier, M. J., de la Torre, J. C. y Peters, C. J. (2007). Field's Virology Lippincott Williams \& Wilkins.

Bui, H. H., Botten, J., Fusseder, N., Pasquetto, V., Mothe, B., Buchmeier, M. J. y Sette, A. (2007). Protein sequence database for pathogenic arenaviruses. Immunome Res 3, 1.

Cajimat, M. N., Milazzo, M. L., Bradley, R. D. y Fulhorst, C. F. (2007). Catarina virus, an arenaviral species principally associated with Neotoma micropus (southern plains woodrat) in Texas. Am J Trop Med Hyg 77, 732-736.

Cajimat, M. N., Milazzo, M. L., Rollin, P. E., Nichol, S. T., Bowen, M. D., Ksiazek, T. G. y Fulhorst, C. F. (2008). Genetic diversity among Bolivian arenaviruses. Virus Res.

Calisher, C. H., Tzianabos, T., Lord, R. D. y Coleman, P. H. (1970). Tamiami virus, a new member of the TaCaribe group. Am J Trop Med Hyg 19, 520526.

Cao, W., Henry, M. D., Borrow, P., Yamada, H., Elder, J. H., Ravkov, E. V., Nichol, S. T., Compans, R. W., Campbell, K. P. y Oldstone, M. B. (1998). Identification of alpha-dystroglycan as a receptor for lymphocytic choriomeningitis virus and Lassa fever virus. Science 282, 2079-2081. 
Casals, J. (1977). Serological reactions with arenaviruses. Medicina (Buenos Aires), 10.

Clark, E. D. B. (1998). Refolding of recombinant proteins. Curr Opin Biotechnol 9, 157-163.

Coto, C. E., Help, G. I. y De Tkaczevski, L. Z. (1972). Biological properties of Junin virus purified from infected mouse brain. 0025-7680 32, 281-286.

Cummins, D., Molinas, F. C., Lerer, G., Maiztegui, J. I., Faint, R. y Machin, S. J. (1990). A plasma inhibitor of platelet aggregation in patients with Argentine hemorrhagic fever. AmJTropMedHyg 42, 470-475.

Charrel, R. N. y de Lamballerie, X. (2009). Zoonotic aspects of arenavirus infections. Vet Microbiol.

Charrel, R. N. y de, L. X. (2003). Arenaviruses other than Lassa virus. Antiviral Res 57, 89-100.

de Bracco, M. M., Rimoldi, M. T., Cossio, P. M., Rabinovich, A., Maiztegui, J. I., Carballal, G. y Arana, R. M. (1978). Argentine hemorrhagic fever. Alterations of the complement system and anti-Junin-virus humoral response. $N$ Engl J Med 299, 216-221.

de Guerrero, L. B., Avila, M. M., Milani, H. L., Ruggiero, H. y Weissenbacher, M. C. (1982). [Prevalence of subclinical Junin virus infection in a select population of an endemic area of argentinian hemorrhagic fever]. 0025-7680 42, 110.

Delgado, S., Erickson, B. R., Agudo, R., Blair, P. J., Vallejo, E., Albarino, C. G., Vargas, J., Comer, J. A., Rollin, P. E., Ksiazek, T. G., Olson, J. G. y Nichol, S. T. (2008). Chapare virus, a newly discovered arenavirus isolated from a fatal hemorrhagic fever case in Bolivia. PLoS Pathog 4, e1000047.

Downs, W. G., Anderson, C. R., Spence, L., Aitken, T. H. G. y Greenhall, A. H. (1963). Tacaribe virus, a new agent isolated from Artibeus bats and mosquitos in trinidad, West Indies. Am J Trop Med Hyg 12, 7.

Eddy, G. A., Wagner, F. S., Scott, S. K. y Mahlandt, B. J. (1975). Protection of monkeys against Machupo virus by the passive administration of Bolivian haemorrhagic fever immunoglobulin (human origin). Bull World Health Organ 52, 723-727.

Emonet, S. F., de la Torre, J. C., Domingo, E. y Sevilla, N. (2009). Arenavirus genetic diversity and its biological implications. Infect Genet Evol 9, 417429.

Enria, D. (2005). Arenaviral hemorrhagic fevers: Argentine hemorrhagic fever and Lassa fever. Emerging neurological infections. . In Neurological Disease and Therapy, p. 505.

Enria, D., Bowen, M. D., Mills, J. N., Shieh, W. J., Bausch, D. y Peters, C. J. (2004). Arenavirus infections. . In Tropical Infectious Diseases: Principles, Pathogens, and Practice, pp. 1191-1212. Edited by R. L. Guerrant, D. H. Walker, P. F. Weller y W. B. Saunders.

Enria, D., Briggiler, A. M. y Feuillade, M. R. (1998). An overview of the epidemiological, ecological and preventive hallmarks of Argenitne Hemorrhagic Fever (Junin virus). Bull Inst Pasteur, 12.

Enria, D., Franco, S. G., Ambrosio, A., Vallejos, D., Levis, S. y Maiztegui, J. (1986). Current status of the treatment of Argentine Hemorrhagic Fever. Med Microbiol Immunol 175, 173-176.

Enría, D. A. y Barrera Oro, J. G. (2002). Junin virus vaccines. In Curr Top Microbiol Immunol, pp. 239-261. 
Enria, D. A., Briggiler, A. M., Fernandez, N. J., Levis, S. C. y Maiztegui, J. I. (1984). Importance of dose of neutralising antibodies in treatment of Argentine haemorrhagic fever with immune plasma. Lancet 2, 255-256.

Enria, D. A., Briggiler, A. M. y Sanchez, Z. (2008). Treatment of Argentine hemorrhagic fever. Antiviral Res 78, 132-139.

Enria, D. A., Damilano, A. J., Briggiler, A. M., Ambrosio, A. M., Fernández, N. J., Feuillade, M. R. y Maiztegui, J. I. (1985). Sindrome neurológico tardío en enfermos de Fiebre Hemorrágica Argentina tratados con plasma inmune. Medicina (Buenos Aires), 6.

Enria, D. A. y Maiztegui, J. I. (1994). Antiviral treatment of Argentine hemorrhagic fever. Antiviral Res 23, 23-31.

Fabiyi, A. (1976). Lassa fever (arenaviruses) as a public health problem. Bull Pan Am Health Organ 10, 335-337.

Fath-Goodin, A., Kroemer, J., Martin, S., Reeves, K. y Webb, B. A. (2006). Polydnavirus genes that enhance the baculovirus expression vector system. Adv Virus Res 68, 75-90.

Fisher-Hoch, S. P., Hutwagner, L., Brown, B. y McCormick, J. B. (2000). Effective vaccine for lassa fever. $J$ Virol 74, 6777-6783.

Freytag, L. C. y Clements, J. D. (2005). Mucosal adjuvants. Vaccine 23, 18041813.

Fulhorst, C. E., Bowen, M. D., Salas, R. A., de Manzione, N. M., Duno, G., Utrera, A., Ksiazek, T. G., Peters, C. J., Nichol, S. T., De Miller, E., Tovar, D., Ramos, B., Vasquez, C. y Tesh, R. B. (1997). Isolation and characterization of pirital virus, a newly discovered South American arenavirus. Am J Trop Med Hyg 56, 548-553.

Fulhorst, C. F., Bennett, S. G., Milazzo, M. L., Murray, H. L., Jr., Webb, J. P., Jr., Cajimat, M. N. y Bradley, R. D. (2002). Bear Canyon virus: an arenavirus naturally associated with the California mouse (Peromyscus californicus). Emerging Infect Dis 8, 717-721.

Fulhorst, C. F., Bowen, M. D., Ksiazek, T. G., Rollin, P. E., Nichol, S. T., Kosoy, M. Y. y Peters, C. J. (1996). Isolation and characterization of Whitewater Arroyo virus, a novel North American arenavirus. Virology 224, 114-120.

Garcia Franco, S., Ambrosio, A. M., Feuillade, M. R. y Maiztegui, J. I. (1988). Evaluation of an enzyme-linked immunosorbent assay for quantitation of antibodies to Junin virus in human sera. J Virol Methods 19, 299-305.

Garcia, J. B., Morzunov, S. P., Levis, S., Rowe, J., Calderon, G., Enria, D., Sabattini, M., Buchmeier, M. J., Bowen, M. D. y St Jeor, S. C. (2000). Genetic diversity of the Junin virus in Argentina: geographic and temporal patterns. Virology 272, 127-136.

George-Chandy, A., Eriksson, K., Lebens, M., Nordstrom, I., Schon, E. y Holmgren, J. (2001). Cholera toxin B subunit as a carrier molecule promotes antigen presentation and increases CD40 and CD86 expression on antigenpresenting cells. Infect Immun 69, 5716-5725.

Ghiringhelli, P. D. (2002). Virus Junín: clonado molecular y analisis estructural y funcional del RNA S y sus productos g,nicos. In Tesis Doctoral.

Ghiringhelli, P. D., Rivera-Pomar, R. V., Lozano, M. E., Grau, O. y Romanowski, V. (1991). Molecular organization of Junin virus S RNA: complete nucleotide sequence, relationship with other members of the Arenaviridae and unusual secondary structures. J Gen Virol 72, 2129-2141. 
Ghiringhelli, P. D. y Romanowski, V. (1994). Quick methylene blue staining for visualizing virus plaques in titration experiments. BioTechniques 17, 464465.

Gomez, R. M., Pozner, R. G., Lazzari, M. A., D'Atri, L. P., Negrotto, S., Chudzinski-Tavassi, A. M., Berria, M. I. y Schattner, M. (2003). Endothelial cell function alteration after Junin virus infection. Thromb Haemost 90, 326-333.

Gong, Z., Jin, Y. y Zhang, Y. (2005). Oral administration of a cholera toxin B subunit-insulin fusion protein produced in silkworm protects against autoimmune diabetes. J Biotechnol 119, 93-105.

Goni, S. E., Iserte, J. A., Ambrosio, A. M., Romanowski, V., Ghiringhelli, P. D. y Lozano, M. E. (2006). Genomic features of attenuated Junin virus vaccine strain candidate. Virus Genes 32, 37-41.

Gonzalez, J. P., Bowen, M. D., Nichol, S. T. y Rico Hesse, R. (1996). Genetic characterization and phylogeny of Sabi virus, an emergent pathogen in Brazil. Virology 221, 318-324.

Gonzalez, J. P., Emonet, S., de Lamballerie, X. y Charrel, R. (2007). Arenaviruses. Curr Top Microbiol Immunol 315, 253-288.

Gonzalez, J. P., McCormick, J. B., Saluzzo, J. F., Herve, J. P., Georges, A. J. y Johnson, K. M. (1983). An arenavirus isolated from wild-caught rodents (Pramys species) in the Central African Republic. Intervirology 19, 105-112.

Gowen, B. B. y Holbrook, M. R. (2008). Animal models of highly pathogenic RNA viral infections: hemorrhagic fever viruses. Antiviral Res 78, 79-90.

Gowrishankar, J. y Manna, D. (1996). How is osmotic regulation of transcription of the Escherichia coli proU operon achieved? A review and a model. Genetica 97, 363-378.

Green, D. E., Mahlandt, B. G. y McKee, K. J. (1987). Experimental Argentine hemorrhagic fever in rhesus macaques: virus-specific variations in pathology. J Med Virol 22, 113-133.

Guidry, J. J., Cardenas, L., Cheng, E. y Clements, J. D. (1997). Role of receptor binding in toxicity, immunogenicity, and adjuvanticity of Escherichia coli heat-labile enterotoxin. Infect Immun 65, 4943-4950.

Gunther, S., Kuhle, O., Rehder, D., Odaibo, G. N., Olaleye, D. O., Emmerich, P., ter Meulen, J. y Schmitz, H. (2001). Antibodies to Lassa virus Z protein and nucleoprotein co-occur in human sera from Lassa fever endemic regions. Med Microbiol Immunol 189, 225-229.

Harandi, A. M., Sanchez, J., Eriksson, K. y Holmgren, J. (2003). Recent developments in mucosal immunomodulatory adjuvants. Curr Opin Investig Drugs 4, 156-161.

Harrison, L. H., Halsey, N. A., McKee, K. T., Jr., Peters, C. J., Barrera Oro, J. G., Briggiler, A. M., Feuillade, M. R. y Maiztegui, J. I. (1999). Clinical case definitions for Argentine hemorrhagic fever. Clin Infect Dis 28, 10911094.

Holmgren, J., Adamsson, J., Anjuere, F., Clemens, J., Czerkinsky, C., Eriksson, K., Flach, C. F., George-Chandy, A., Harandi, A. M., Lebens, M., Lehner, T., Lindblad, M., Nygren, E., Raghavan, S., Sanchez, J., Stanford, M., Sun, J. B., Svennerholm, A. M. y Tengvall, S. (2005). Mucosal adjuvants and anti-infection and anti-immunopathology vaccines based on cholera toxin, cholera toxin B subunit and CpG DNA. Immunol Lett 97, 181-188. 
Holland, J., Spindler, K., Horodyski, F., Grabau, E., Nichol, S. y VandePol, S. (1982). Rapid evolution of RNA genomes. Science 215, 1577-1585.

Homberger, F. R., Romano, T. P., Seiler, P., Hansen, G. M. y Smith, A. L. (1995). Enzyme-linked immunosorbent assay for detection of antibody to lymphocytic choriomeningitis virus in mouse sera, with recombinant nucleoprotein as antigen. Lab Anim Sci 45, 493-496.

Jeney, C., Dobay, O., Lengyel, A., Adam, E. y Nasz, I. (1999). Taguchi optimisation of ELISA procedures. J Immunol Methods 223, 137-146.

Johnson, K. M., Webb, P. A., Kuns, M. L. y Valverde, L. (1967). On the mode of transmission of Bolivian hemorrhagic fever. Jpn J Med Sci Biol, 7.

Johnson, K. M., Wiebenga, N. H., Mackenzie, R. B., Kuns, M. L., Tauraso, N. M., Shelokov, A., Webb, P. A., Justines, G. y Beye, H. K. (1965). Virus Isolations from Human Cases of Hemorrhagic Fever in Bolivia. Proc Soc Exp Biol Med 118, 113-118.

Kenyon, R. H., McKee, K. J., Zack, P. M., Rippy, M. K., Vogel, A. P., York, C., Meegan, J., Crabbs, C. y Peters, C. J. (1992). Aerosol infection of rhesus macaques with Junin virus. Intervirology 33, 23-31.

Lebens, M., Shahabi, V., Backstrom, M., Houze, T., Lindblad, N. y Holmgren, J. (1996). Synthesis of hybrid molecules between heat-labile enterotoxin and cholera toxin B subunits: potential for use in a broad-spectrum vaccine. Infect Immun 64, 2144-2150.

Lecompte, E., ter Meulen, J., Emonet, S., Daffis, S. y Charrel, R. N. (2007). Genetic identification of Kodoko virus, a novel arenavirus of the African pigmy mouse (Mus Nannomys minutoides) in West Africa. Virology 364, 178-183.

Levis, S. C., Saavedra, M. C., Ceccoli, C., Falcoff, E., Feuillade, M. R., Enria, D. A., Maiztegui, J. I. y Falcoff, R. (1984). Endogenous interferon in Argentine hemorrhagic fever. J Infect Dis 149, 428-433.

Levis, S. C., Saavedra, M. C., Ceccoli, C., Feuillade, M. R., Enria, D. A., Maiztegui, J. I. y Falcoff, R. (1985). Correlation between endogenous interferon and the clinical evolution of patients with Argentine hemorrhagic fever. . J Interferon Res 3, 7.

Liang, Y., Lan, S. y Ly, H. (2009). Molecular determinants of Pichinde virus infection of guinea pigs--a small animal model system for arenaviral hemorrhagic fevers. Ann N Y Acad Sci 1171 Suppl 1, E65-74.

Lisieux, T., Coimbra, M., Nassar, E. S., Burattini, M. N., de Souza, L. T., Ferreira, I., Rocco, I. M., da Rosa, A. P., Vasconcelos, P. F., Pinheiro, F. P. y et al. (1994). New arenavirus isolated in Brazil. Lancet 343, 391-392.

Lopez, N., Scolaro, L., Rossi, C., Jacamo, R., Candurra, N., Pujol, C., Damonte, E. B. y Franze-Fernandez, M. T. (2000). Homologous and heterologous glycoproteins induce protection against Junin virus challenge in guinea pigs. J Gen Virol 81, 1273-1281.

Lozano, M. E., Enria, D., Maiztegui, J. I., Grau, O. y Romanowski, V. (1995). Rapid diagnosis of Argentine hemorrhagic fever by reverse transcriptase PCR-based assay. J Clin Microbiol 33, 1327-1332.

Lozano, M. E., Ghiringhelli, P. D., Romanowski, V. y Grau, O. (1993). A simple nucleic acid amplification assay for the rapid detection of Junin virus in whole blood samples. Virus Res 27, 37-53. 
Lukashevich, L. S., Clegg, J. C. y Sidibe, K. (1993). Lassa virus activity in Guinea: distribution of human antiviral antibody defined using enzyme-linked immunosorbent assay with recombinant antigen. J Med Virol 40, 210-217.

Lycke, N. (2005). Targeted vaccine adjuvants based on modified cholera toxin. Curr Mol Med 5, 591-597.

Lloyd, G., Barber, G. N., Clegg, J. C. y Kelly, P. (1989). Identification of Lassa fever virus infection with recombinant nucleocapsid protein antigen. Lancet 2, 1222.

Maiztegui, J., Feuillade, M. y Briggiler, A. (1986). Progressive extension of the endemic area and changing incidence of Argentine Hemorrhagic Fever. Med Microbiol Immunol 175, 149-152.

Maiztegui, J. y Sabattini, M. (1977). Extensión progresiva del área endémica de fiebre hemorrágica argentina. Medicina (Buenos Aires) 37, 5.

Maiztegui, J. I. (1975a). Clinical and epidemiological patterns of Argentine haemorrhagic fever, pp. 385-575: Bull . WHO.

Maiztegui, J. I. (1975b). Clinical and epidemiological patterns of Argentine haemorrhagic fever. Bull World Health Organ 52, 567-575.

Maiztegui, J. I., Fernandez, N. J. y de Damilano, A. J. (1979). Efficacy of immune plasma in treatment of Argentine haemorrhagic fever and association between treatment and a late neurological syndrome. Lancet 2, 1216-1217.

Maiztegui, J. I., Laguens, R. P., Cossio, P. M., Casanova, M. B., de la Vega, M. T., Ritacco, V., Segal, A., Fernandez, N. J. y Arana, R. M. (1975). Ultrastructural and immunohistochemical studies in five cases of Argentine hemorrhagic fever. J Infect Dis 132, 35-53.

Maiztegui, J. I., McKee, K. T., Jr., Barrera Oro, J. G., Harrison, L. H., Gibbs, P. H., Feuillade, M. R., Enria, D. A., Briggiler, A. M., Levis, S. C., Ambrosio, A. M., Halsey, N. A. y Peters, C. J. (1998). Protective efficacy of a live attenuated vaccine against Argentine hemorrhagic fever. AHF Study Group. JInfectDis 177, 277-283.

Mando, O. G. (1977). Hepatic and enzymatic alterations in Argentine hemorrhagic fever. Medicina (Buenos Aires), 3.

Matsuo, K., Yoshikawa, T., Asanuma, H., Iwasaki, T., Hagiwara, Y., Chen, Z., Kadowaki, S. E., Tsujimoto, H., Kurata, T. y Tamura, S. I. (2000). Induction of innate immunity by nasal influenza vaccine administered in combination with an adjuvant (cholera toxin). Vaccine 18, 2713-2722.

Matsuura, Y., Possee, R. D. y Bishop, D. H. (1986). Expression of the S-coded genes of lymphocytic choriomeningitis arenavirus using a baculovirus vector. J Gen Virol 67 ( Pt 8), 1515-1529.

Menezes, C. A., Amianti, J., Harayama, H. S., Koga, P. C., Trabulsi, L. R. y Piazza, R. M. (2002). Inhibition of Escherichia coli heat-labile enterotoxin by neoglycoprotein and anti-lectin antibodies which mimic GM1 receptor. FEMS Microbiol Lett 216, 67-70.

Merritt, E. A., Sarfaty, S., van den Akker, F., L'Hoir, C., Martial, J. A. y Hol, W. G. (1994). Crystal structure of cholera toxin B-pentamer bound to receptor GM1 pentasaccharide. Protein Sci 3, 166-175.

Merryweather, A. T., Weyer, U., Harris, M. P., Hirst, M., Booth, T. y Possee, R. D. (1990). Construction of genetically engineered baculovirus insecticides containing the Bacillus thuringiensis subsp. kurstaki HD-73 delta endotoxin. J Gen Virol 71, 1535-1544. 
Meyer, B. J., de la Torre, J. C. y Southern, P. J. (2002). Arenaviruses: genomic RNAs, transcription, and replication. Curr Top Microbiol Immunol 262, 139157.

Mifune, K., Carter, M. y Rawls, W. (1971). Characterization studies of the Pichinde virus-a member of the arenavirus group. Proceedings of the Society for Experimental Biology \& Medicine 136, 637-644.

Mills, J. N., Calderon, G. E., Ellis, B. A., McKee, K. T., Ksiazek, T. G., Oro, J. G., Peters, C. J., Childs, J. E. y Maiztegui, J. I. (1991a). [New findings on Junin virus infection in rodents inside and outside the endemic area of hemorrhagic fever in Argentina]. [Spanish]. 0025-7680 51, 519-523.

Mills, J. N., Ellis, B. A., Childs, J. E., McKee, K. T., Jr., Maiztegui, J. I., Peters, C. J., Ksiazek, T. G. y Jahrling, P. B. (1994). Prevalence of infection with Junin virus in rodent populations in the epidemic area of Argentine hemorrhagic fever. Am J Trop Med Hyg 51, 554-562.

Mills, J. N., Ellis, B. A., McKee, K. J., Ksiazek, T. G., Oro, J. G., Maiztegui, J. I., Calderon, G. E., Peters, C. J. y Childs, J. E. (1991b). Junin virus activity in rodents from endemic and nonendemic loci in central Argentina. Am J Trop Med Hyg 44, 589-597.

Mills, J. N., Ellis, B. A., McKee, K. T., Jr., Calderon, G. E., Maiztegui, J. I., Nelson, G. O., Ksiazek, T. G., Peters, C. J. y Childs, J. E. (1992). A longitudinal study of Junin virus activity in the rodent reservoir of Argentine hemorrhagic fever. Am J Trop Med Hyg 47, 749-763.

Mills, J. N., Ellis, B. A., McKee, K. T., Jr., Ksiazek, T. G., Oro, J. G., Maiztegui, J. I., Calderon, G. E., Peters, C. J. y Childs, J. E. (1991c). Junin virus activity in rodents from endemic and nonendemic loci in central Argentina. Am J Trop Med Hyg 44, 589-597.

Moncayo, A. C., Hice, C. L., Watts, D. M., Travassos de Rosa, A. P., Guzman, H., Russell, K. L., Calampa, C., Gozalo, A., Popov, V. L., Weaver, S. C. y Tesh, R. B. (2001). Allpahuayo virus: a newly recognized arenavirus (arenaviridae) from arboreal rice rats (oecomys bicolor and oecomys paricola) in northeastern peru. Virology 284, 277-286.

Morales, M. A., Calderon, G. E., Riera, L. M., Ambrosio, A. M., Enria, D. A. y Sabattini, M. S. (2002). Evaluation of an enzyme-linked immunosorbent assay for detection of antibodies to Junin virus in rodents. $J$ Virol Methods 103, 57-66.

Myers, P. (2009). "Rodentia" (On-line). Animal Diversity Web: University of Michigan.

Nakamura, Y., Gojobori, T. y Ikemura, T. (2000). Codon usage tabulated from international DNA sequence databases: status for the year 2000. Nucleic Acids Res 28, 292.

O'Reilly, D. R., Miller, L. K. y Luckow, V. A. (1992). Baculovirus Expression Vectors: A Laboratory Manual. New York: W. H. Freeman and Company.

Obuchowski, N. A., Lieber, M. L. y Wians, F. H., Jr. (2004). ROC curves in clinical chemistry: uses, misuses, and possible solutions. Clin Chem 50, 1118-1125.

Palacios, G., Druce, J., Du, L., Tran, T., Birch, C., Briese, T., Conlan, S., Quan, P. L., Hui, J., Marshall, J., Simons, J. F., Egholm, M., Paddock, C. D., Shieh, W. J., Goldsmith, C. S., Zaki, S. R., Catton, M. y Lipkin, W. I. (2008). A new arenavirus in a cluster of fatal transplant-associated diseases. $N$ Engl J Med 358, 991-998. 
Parodi, A. S., Rugiero, H. R., Greenway, D. J., Mettler, N. y Boxaca, M. (1961). [Isolation of the Junin virus from rodents of non-epidemic areas.]. Prensa Med Argent 48, 2321-2322.

Parodi, A. S., Rugiero, H. R., Greenway, D. J., Mettler, N., Martinez, A., Boxaca, M. y De La Barrera, J. M. (1959). [Isolation of the Junin virus (epidemic hemorrhagic fever) from the mites of the epidemic area (Echinolaelaps echidninus, Barlese).]. Prensa Med Argent 46, 2242-2244.

Partidos, C. D., Beignon, A. S., Briand, J. P. y Muller, S. (2004). Modulation of immune responses with transcutaneously deliverable adjuvants. Vaccine 22, 2385-2390.

Pascale, J. M., Shaw, M. M., Durant, P. J., Amador, A. A., Bartlett, M. S., Smith, J. W., Gregory, R. L. y McLaughlin, G. L. (1999). Intranasal immunization confers protection against murine Pneumocystis carinii lung infection. Infect Immun 67, 805-809.

Perez, M., Craven, R. C. y de la Torre, J. C. (2003). The small RING finger protein $\mathrm{Z}$ drives arenavirus budding: implications for antiviral strategies. ProcNatlAcadSciUSA 100, 12978-12983.

Perez, M., Greenwald, D. L. y de la Torre, J. C. (2004). Myristoylation of the RING finger Z protein is essential for arenavirus budding. JVirol 78, 1144311448.

Peters, C. J. y Oldstone, M. B. A. (2002). Human infection with arenaviruses in the americas. In Arenaviruses I: the epidemiology, molecular and cell biology of arenaviruses, pp. 65-74. Edited by R. W. Compans, M. Cooper, H. Koprowski, M. B. A. Oldstone, M. Potter y P. K. Vogt: Springer.

Peters, C. J., Webb, P. A. y Johnson, K. M. (1973). Measurement of antibodies to Machupo virus by the indirect fluorescent technique. Proc Soc Exp Biol Med 142, 526-531.

Pinheiro, F. P., Shope, R. E., Andrade, A. H. P., Bensabath, G., Cacios, G. V. y Casals, J. (1966). Amaparí, a new virus of the Tacaribe group from rodents and mites of Amapa territory, Brazil. . Proc Soc Exp Biol Med, 5.

Pirosky, I., Zuccarini, J., Molinelli, E. A., Di Pietro, A., Martini, P., Ferreyra, B., Gutman, F. L. y Vazquez, T. (1959). Virosis hemorrágica del noroeste bonaerense. Endemoepidémica, febril, enantemática y leucopénica. La primera inoculación experimental al hombre. Orientación Médica, 5.

Radoshitzky, S. R., Abraham, J., Spiropoulou, C. F., Kuhn, J. H., Nguyen, D., Li, W., Nagel, J., Schmidt, P. J., Nunberg, J. H., Andrews, N. C., Farzan, M. y Choe, H. (2007). Transferrin receptor 1 is a cellular receptor for New World haemorrhagic fever arenaviruses. Nature 446, 92-96.

Radoshitzky, S. R., Kuhn, J. H., Spiropoulou, C. F., Albariño, C. G., Nguyen, D. P., Salazar-Bravo, J., Dorfman, T., Lee, A. S., Wang, E., Ross, S. R., Choe, H. y Farzan, M. (2008). Receptor determinants of zoonotic transmission of New World hemorrhagic fever arenaviruses. Proc Natl Acad Sci U S A 105, 2664-2669.

Ramos, C. R., Abreu, P. A., Nascimento, A. L. y Ho, P. L. (2004). A high-copy T7 Escherichia coli expression vector for the production of recombinant proteins with a minimal N-terminal His-tagged fusion peptide. Braz J Med Biol Res 37, 1103-1109.

Rawls, W. E., Chan, M. A. y Gee, S. R. (1981). Can J Microbiol 7.

Reed, L. J. y Muench, H. (1938). A simple method of estimating fifty percent endpoints. The American Journal of Hygiene, 493-497. 
Reignier, T., Oldenburg, J., Noble, B., Lamb, E., Romanowski, V., Buchmeier, M. J. y Cannon, P. M. (2006). Receptor use by pathogenic arenaviruses. Virology 353, 111-120.

Riera, L. M., Feuillade, M. R., Saavedra, M. C. y Ambrosio, A. M. (1997). Evaluation of an enzyme immunosorbent assay for the diagnosis of Argentine haemorrhagic fever. Acta Virol 41, 305-310.

Rivera Pomar, R. V., Manzella, E. M., Ghiringhelli, P. D., Grau, O. y Romanowski, V. (1991). Patterns of transient expression of the arenavirus nucleocapsid protein gene in transfected cells. MicroscElectron BiolCelular 15, 41-55.

Rodighiero, C., Fujinaga, Y., Hirst, T. R. y Lencer, W. I. (2001). A cholera toxin B-subunit variant that binds ganglioside G(M1) but fails to induce toxicity. $J$ Biol Chem 276, 36939-36945.

Rodriguez-Carreno, M. P., Nelson, M. S., Botten, J., Smith-Nixon, K., Buchmeier, M. J. y Whitton, J. L. (2005). Evaluating the immunogenicity and protective efficacy of a DNA vaccine encoding Lassa virus nucleoprotein. Virology 335, 87-98.

Rojek, J. M. y Kunz, S. (2008). Cell entry by human pathogenic arenaviruses. Cell Microbiol.

Romanowski, V. y Bishop, D. H. (1983). The formation of arenaviruses that are genetically diploid. Virology 126, 87-95.

Rotz, L. D., Khan, A. S., Lillibridge, S. R., Ostroff, S. M. y Hughes, J. M. (2002). Public health assessment of potential biological terrorism agents. Emerging Infect Dis, 225-230.

Rugiero, H. R., Cintora, F. A., Magnoni, C., Ruggiero, H., Gonzalezcambaceres, C., Maglio, F., Astarloa, L., Squassi, G., Giacosa, A. y Fernandez, D. (1964a). [Argentinian Hemorrhagic Fever. IV. Clinical Forms.]. Rev Asoc Med Argent 78, 500-510.

Rugiero, H. R., Milani, H., Giacosa, A., Fernandez, D., Cintora, F. A., Magnoni, C., Ruggiero, H., Astarloa, L., Maglio, F., Gonzalezcambaceres, C. y Squassi, G. (1964b). [Argentinian Hemorrhagic Fever. V. Clinical Laboratory Diagnosis. Diagnostic Importance and Clinical Correlations.]. Rev Asoc Med Argent 78, 611-618.

Rugiero, H. R., Ruggiero, H., Gonzalezcambaceres, C., Cintora, F. A., Maglio, F., Magnoni, C., Astarloa, L., Squassi, G., Giacosa, A. y Fernandez, D. (1964c). [Argentine Hemorrhagic Fever. II. Descriptive Clinical Study.]. Rev Asoc Med Argent 78, 281-294.

Sabattini, M. S. y Gonzalez, L. E. (1967). Direct identification of Junín virus in infected wild rodents in nature. Rev Soc Argent Biol 43, 252-260.

Sahdev, S., Khattar, S. K. y Saini, K. S. (2008). Production of active eukaryotic proteins through bacterial expression systems: a review of the existing biotechnology strategies. Mol Cell Biochem 307, 249-264.

Saijo, M., Georges-Courbot, M. C., Marianneau, P., Romanowski, V., Fukushi, S., Mizutani, T., Georges, A. J., Kurata, T., Kurane, I. y Morikawa, S. (2007). Development of recombinant nucleoprotein-based diagnostic systems for lassa Fever. Clin Vaccine Immunol 14, 1182-1189.

Salas, R., de, M. N., Tesh, R. B., Rico, H. R., Shope, R. E., Betancourt, A., Godoy, O., Bruzual, R., Pacheco, M. E., Ramos, B. y et, a. l. (1991). Venezuelan haemorrhagic fever. Lancet 338, 1033-1036. 
Salazar-Bravo, J., Ruedas, L. A. y Yates, T. L. (2002). Mammalian reservoirs of arenavirus. In Arenaviruses I: the epidemiology, molecular and cell biology of arenaviruses, pp. 25-63. Edited by R. W. Compans, M. Cooper, H. Koprowski, M. B. A. Oldstone, M. Potter y P. K. Vogt: Springer.

Salvato, M. S., Clegg, J. C. S., Buchmeier, M. J., Charrel, R. N., Gonzales, J. P., Lukashevich, I. S., Peters, C. J., Rico-Hesse, R. y Romanowski, V. (2005). Arenaviridae In Virus Taxonomy VIIIth report of the ICTV, pp. 725-733. Edited by C. M. Fauquet, J. Maniloff, M. A. Mayo, U. Desselberger y L. A. Ball. London: Elsevier/Academic Press.

Sambrook, J., Fritsch, E. F. y Maniatis, T. (1989). Molecular cloning. A laboratory manual. Cold Spring Harbor, Nueva York: Cold spring Harbor Laboratory Press.

Sanchez, A., Pifat, D. Y., Kenyon, R. H., Peters, C. J., McCormick, J. B. y Kiley, M. P. (1989). Junin virus monoclonal antibodies: characterization and crossreactivity with other arenaviruses. J Gen Virol 70, 1125-1132.

Sevilla, N., Domingo, E. y de la Torre, J. C. (2002). Contribution of LCMV towards deciphering biology of quasispecies in vivo. Curr Top Microbiol Immunol 263, 197-220.

Silva, A. J., Eko, F. O. y Benitez, J. A. (2008). Exploiting cholera vaccines as a versatile antigen delivery platform. Biotechnol Lett 30, 571-579.

Singh, S. R., Hulett, K., Pillai, S. R., Dennis, V. A., Oh, M. K. y Scissum-Gunn, K. (2006). Mucosal immunization with recombinant MOMP genetically linked with modified cholera toxin confers protection against Chlamydia trachomatis infection. Vaccine 24, 1213-1224.

Spangler, B. D. (1992). Structure and function of cholera toxin and the related Escherichia coli heat-labile enterotoxin. Microbiol Rev 56, 622-647.

Staneck, L. D., Trowbridge, R. S., Welsh, R. M., Wright, E. A. y Pfau, C. J. (1972). Arenaviruses: cellular response to long-term in vitro infection with parana and lymphocytic choriomeningitis viruses. Infect Immun 6, 444-450.

Strecker, T., Eichler, R., Meulen, J., Weissenhorn, W., Dieter, K. H., Garten, W. y Lenz, O. (2003). Lassa virus $Z$ protein is a matrix protein and sufficient for the release of virus-like particles [corrected]. JVirol 77, 10700-10705.

Swanepoel, R., Leman, P. A., Shepherd, A. J., Shepherd, S. P., Kiley, M. P. y McCormick, J. B. (1985). Identification of Ippy as a Lassa-fever-related virus. Lancet 1, 639.

Taguchi, G. (1993). Taguchi Methods. Dearborn, Michigan: ASI Press.

Tamura, S., Miyata, K., Matsuo, K., Asanuma, H., Takahashi, H., Nakajima, K., Suzuki, Y., Aizawa, C. y Kurata, T. (1996). Acceleration of influenza virus clearance by Th1 cells in the nasal site of mice immunized intranasally with adjuvant-combined recombinant nucleoprotein. J Immunol 156, 38923900.

Ter Meulen, J., Koulemou, K., Wittekindt, T., Windisch, K., Strigl, S., Conde, S. y Schmitz, H. (1998). Detection of Lassa virus antinucleoprotein immunoglobulin G (IgG) and IgM antibodies by a simple recombinant immunoblot assay for field use. J Clin Microbiol 36, 3143-3148.

Tochikubo, K., Isaka, M., Yasuda, Y., Kozuka, S., Matano, K., Miura, Y. y Taniguchi, T. (1998). Recombinant cholera toxin B subunit acts as an adjuvant for the mucosal and systemic responses of mice to mucosally coadministered bovine serum albumin. Vaccine 16, 150-155. 
Tortorici, M. A., Ghiringhelli, P. D., Lozano, M. E., Albarino, C. G. y Romanowski, V. (2001). Zinc-binding properties of Junin virus nucleocapsid protein. J Gen Virol 82, 121-128.

Vanden Broeck, D., Horvath, C. y De Wolf, M. J. (2007). Vibrio cholerae: cholera toxin. Int J Biochem Cell Biol 39, 1771-1775.

Vezza, A. C., Cash, P., Jahrling, P., Eddy, G. y Bishop, D. H. (1980). Arenavirus recombination: the formation of recombinants between prototype pichinde and pichinde munchique viruses and evidence that arenavirus S RNA codes for N polypeptide. Virology 106, 250-260.

Vieth, S., Drosten, C., Charrel, R., Feldmann, H. y Gunther, S. (2005). Establishment of conventional and fluorescence resonance energy transferbased real-time PCR assays for detection of pathogenic New World arenaviruses. J Clin Virol 32, 229-235.

Webb, H. E., Molomut, N., Padnos, M. y Wetherley, M. G. (1975). The treatment of 18 cases of malignant disease with an arenavirus. Clinical Oncology 1, 157-169.

Webb, P. A., Johnson, K. M., Hibbs, J. B. y Kuns, M. L. (1970). Parana, a new Tacaribe complex virus from Paraguay. Arch Gesamte Virusforsch 32, 379388.

Weissenbacher, M. C., Calello, M. A., Carballal, G., Planes, N., de la Vega, M. T. y Kravetz, F. (1985). [Junin virus activity in humans and rodents of nonendemic areas of the province of Buenos Aires]. 0025-7680 45, 263-268.

Weissenbacher, M. C., de Guerrero, L. B. y Boxaca, M. C. (1975). Experimental biology and pathogenesis of Junin virus infection in animals and man. Bull World Health Organ 52, 507-515.

Weissenbacher, M. C., Grela, M. E., Sabattini, M. S., Maiztegui, J. I., Coto, C. E., Frigerio, M. J., Cossio, P. M., Rabinovich, A. S. y Barrera Oro, J. G. (1978). Inapparent infections with Junin virus among laboratory workers. $J$ Infect Dis 137, 309-313.

Weissenbacher, M. C., Laguens, R. P. y Coto, C. E. (1987). Argentine hemorrhagic fever. Curr Top Microbiol Immunol 134, 79-116.

Weissenbacher, M. C., Sabattini, M. S., Avila, M. M., Sangiorgio, P. M., de, S. M., Contigiani, M. S., Levis, S. C. y Maiztegui, J. I. (1983). Junin virus activity in two rural populations of the Argentine hemorrhagic fever (AHF) endemic area. J Med Virol 12, 273-280.

Weyer, U., Knight, S. y Possee, R. D. (1990). Analysis of very late gene expression by Autographa californica nuclear polyhedrosis virus and the further development of multiple expression vectors. J Gen Virol 71, 1525-1534.

Whitton, J. L. (2002). Designing Arenaviral Vaccines. In Curr Top Microbiol Immunol, pp. 221-238.

Wulff, H., McIntosh, B. M., Hamner, D. B. y Johnson, K. M. (1977). Isolation of an arenavirus closely related to Lassa virus from Mastomys natalensis in south-east Africa. Bull WHO 55, 441-444.

Yasuda, Y., Isaka, M., Taniguchi, T., Zhao, Y., Matano, K., Matsui, H., Morokuma, K., Maeyama, J., Ohkuma, K., Goto, N. y Tochikubo, K. (2003). Frequent nasal administrations of recombinant cholera toxin B subunit (rCTB)-containing tetanus and diphtheria toxoid vaccines induced antigen-specific serum and mucosal immune responses in the presence of anti-rCTB antibodies. Vaccine 21, 2954-2963. 
York, J., Romanowski, V., Lu, M. y Nunberg, J. H. (2004). The signal peptide of the Junin arenavirus envelope glycoprotein is myristoylated and forms an essential subunit of the mature G1-G2 complex. J Virol 78, 10783-10792.

Yun, N. E., Linde, N. S., Dziuba, N., Zacks, M. A., Smith, J. N., Smith, J. K., Aronson, J. F., Chumakova, O. V., Lander, H. M., Peters, C. J. y Paessler, S. (2008). Pathogenesis of XJ and Romero strains of Junin virus in two strains of guinea pigs. Am J Trop Med Hyg 79, 275-282.

Zweig, M. H. y Campbell, G. (1993). Receiver-operating characteristic (ROC) plots: a fundamental evaluation tool in clinical medicine. Clin Chem 39, 561577. 
Materiales y métodos 


\section{Células de insecto}

Para el trabajo con baculovirus se emplearon dos líneas celulares: Sf9, derivada de la oruga Spodoptera frugiperda y High 5 o Tn5 (BTI-TN-5B1-4), que deriva de la oruga Trichoplusia ni. Los cultivos se realizaron en placas de Petri de $36 \mathrm{~mm}$ de diámetro y en frascos de poliestireno de 25 y $80 \mathrm{~cm}^{2}$ de superficie (Nunc). Fueron mantenidos en estufa a $28^{\circ} \mathrm{C}$ en medio de cultivo TC 100 (JRH Biosciences), suplementado con 10\% (v/v) de suero fetal bovino (SFB, Bioser) y $50 \mu \mathrm{g} / \mathrm{ml}$ de gentamicina (Parafarm). Los repiques celulares se efectuaron cuando el cultivo presentaba $90 \%$ de confluencia. A tal fin, se emplearon rastrillos de silicona para desprender las células y luego diluirlas (entre 1:4 y 1:10) en medio de cultivo nuevo.

\section{Células de mamífero}

Se emplearon células Vero E6, derivadas de células de riñón de mono verde africano, Cercopithecus aethiops; células BHK-21, derivadas de fibroblastos de riñón de hámster (Mesocricetus auratus) y células HeLa, derivadas de un carcinoma de cuello uterino humano. Los cultivos se mantuvieron a $37^{\circ} \mathrm{C}$ en una atmosfera con $5 \% \mathrm{CO}_{2}$, empleándose medio DMEM (Dubelcco's Modified Eagle's Medium) suplementado con 10\% o 2\% de SFB para expansión y mantenimiento, respectivamente. Además, contenían $2 \mathrm{mM}$ glutamina, $50 \mu \mathrm{g} / \mathrm{ml}$ gentamicina (Parafarm, Argentina), $1,5 \mu \mathrm{g} / \mathrm{ml}$ de anfotericina B (Parafarm, Argentina). Los pasajes se efectuaron por tripsinización de la monocapa con una solución de tripsina-EDTA en PBS.

\section{Hibridomas}

Los hibridomas fueron desarrollados en colaboración con el grupo del Dr. Shigeru Morikawa del Department of Virology, National Institute of Infectious Diseases, Tokyo. Brevemente, los hibridomas y la línea de células parentales P3/Ag568, fueron mantenidos en medio RPMI 1640 (Invitrogen) suplementado con $10 \%(\mathrm{v} / \mathrm{v})$ de SFB y $50 \mu \mathrm{g} / \mathrm{ml}$ de gentamicina. Para la 
selección de los hibridomas se agregó el suplemento de hipoxantinaaminopterina-timidina (Invitrogen) según las recomendaciones del fabricante.

\section{Baculovirus recombinantes}

Los baculovirus recombinantes de Autografa californica multiple nucleopolyhedrovirus (rAcMNPV), que poseen el gen que codifica para la proteína $\mathrm{N}$ de JUNV (cepa MC2), fueron generados por recombinación homóloga en las regiones upstream y downstream del gen de poliedrina (polh). Se desarrollaron dos variantes, AcJUN-N+ y AcJUN-N. La primera de ellas expresa poliedrina, además, de N de JUNV, (Ghiringhelli, 2002). Los stocks virales fueron amplificados, titulados y mantenidos a $-80 \mathrm{C}$ antes de su utilización como antígeno.

El baculovirus Ac-His-LASV-NP, que expresa la proteína $\mathrm{N}$ de LASV, fue descripto en otro trabajo (Saijo et al., 2007). Los siguientes fueron obtenidos por el grupo del Dr. Shigeru Morikawa, Department of Virology, National Institute of Infectious Diseases, Tokyo. Brevemente, el cDNA de las nucleoproteínas de MACV, GTOV, SABV y CHPV se obtuvo por síntesis química (Codon Devices, Cambridge, MA, EEUU). Los números de registro en GenBank para las secuencias de N de MACV, GTOV, SABV, y CHPV son NC_005078, AF485258, NC_006317 y NC_010562, respectivamente. Los cDNA fueron digeridos con BamHI y subclonados en el vector de transferencia pAcYM1 (Matsuura et al., 1986). Los vectores de transferencia resultantes fueron co-transfectados con el DNA linealizado BacPAK6 (Clontech, Mountain View, CA, EEUU) en células Tn5. Los baculovirus recombinantes se obtuvieron siguiendo las instrucciones del fabricante (Clontech, Moun- tain View, CA, EEUU) y fueron denominados Ac-MACV-N, Ac-GTOV-N, Ac-SABV-N, y Ac-CHPV-N, respectivamente.

\section{Virus Junín}

Se emplearon dos cepas de JUNV, la atenuada vacunal, Candid \#1 (Maiztegui et al., 1998) y la cepa patogénica P3441, aislada de un paciente 
con FHA (Gomez et al., 2003).

\section{Infección de células de insecto con Baculovirus}

Las infecciones se realizaron sobre monocapas celulares con aproximadamente un $70 \%$ de confluencia. El inóculo viral de $500 \mu \mathrm{l}$ para frascos de $80 \mathrm{~cm}^{2}$ y $200 \mu \mathrm{l}$ para placas de $35 \mathrm{~mm}$ de diámetro se incubó a temperatura ambiente durante $1 \mathrm{~h}$ con rotación cada 10 min.

\section{Infección de células de mamífero con JUNV}

La producción de virus se llevó a cabo in vitro infectando células BHK-21, teniendo en cuenta los datos publicados por Martínez Segovia et al. (1967). Brevemente, las células en crecimiento exponencial (con una cobertura del $50 \%$ de la superficie) se lavaron con PBS y se inocularon con el stock de virus diluido en medio MEM a una multiplicidad de infección (MOI, del inglés, multiplicity of infection) de 0,1 unidades formadoras de placas por célula. Luego de un período de adsorción de 1 h a $37^{\circ} \mathrm{C}$, las monocapas infectadas se lavaron con PBS y se incubaron a $37^{\circ} \mathrm{C}$ con medio de cultivo de mantenimiento ( $2 \%$ SFB).

\section{Recuentos celulares}

Las células resuspendidas fueron contadas utilizando cámara de Neubauer con el siguiente cálculo:

$\mathbf{C}=\frac{\sum_{i=1}^{4} n_{i}}{4} \times \frac{v}{0.1}$, donde $\mathrm{n}$ es el número de células por cada campo de la cámara, $v$ el volumen $(\mu \mathrm{l})$ en que se resuspendieron las células y $\mathrm{C}$ el número total de células por placa. 


\section{Cinética de expresión de $\mathbf{N}$ en células de insecto}

El análisis de la cinética de expresión fue realizado básicamente como se describe en O'Reilly et al. (1992). Brevemente, se realizaron mediante la infección de células High 5 y Sf9 con los virus Ac-JUN-N+ (polh ${ }^{+}$) y Ac-JUN$N$ (polh').

Las células duplicadas en frascos T80 $\left(80 \mathrm{~cm}^{2}\right)$ con un $80 \%$ de confluencia fueron resuspendidas en $28 \mathrm{ml}$ de medio de cultivo completo, utilizando rastrillos de silicona. Se colocaron $2 \mathrm{ml}$ de la suspensión celular en cada placa de $35 \mathrm{~mm}$ de diámetro $\left(9,62 \mathrm{~cm}^{2}\right)$ con el fin de obtener aproximadamente una monocapa con un $50 \%$ de confluencia. Las placas fueron incubadas por $2 \mathrm{~h}$ en estufa a $27^{\circ} \mathrm{C}$ para permitir la adhesión. Antes de proceder con la infección, se realizó un recuento celular de placas seleccionadas al azar, como se indicó previamente. A partir del número de células por placa determinado, se calcularon las diluciones necesarias para infectar con multiplicidades de infección de 0,1, 1 y $10 \mathrm{ufp} /$ célula. Como controles, se infectaron monocapas celulares con el baculovirus AcMNPV wild type (cepa $C-6$ ) y con un baculovirus recombinante que expresa $\beta$ galactosidasa (AcMNPV-Z). Dichos virus se emplearon según se utilizase Ac-JUN-N+ o Ac-JUN-N, respectivamente. Además, se realizaron controles negativos utilizando como inóculo medio de cultivo sin virus (mock).

Las diluciones del inóculo viral y la infección de las placas se realizaron como se indicó con anterioridad y por duplicado. A partir de ese momento las células fueron cosechadas cada $24 \mathrm{~h}$ (hasta $96 \mathrm{~h}$ ), como se indica a continuación.

En el momento de la cosecha, las placas fueron colocadas sobre hielo. La monocapa celular fue resuspendida en el medio de cultivo que contenía cada placa utilizando una espátula de silicona. Esta suspensión fue transferida a tubos cónicos de $15 \mathrm{ml}$ y centrifugada a $4^{\circ} \mathrm{C}$ durante $5 \mathrm{~min}$ a 1000 x g. Se descartó el sobrenadante y se resuspendió el pellet celular en $1 \mathrm{ml}$ de PBS. Se repitió la centrifugación y, nuevamente, se descartó el sobrenadante. Este lavado con PBS se repitió una vez más y, luego el pellet fue congelado a $-20^{\circ} \mathrm{C}$ para su posterior análisis. La expresión proteica fue 
evaluada mediante SDS-PAGE.

\section{Expresión y purificación parcial de antígenos para ELISA}

Se infectaron células Tn5 bajo una MOI de 10. Fueron cosechadas a las 72 h posinfeccion $(\mathrm{PI})$, lavadas con PBS y resuspendidas en PBS con urea $2 \mathrm{M}$ y triton-X100 1\%. La solución también contenía un cocktail de inhibidores de proteasas $(100 \mu \mathrm{M}$ leupeptina, $1 \mu \mathrm{M}$ pepstatina A, $1 \mathrm{mM}$ PMSF y $10 \mathrm{mM}$ EDTA). Luego de $2 \mathrm{~h}$ de incubación con agitación, el lisado celular fue centrifugado a $17.000 \times \mathrm{g}$ por $5 \mathrm{~min}$. Finalmente, el pellet fue resuspendido con una solución caotrópica urea $10 \mathrm{M}$, centrifugado, cuantificado por el método de Bradford (coomasie brilliant blue G-250) y diluido a una concentración final de $50 \mu \mathrm{g} / \mathrm{ml}$ (urea $10 \mathrm{M}$ en PBS). Para el coating de las placas de ELISA, el antígeno fue llevado a una concentración final de $5 \mu \mathrm{g} / \mathrm{ml}$ de proteína en urea 4 M en PBS.

\section{Expresión de versiones truncadas de $\mathbf{N}$ de JUNV}

Se construyó una serie de formas truncadas de la proteína $\mathrm{N}$ de JUNV fusionadas a glutation S-transferasa (GST) con el fin de determinar los epitopes reconocidos por los mAb. El DNA correspondiente a cada uno de las versiones truncadas de $\mathrm{N}$ fue amplificado por PCR con primers que incluyeron sitios BamHI y EcoRI (ver Primers). El DNA amplificado fue clonado en el vector pGEX-2T (Amersham Pharmacia Biotech, Buckinghamshire, Inglaterra). La proteína $\mathrm{N}$ completa $\mathrm{O}$ las versiones truncadas (todas fusionadas a GST) fueron expresadas en E. coli BL21.

\section{Titulación de baculovirus}

Las titulaciones se realizaron como se indica en O'Reilly et al. (1992), aunque con modificaciones. Las células (Sf9) de un frasco confluente de $80 \mathrm{~cm}^{2}$ fueron resuspendidas con un rastrillo de silicona en $28 \mathrm{ml}$ de medio de cultivo TC 100. Luego, se sembraron $2 \mathrm{ml}$ de la suspensión por cada placa de $36 \mathrm{~mm}$ de diámetro y se incubaron a $28^{\circ} \mathrm{C}$ durante $2 \mathrm{~h}$ para permitir 
el pegado al plástico obteniéndose una cobertura del $50 \%$ de la superficie $\left(\sim 5 \mathrm{~cm}^{2}\right)$. Se realizaron diluciones seriadas desde $10^{-1}$ a $10^{-8}$ de la suspensión viral a titular en medio de cultivo completo. La infección se llevó a cabo como se indicó previamente. Todas las infecciones se realizaron por duplicado con 0,2 $\mathrm{ml}$ de cada dilución. Luego de la adsorción de $1 \mathrm{~h}$, se descartó el inóculo y rápidamente se cubrió la monocapa celular con $2 \mathrm{ml}$ de agarosa SeaPlaque (FMC, EE.UU.) 1,5\% $\mathrm{p} / \mathrm{v}$, diluida en medio de cultivo completo. Luego de que la agarosa solidificase, se agregó $1 \mathrm{ml}$ de medio de cultivo completo para evitar la desecación. Las placas fueron incubadas en la estufa a $28^{\circ} \mathrm{C}$ durante 5 días. Luego de descartar el sobrenadante, las células se fijaron y tiñeron con azul de metileno (Ghiringhelli y Romanowski, 1994). Cada placa de lisis fue confirmada por microscopía, aunque esto sólo fue posible con los virus recombinantes que poseían poliedrina. El título viral se determinó con el siguiente cálculo:

$\mathrm{T}=\mathrm{p}_{\times} 5 \times \mathrm{d}^{-1}$, donde $\mathrm{p}$ es el número de placas de lisis, $\mathrm{d}^{-1}$ es la inversa de la dilución y $\mathrm{T}$ el título viral ( $\mathrm{ufp} / \mathrm{ml})$.

\section{Titulación de JUNV}

Para la titulacón de JUNV se emplearon células Vero E6 en placas de $35 \mathrm{~mm}$ (placas de 6 wells). Las células fueron infectadas cuando presentaban aproximadamente el $50 \%$ de confluencia. Con ese fin, fueron cubiertas con $500 \mu \mathrm{l}$ de la suspensión viral durante $1 \mathrm{~h}$ en estufa gaseada y a $37^{\circ} \mathrm{C}$. Luego, se removió el inóculo viral y la monocapa celular se cubrió con una solución de metil-celulosa. Al quinto día p.i., las células fueron fijadas al cubrirlas con aproximadamente $2 \mathrm{ml}$ de una solución $4 \%$ de paraformaldehído durante $30 \mathrm{~min}$, tras lo cual se descartó el sobrenadante y se tiñó la monocapa celular con cristal violeta $0,2 \%$ (final). Tras $5 \mathrm{~min}$, se decoloró con agua corriente hasta alcanzar el nivel de contraste deseado. El título viral se calculó como se describió previamente (titulación baculovirus). 


\section{Densitometría}

La estimación de la concentración de $\mathrm{N}$ se efectuó mediante el análisis densitométrico de los geles resultantes de SDS-PAGE y teñidos con Coomasie brilliant blue R-250. A tal fin, se empleó el programa Labworks 4.6 (UVP, EEUU). Para obtener la curva patrón que permitiera inferir la concentración de $\mathrm{N}$, se realizaron diluciones de BSA de concentración conocida. Los valores de intensidad fueron analizados con el programa Microsoft Excel. Con éste se realizó una regresión lineal y se obtuvo la ecuación de la curva patrón, que luego permitió inferir la concentración de la muestra incógnita.

\section{Cuantificación de proteínas}

La cuantificación de proteínas se realizó mediante una adaptación del método de Bradford (Bradford, 1976). Fue escalado para minimizar el uso de muestra. Se resuspendieron $6 \mu \mathrm{l}$ de cada muestra en $300 \mu \mathrm{l}$ del reactivo de Bradford, diluido $1 / 5$ en agua. Luego de 15 min de incubación, $150 \mu$ fueron transferidos a un well de una placa de 96 wells y se midió la absorbancia a $595 \mathrm{~nm}$ de longitud de onda con $465 \mathrm{~nm}$ como referencia. La curva patrón se realizó con BSA.

\section{Western blot}

Los geles de poliacrilamida con SDS se realizaron en forma estándar (Sambrook et al., 1989) y usando el dispositivo Mini-PROTEAN Tetra Cell Gel (Bio-Rad). Luego del SDS-PAGE, se realizó la transferencia desde el gel a una membrana de nylon (Hybond ${ }^{\mathrm{TM}} \mathrm{P}$, Amersham Biosciences) mediante electroelución semiseca. A tal fin se utilizó el equipo Trans-Blot $\AA$ SD (BioRad), siguiendo las instrucciones del fabricante. Brevemente, la membrana y el gel fueron equilibrados en el buffer de transferencia $(48 \mathrm{mM}$ Tris, $39 \mathrm{mM}$ glicina y $20 \%$ metanol) por $15 \mathrm{~min}$. Luego, se colocaron 2 papeles de filtro embebidos en el buffer de transferencia sobre el ánodo. Sobre éstos se colocó la membrana, el gel, otros 2 papeles de filtro y el 
cátodo (tapa). La transferencia se realizó por $30 \mathrm{~min}$ a $15 \mathrm{~V}$. La eficacia de la transferencia fue evaluada por tinción de la membrana con rojo Ponceau $\mathrm{S}$ ( $0,2 \%$ en $3 \%$ ácido tricloroacético y $3 \%$ ácido sulfosalicílico). La eficiencia de la transferencia se evaluó mediante la tinción del gel con Coomasie Blue.

La membrana fue bloqueada toda la noche con una solución $5 \%$ leche descremada y $0,1 \%$ tween $20(\mathrm{PLT})$ a $4^{\circ} \mathrm{C}$ o $30 \mathrm{~min}$ a $37^{\circ} \mathrm{C}$. Luego se realizó una incubación por $2 \mathrm{~h}$ a $37^{\circ} \mathrm{C}$, o toda la noche a $4^{\circ} \mathrm{C}$, con una dilución apropiada del anticuerpo primario, tras lo cual se hicieron lavados (3-5) con una solución $0,1 \%$ tween 20 en PBS con incubaciones de 10 min a $37^{\circ} \mathrm{C}$. Tras la incubación con el anticuerpo primario, se realizó un nuevo lavado de la membrana y se incubó con una dilución apropiada del anticuerpo secundario. Luego 1 o $2 \mathrm{~h}$ a $37^{\circ} \mathrm{C}$, se repitieron los lavados de la membrana. En el caso de emplear un anticuerpo secundario biotinilado, se realizó una tercera tanda de lavados e incubación con la estreptavidina conjugada a peroxidasa. Tras un último lavado, se incubó la membrana con el reactivo cromogénico, diaminometilbencidina (DAB) 0 con el reactivo quimioluminiscente Luminol (ECL) y se hizo la captura de imágenes con el dispositivo EC3 ${ }^{\text {TM }} 500$ Imaging System (UVP). 


\section{Optimización del protocolo de IgG-ELISA por el método de Taguchi}

Los distintos parámetros del ensayo del IgG-ELISA fueron optimizados utilizando el método de Taguchi, esencialmente como se describió previamente (Jeney et al., 1999; Taguchi, 1993). Según la nomenclatura definida en este método, un factor es cualquier variable del ensayo, como por ejemplo la concentración de uno de los reactivos o un tiempo de incubación. Los niveles de un factor son los valores que se asignan a las variables. A diferencia del trabajo de Jeney et al. (1999), se escogió un diseño L-18 sin modificar, el cual permite estudiar, con dieciocho experimentos, dos niveles de un factor y tres niveles de siete factores (Taguchi, 1993). Con esto se puede optimizar la mayoría de los parámetros que componen un ELISA. Los factores y sus niveles fueron asignados como se indica en la Tabla 7 y el último factor se empleó como control interno de errores (ie). Además, se estudió el efecto de los distintos factores sobre el background, por lo que se incluyeron 18 experimentos más. Todos fueron realizados por triplicado y distribuidos al azar en los 60 wells internos de 3 placas de 96 wells (asignadas de acuerdo a los tiempos de incubación). Los valores de absorbancia a $492 \mathrm{~nm}$ para cada experimento, fueron convertidos con la transformación "larger is better", en el caso del estudio de señal positiva y "smaller is better", para el estudio del background (Taguchi, 1993). Además, se evaluó una tercera fórmula que combina las transformaciones

Tabla 7. Factores y niveles evaluados para optimizar el IgG ELISA con el método de Taguchi.

\begin{tabular}{ccccc}
\hline Factor & Descripción & \multicolumn{3}{c}{ Nivel } \\
\hline & & 1 & 2 & 3 \\
\cline { 3 - 5 } T & Conc. tween 20 en PLT & $0.05 \%$ & $0.1 \%$ & - \\
N & Conc. N (coating) & $0.2^{\mu g} /$ well & $0.5^{\mu g} /$ well & $1^{\mu g} /$ well \\
U & Conc. Urea (coating) & 0 & $4 \mathrm{M}$ & $8 \mathrm{M}$ \\
A & anti IgG humana (dil.) & $1 / 500$ & $1 / 1000$ & $1 / 2000$ \\
S & Streptavidina/HRP (dil.) & $1 / 500$ & $1 / 1000$ & $1 / 2000$ \\
I & Tiempo de incubación & $30 \mathrm{~min}$ & $1 \mathrm{~h}$ & $2 \mathrm{~h}$ \\
D & Tiempo de desarrollo & $8 \mathrm{~min}$ & $12 \mathrm{~min}$ & $16 \mathrm{~min}$ \\
ie & Error (control interno) & - & - & - \\
\hline
\end{tabular}


anteriores en un cociente (señal/background):

$$
\frac{\mathrm{S}}{\mathrm{N}}=-10 \log _{10}\left(\frac{\left(\frac{1}{\mathrm{a}_{1}{ }^{2}}+\frac{1}{\mathrm{a}_{2}{ }^{2}}+\frac{1}{\mathrm{a}_{3}{ }^{2}}\right)}{\left(\frac{1}{\mathrm{~b}_{1}{ }^{2}}+\frac{1}{\mathrm{~b}_{2}{ }^{2}}+\frac{1}{\mathrm{~b}_{3}{ }^{2}}\right)}\right)
$$

Donde a y b son los triplicados de la señal positiva y background, respectivamente.

Todos los cálculos se realizaron con el programa Qualitek-4 (Nutek, Inc.) y JMP v.5.1 (SAS Institute Inc.).

\section{Muestras de sueros humanos}

Las 36 muestras positivas para FHA fueron provistas por las Dras. Silvana Levis y Delia Enría del Instituto Nacional de Enfermedades Virales Humanas (INEVH), ANLIS, Pergamino, Argentina. La positividad de dichas muestras fue establecida previamente en el INEVH ya sea por ELISA o mediante el test de neutralización (NT). Como control negativo se utilizaron 120 muestras normales y no provenientes del área endémica (La Plata).

\section{IgG-ELISA}

Todas las soluciones fueron realizadas con PBS. Se emplearon placas de 96 wells (Maxisorp, Nunc). El coating se realizó durante toda la noche a temperatura ambiente. En cada well se colocaron $100 \mu \mathrm{l}$ de una solución $4 \mathrm{M}$ urea y $5 \mathrm{ng} / \mu \mathrm{l}$ de lisado celular con proteína $\mathrm{N}$ del virus Junín $(0,5 \mu \mathrm{g} /$ well$)$. En el día siguiente, se descartó la solución de coating y se realizó el bloqueo con $250 \mu \mathrm{l}$ por well de PLT durante $2 \mathrm{~h}$ a $37^{\circ} \mathrm{C}$. Luego, la solución de bloqueo fue descartada y las placas se conservaron a $-20^{\circ} \mathrm{C}$ hasta su uso. Las microplacas se incubaron con diluciones de los sueros humanos 1:400 en PLT durante $2 \mathrm{~h}$ a $37^{\circ} \mathrm{C}$ y se realizaron cinco lavados con una solución $0,1 \%$ tween 20 (PBT), procurando en cada paso quitar todo el líquido invirtiendo para ello la placa sobre un papel absorbente (todos los lavados posteriores se realizaron de la misma manera). Por razones de bio- 
seguridad, todas las etapas del ELISA que implicaran la manipulación de sueros humanos (y las posteriores) fueron realizadas dentro de un gabinete de flujo laminar vertical apropiado. Posteriormente, se realizaron incubaciones con sus respectivos lavados, empleando primero el anticuerpo de conejo anti IgG humana (E0482, Dako Cytomation), diluido 1:2000 en PLT y, luego, estreptavidina conjugada a peroxidasa (P0397, Dako Cytomation), diluida 1:1000 en PLT. Tras una última ronda de lavados, se agregaron $100 \mathrm{\mu l} /$ well de tetrametilbencidina (1-Step Turbo TMB-ELISA, Pierce). Las placas se incubaron con esa solución por $45 \mathrm{~min}$ al resguardo de la luz (16 min para diluciones 1:10 de suero) y finalmente la reacción se detuvo con $100 \mu \mathrm{l}$ de $\mathrm{HCl} 2 \mathrm{M}$. Se midió la absorbancia a $450 \mathrm{~nm}$ de longitud de onda (Tecan Absorbance Microplate Reader). A estos valores se les restó el background obtenido para cada uno de los sueros, pero en wells cubiertos (etapa de coating) con LacZ producida y purificada a partir de células de insecto infectadas con un baculovirus recombinante siguiendo el mismo protocolo que para N. Es crítico que los wells de la señal y background provengan de la misma placa. La variabilidad del ensayo fue calculada con un control positivo de moderada reactividad. La variación intra-ensayo, CV $\mathrm{x}$ 100 (CV: coeficiente de variación), fue calculada como la media de 3 ensayos independientes. La variación inter-ensayo fue calculada sobre 3 ensayos independientes a partir de la media de los duplicados.

\section{IgG ELISA mAb}

Las placas de ELISA (Nunc) se cubrieron con aproximadamente 100 ng/well de $\mathrm{N}$ perteneciente JUNV, MACV, GTOV, SABV, CHPV, o His-LASV purificada de baculovirus a $4^{\circ} \mathrm{C}$ ON (del inglés, overnight). Luego, cada well de la placa fue cubierto con $200 \mu$ de PLT, seguido de incubación por $1 \mathrm{~h}$ a $37^{\circ} \mathrm{C}$ para el bloqueo. Las placas fueron lavadas 3 veces con PBS conteniendo $0,05 \%$ tween 20 (PBST) y luego inoculadas con los mAb (100 $\mu \mathrm{l} /$ well), diluidos $1: 1000$ con PLT. Luego de $1 \mathrm{~h}$ de incubación, las placas fueron lavadas 3 veces con PBST para luego ser inoculadas con anticuerpo IgG cabra anti-ratón marcado con peroxidasa de rábano (HRP; 1:1000 Zymed). Luego de $1 \mathrm{~h}$ de incubación, las placas fueron lavadas y cubiertas 
con $100 \mu \mathrm{l}$ de solución ABTS [ácido 2,2'-azino-bis(3-etilbenzotiazolin-6sulfónico)] (Roche) fueron agregados a cada well. Las placas fueron incubadas por 30 min a temperatura ambiente, y se midió la densidad óptica a $405 \mathrm{~nm}\left(\mathrm{DO}_{405}\right)$ y a $490 \mathrm{~nm}$ como referencia. El valor ajustado $\mathrm{DO}_{405}$ fue calculado sustrayendo el valor a $\mathrm{DO}_{405}$ de los wells cubiertos con antígeno negativos con aquellos de los wells respectivos.

\section{Producción de anticuerpos monoclonales}

Este trabajo se realizó en el laboratorio del Dr. Shigeru Morikawa. Brevemente, se inmunizaron ratones $B A L B / c$ mediante tres inoculaciones con rN de JUNV parcialmente purificada. Los esplenocitos fueron obtenidos 3 días después de la última inmunización y fusionados con células P3/Ag568 utilizando polietilenglicol (Invitrogen). Los sobrenadantes de los cultivos de los hibridomas fueron analizados por ELISA utilizando rN de JUNV purificada como antígeno en presencia de urea $2 \mathrm{M}$. Los anticuerpos monoclonales fueron purificados del sobrenadante de los cultivos utilizando el kit MAbTrap GII (GE Healthcare Bio-Sciences) de acuerdo con las instrucciones del fabricante. La concentración de cada mAb purificado fue determinada por el método de cuantificación de proteínas de Bradford (Bio-Rad Laboratories).

\section{Mapeo de los epitopes de los anticuerpos monoclonales}

Los epitopes de los mAb C6-9 y C11-12 fueron determinados por bloqueo de epitopes en ELISA, utilizando péptidos sintéticos (ENZO Life Sciences). Los decapéptidos fueron sintetizados químicamente corriendo una posición aminoacídica por vez, con la consecuente superposición de 9 aa con el decapéptido anterior. De esta forma, se abarcó las regiones en $\mathrm{N}$ desde el aa 5 al 29, para el mAb C6-9, y del aa 543 al 564 para el C11-12. Las placas de ELISA fueron cubiertas con $\mathrm{N}$ de JUNV semi-purificada y expresada con el sistema de expresión de baculovirus (aproximadamente $100 \mathrm{ng} /$ well) a $4^{\circ} \mathrm{C}$, ON. Luego, cada well fue inoculado con $200 \mu \mathrm{l}$ de PBS-M, seguido de incubación por $1 \mathrm{~h}$ para bloqueo. Los mAb C6-9 o C-11-12 fueron mezclados con cada péptidos $\left(1 \mu \mathrm{g} /\right.$ well) e incubados por $1 \mathrm{~h}$ a $37^{\circ} \mathrm{C}$, y luego la mezcla 
fue agregada a cada well de la placa. Luego de $1 \mathrm{~h}$ de incubación, las placas fueron lavadas 3 veces con PBST, para luego ser incubadas con anticuerpo IgG cabra anti-ratón marcado con HRP (1:1,000; Zymed). El siguiente procedimiento fue realizado como descripto en el ELISA IgG ELISA. Para el mAb E4-2, el epitope fue determinado por ELISA utilizando $\mathrm{N}$ de JUNV fusionada a GST y fragmentos de $\mathrm{N}$ también fusionados a GST. Las placas de ELISA fueron cubiertas con las fusiones a GST purificadas ( 100 ng/well) y siguiendo el método de IgG-ELISA mAb descripto anteriormente. Para la detección se usó el mAb E4-2 o el mAb anti-GST diluidos 1:2000 o 1:500, respectivamente. El valor de $\mathrm{DO}_{405}$ ajustado se calculó haciendo el cociente entre el valor de DO (405 nm) obtenido con el mAb E4-2 y el correspondiente al mAb anti-GST.

\section{Ag-ELISA}

Para el ELISA de captura de antígeno, Ag ELISA, cada well de una placa de 96 wells (Nunc) fue cubierto con 100 ng/well de los mAb C6-9, C11-12 o E4-2 (100 $\mu$ l en PBS). Se dejó ON a $4^{\circ} \mathrm{C}$ y luego se bloqueó $1 \mathrm{~h}$ a temperatura ambiente con PLT $(300 \mu \mathrm{l})$. Luego se lavó con PBST, y se agregaron $100 \mu \mathrm{l}$ de muestra conteniendo diluciones seriadas de $\mathrm{rN}$ de JUNV, MACV, GTOV, SABV, CHPV, o LASV, y las placas fueron incubadas por $1 \mathrm{~h}$ a $37^{\circ} \mathrm{C}$. Las placas fueron luego lavadas con PBST, para luego agregar $100 \mu \mathrm{l}$ de anticuerpo policlonal de conejo contra rNP de JUNV diluida 1:500 en PLT. Luego de $1 \mathrm{~h}$ de incubación a $37^{\circ} \mathrm{C}$, las placas fueron lavadas con PBST, y se agregó IgG de cabra anti-conejo conjugado con HRP (Zymed, EEUU) por $1 \mathrm{~h}$ a temperatura ambiente. Luego de extensivos lavados con PBST, se agrego $100 \mu \mathrm{l}$ de una solución substrato de ABTS (Roche, Germany), y la DO fue medida a $405 \mathrm{~nm}$ con $490 \mathrm{~nm}$ como valor de referencia luego de 30 min de incubación a temperatura ambiente. La DO de los wells controles con antígeno fue medida. Los valores ajustados de $\mathrm{DO}_{405}$ fueron calculados por sustracción de los valores de $\mathrm{DO}_{405}$ con los valores de los controles negativos correspondientes. La media y la desviación estándar fueron calculados de las DO de 12 wells controles negativos y el valor de la línea de corte fue definido por la media más 3 desviaciones estándares. 


\section{Expresión en pequeña escala}

Se transformaron bacterias BL21-SI electrocompetentes con $0,5 \mu \mathrm{l}$ (aproximadamente $200 \mathrm{ng}$ ) de los plásmidos: pAEctxB-Z, pAEctxB-G1, pAEctxB-G2, pAEctxB-GPC, pAEctxB-N y pAEctxB-EGFP. Se inoculó un frasco con $2 \mathrm{ml}$ de LB (Ampicilina $100 \mu \mathrm{g} / \mathrm{ml}$ ) y se dejó ON a $37^{\circ} \mathrm{C}$ y agitación de $200 \mathrm{rpm}$. Al día siguiente se hizo una dilución 1:30 de dicho cultivo y se dejó crecer en un frasco de penicilina (6 ml de LB y Ampicilina). Cuando se alcanzó una DO600 de 0,6 - 0,8 se indujo con $\mathrm{NaCl} 300$ mM. Se tomaron muestras al momento de la inducción y entre 2 y $4 \mathrm{~h}$ post-inducción. Las muestras se hicieron a partir de $1 \mathrm{ml}$ de cultivo, el cual fue centrifugado $30 \mathrm{~s}$ a $14.000 \mathrm{xg}$ y congelado $\left(-20^{\circ} \mathrm{C}\right)$ para su posterior análisis por SDSPAGE. La resuspensión se hizo oportunamente en $100 \mu \mathrm{l}$ de agua (resuspendido con vortex) y $100 \mu$ l de sample buffer $2 X$.

\section{Inmunización y vacunación de cobayos}

Cinco grupos de cinco cobayos macho jóvenes ( $\sim 5$ semanas) fueron inmunizados tres veces por la vía subcutánea, con al menos dos semanas entre cada inoculación. Cada dosis tuvo un volumen final de $500 \mu \mathrm{l}$ y $50 \mu \mathrm{g}$ de $\mathrm{Al}(\mathrm{OH})_{3}$ como adyuvante (en PBS). Los grupos (+) y (-) fueron inoculados sólo con el adyuvante. Por su parte, los grupos CTB-Z CTB-EGFP fueron inoculados con $\sim 20$ ug de las correspondientes proteínas recombinantes (por dosis). El control de vacunación, fue inoculado 30 días antes del desafío por la vía intramuscular con $500 \mu \mathrm{l}$ de una suspensión $10^{3} \mathrm{ufp} / \mathrm{ml}$ de Candid \#1 diluido en PBS (sobrenadante de medio de cultivo proveniente de la amplificación del virus en cultivo celular, como se detalló anteriormente).

\section{Cálculo de $\mathrm{DL}_{50}$}

El cálculo se hizo de acuerdo al método de Reed y Muench (Reed y Muench, 1938). 


\section{Desafío}

El desafío de cobayos con JUNV fue realizado en la Unidad Operativa Centro de Contención Biológica (UOCCB) del instituto ANLIS-Malbrán. Todo el trabajo en el laboratorio BSL3A fue realizado siguiendo protocolos operativos estándares que debieron escribirse a tal fin o que ya habían sido elaborados por el personal de dicho instituto. Los cobayos fueron ingresados al BSL3A $48 \mathrm{~h}$ antes de iniciar el ensayo con el fin de permitirles la habituación al nuevo ambiente. La inoculación de los animales se realizó por la vía intraperitoneal, con una dosis de $0,5 \mathrm{ml}\left(10^{2} \mathrm{ufp} / \mathrm{ml}\right)$ en PBS. Todos los días se verificó la disponibilidad de agua y alimento de los animales y se llevó un registro de los animales vivos por grupo. El ensayo finalizó a los 15 días p.i.

\section{Medio de cultivo TC 100}

El medio se preparó disolviendo $20,56 \mathrm{~g} / \mathrm{l}$ y agregando luego de $30 \mathrm{~min}$ de agitación, 0,35 g/l de $\mathrm{NaHCO}_{3}$. Luego se ajustó el pH a 6,2 y se agregaron $2,8 \mathrm{~g} / \mathrm{l}$ de $\mathrm{NaCl}$. Finalmente, el medio fue esterilizado por filtración.

\section{Primers}

\begin{tabular}{|l|l|c|}
\hline \multicolumn{1}{|c|}{ Nombre } & \multicolumn{1}{c|}{ Secuencia } & bases \\
\hline EGFPHindIIIR & CTGATAAGCTTCTAGAGTCGCGGCCG & 26 \\
\hline EGFPMlulF & TCCATCACGCGTATGGTGAGCAAGGGC & 27 \\
\hline G1FKpn-Mlu & GCAGGTACCATGACGCGTGAAGAAGCTTTTAAAATC & 36 \\
\hline G1RXho-Hind & ACCACTCGAGAAGCTTCTATAAAGACCTCCTTGGAAG & 37 \\
\hline G2FKpn-Mlu & CTTGGTACCATGACGCGTAAAGCATTCTTTTCCTGG & 36 \\
\hline G2RPs-Xh & CTGCAGCTCGAGTTAGTGTCCTCTGC & 26 \\
\hline G2RXho-Hind & GACCCTCGAGAAGCTTCTATGTCCTCTGCGCCAAAC & 36 \\
\hline GPC-HindlIIR & ACCACCAAGCTTTTAGTGTCCTCT & 24 \\
\hline GPC-MluIF & AATTAAACGCGTATGGGGCAATTC & 24 \\
\hline HisTag (CtxBXho1F) & CATCACCATCACCATCACCTCG & 22 \\
\hline N-HindIIIR & GCCGCCAAGCTTTTACAGTGCATA & 24 \\
\hline N-MlulF & GCCGCCACGCGTATGGCACACTCCAAAGAGGTTCCGAGCT & 40 \\
\hline N2 & GAGATCTGGATCCTTACAGTGCATAGGCTGC & 31 \\
\hline pRSETR & TAGTTATTGCTCAGCGGTGG & 20 \\
\hline SP-G1FBa-Kp & GGTACCGGATCCATGGGGCAATTCAT & 26 \\
\hline Z-HindIIIR & ATAATAAAGCTTCTATGGTGGTGG & 24 \\
\hline Z-MlulF & AATTAAACGCGTATGGGCAACTGC & 24 \\
\hline
\end{tabular}




\begin{tabular}{|l|l|l|}
\hline Zfwd & CGCGGTACCACCATGGGCAACTGCAAC & 27 \\
\hline Zrev & GCGTCTAGATGGCCTATGGTGGTGGTG & 27 \\
\hline GST-NF1 & GTGGATCCCCCATGGCACACTCCAAAGAGGTTC & 33 \\
\hline GST-NF384 & GTGGATCCCAGCTACTGACCCTGTTGAGATG & 31 \\
\hline GST-NF465 & GTGGATCCATGGAAGAAGAGATCTTAAGC & 29 \\
\hline GST-NF524 & GTGGATCCCACACTGTGCTCTGCTAGACTG & 30 \\
\hline GST-NF54 & GTGGATCCTCAGAAAGACTAAAAGGGGGGA & 30 \\
\hline GST-NR117 & AAGAATTCACTCTGCTCTTCTAATCTTGTT & 30 \\
\hline GST-NR235 & AAGAATTCAGTTGATGGAGCTTTCATCCTTAG & 32 \\
\hline GST-NR564 & AAGAATTCTTACAGTGCATAGGCTGCCTTC & 30 \\
\hline GST-NR59 & AAGAATTCACCTTTTAGTCTTTCTGAGTGCCC & 32 \\
\hline
\end{tabular}

\section{PCR}

Las reacciones de amplificación de los ácidos nucleicos se realizaron en un ciclador térmico Eppendorf (Mastercycler Gradient). En las reacciones en las que se iba a utilizar el producto de amplificación para clonación, se utilizó la Platinum Pfx DNA Polimerasa con actividad proof-reading (Promega). En estas reacciones se usó el buffer de esta enzima 1 X; 1 mM MgSO4; 0,25 $\mathrm{mM}$ de cada dNTP; $1 \mu \mathrm{M}$ de los primers correspondientes; $0,5 \mathrm{U}$ de la Platinum Pfx DNA Polimerasa y aproximadamente 0,1 a $0,3 \mathrm{ng}$ de DNA molde en un volumen final de $10 \mu$ l. Las demás reacciones de amplificación, se realizaron con buffer de Taq Polimerasa $1 \mathrm{X} ; 2 \mathrm{mM} \mathrm{MgCl}$; 0,25 mM de cada dNTP; 0,5 $\mu \mathrm{M}$ de los primers correspondientes; $1 \mathrm{U}$ de la enzima Taq Polimerasa (Productos Bio-lógicos, Argentina), en un volumen final de $10 \mu$ l.

\section{Colony PCR}

Con escarbadientes estériles se tocaron colonias de las transformaciones y cada una se resuspendió en $10 \mu \mathrm{l}$ de agua bidestilada. El material remanente en el palillo se utilizó para realizar una estría en medio selectivo LB-agar con kanamicina $(50 \mu \mathrm{g} / \mathrm{ml})$ o ampicilina $(100 \mu \mathrm{g} / \mathrm{ml})$. La suspensión fue luego hervida durante 3 min. Posteriormente, cada tubo se centrifugó a $17000 \times \mathrm{g}$ durante $5 \mathrm{~min}$. Un microlitro de cada sobrenadante fue empleado como molde para reacciones de PCR. 


\section{Números de acceso de GeneBank}

Los números de acceso en GenBank para las secuencias estudiadas del

RNA S son:

JUNV: NC_005081, DQ272266, AY746353, AY619641, AY358023, D10072, U70802, U70803 y U70804.

MACV: NC_005078, AY924208, AY924207, AY924206, AY924205, AY924204, AY924203, AY924202, AY571959, AY624355, AY619645, AY571904, AF485260 y AY129248.

GTOV: NC_005077, AY497548, AF485258 y AY129247.

SABV: NC_006317.

CHPV, NC_010562.

LASV, AF246121.2. 


\section{Glosario}

aa: amino ácido.

$\mathrm{ABC}_{\mathrm{ROC}}$ : área bajo la curva ROC.

ANLIS: Administración Nacional de Laboratorios e Institutos de Salud.

BSA: seroalbúmina bovina (del inglés bovine serum albumin).

BSL3: laboratorio de seguridad biológica nivel tres, nivel de contención con presión negativa.

BSL3A: laboratorio de seguridad biológica nivel tres apto para el trabajo con animales.

Buffer: solución tampón.

Candid \#1: cepa atenuada de JUNV actualmente en uso en programa de vacunación contra la fiebre hemorrágica argentina (INEVH, Pergamino).

CHPV: virus Chapare.

CSB: cabina de seguridad biológica.

CT: toxina colérica.

CV: coeficiente de variación.

CTA: subunidad A de la toxina colérica y responsable de los síntomas de la enfermedad.

CTB: subunidad B de la toxina colérica.

Desafío: en virología, se refiere al procedimiento por el cual se enfrenta un grupo de animales a un determinado patógeno y se evalúa su supervivencia. Usualmente, se realiza para evaluar las propiedades protectoras de una posible vacuna, por lo que los animales son previamente inmunizados.

DL $_{50}$ : dosis letal 50 , es la dosis necesaria, en este caso de virus, para matar el $50 \%$ de la población infectada.

ELISA: siglas de, enzyme linked immunosorbent assay: enzimoinmunoensayo.

FHA: fiebre hemorrágica argentina. 
GTOV: virus Guanarito.

IBBM: Instituto de Biotecnología y Biología Molecular.

IC: intervalo de confianza.

IM: intramuscular

INEVH: Instituto Nacional de Enfermedades Virales Humanas (ANLIS).

JUNV: virus Junín

kDa: kilo dalton.

LASV: virus Lassa.

MACV: virus Machupo.

MC2: cepa de virus Junín de patogenicidad moderada y aislada de un roedor (Anon et al., 1976).

Mock: gupo de animales inoculado durante la etapa de inmunizaciones solamente con PBS (sin virus o proteína recombinante) y que se utiliza como control (deben morir al ser inoculados con el virus).

Nts.: nucleótidos.

NW-A: linaje A de arenavirus del nuevo mundo (new world).

NW-B: linaje B de arenavirus del nuevo mundo (new world).

OW: arenavirus del viejo mundo (old world)

P3441: cepa patógena de virus Junín aislada de un paciente humano (Gomez et al., 2003).

pb: pares de bases

PBS: solución tampón de fosfato salino (siglas del inglés, Phosphate buffered saline).

PCR: siglas en inglés para la reacción en cadena de la polimerasa.

PMSF: fluoruro de fenilmetilsulfonilo (inhibidor de proteasas de serina).

Primer: fragmento corto de ADN ( 20 pb) utilizado para iniciar la síntesis de ADN en reacciones de PCR. Conocido en castellano como cebador (aunque poco utilizado). 
Proteína quimérica: proteína formada por dos proteínas distintas e independientes que fueron fusionadas empleando técnicas de ingeniería genética.

ROC: siglas en inglés de receiver operating characteristics.

SABV: virus Sabiá.

SFB: suero fetal bovino.

ufp: unidades formadoras de placas. Unidad utilizada en virología para establecer la cantidad de partículas virales capaces de originar placas en cultivos celulares (titulación).

UOCCB: Unidad Operativa Centro de Contención Biológica. 


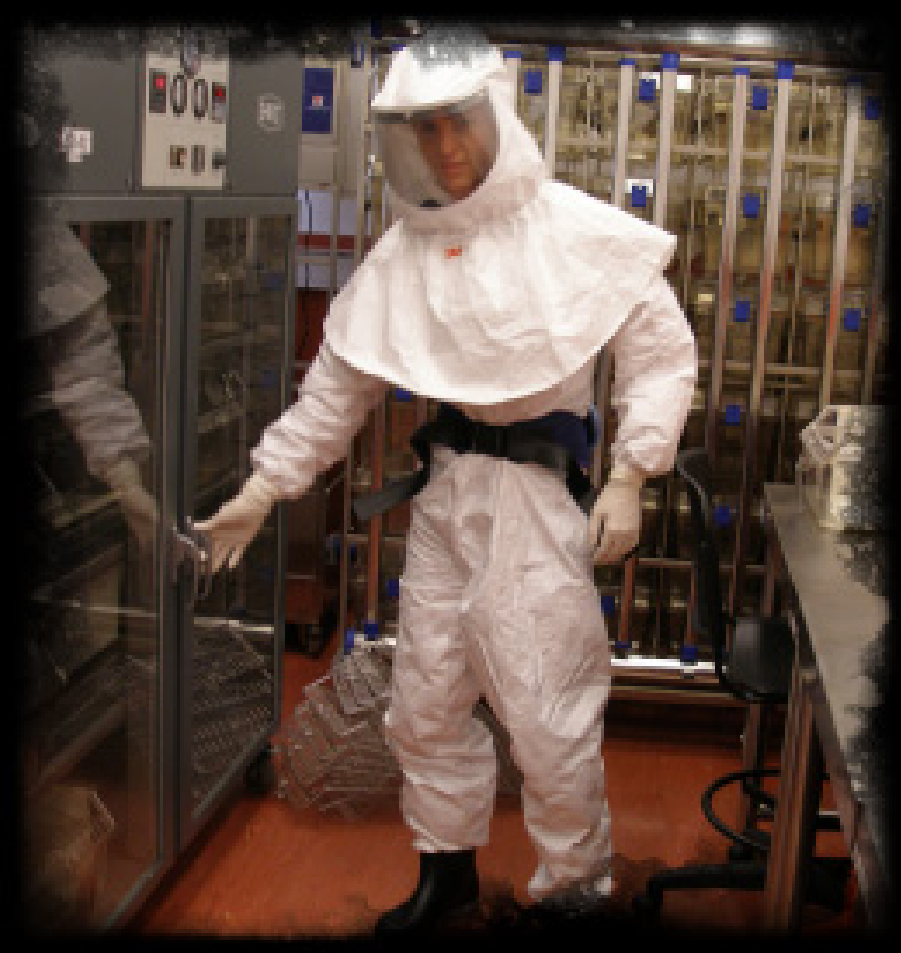

El autor con el equipo de protección biológica en el baboratorio BS-3 (UDCCB-Arlis-Malbrán)

La fiebre hemorrágica argentina (FHA), cuyo agente etiológico es el virus Junín, es una enfermedad endémica caracterizada por alteraciones cardiovasculares, hematológicas, inmunológicas y neurológicas. Posee una mortalidad aproximada de entre un 15 y un $30 \%$ en casos no tratados. Actualmente, el área endémica cubre más de $150,000 \mathrm{~km}^{2}$,y pone en riesgo a más de 5 millones de habitantes, principalmente trabajadores rurales de la zona agrícolo-ganadera más importante del país. En consecuencia, esta enfermedad tiene un impacto considerable en la salud de la población y a su vez en la economía de la Argentina.

Durante la última década se ha aplicado una vacuna a virus atenuado que resultó efectiva. Sin embargo, los riesgos asociados a su uso, tanto por la manipulación viral para la producción de la vacuna como la posible reversión de la atenuación en la cepa vacunal, ponen de manifiesto la necesidad de desarrollar nuevas estrategias preventivas. Sumado a esto, los métodos inmunológicos actualmente empleados para el seguimiento epidemiológico de la FHA también requieren la producción de los antígenos a partir de cultivos celulares infectados con la cepa virulenta y la utilización de laboratorios con un nivel de seguridad adecuado a tal fin.

Los objetivos centrales de esta tesis doctoral fueron, en consecuencia, el desarrollo de un método de diagnóstico que no implique la manipulación del virus patógeno y que, en cambio, emplee antígenos virales producidos mediante técnicas de DNA recombinante. Por otra parte, la producción de proteinas recombinantes quiméricas que pudieran en un futuro utilizarse como una vacuna alternativa para la prevención de la FHA.

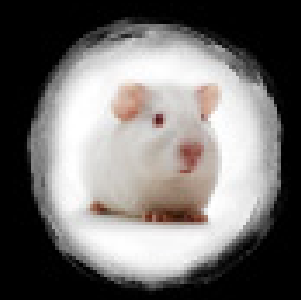

